\title{
Corporate social responsibility disclosure: management, commitment, and stakeholder influence
}

Citation for published version (APA):

Thijssens, T. J. G. I. (2012). Corporate social responsibility disclosure: management, commitment, and stakeholder influence. [Doctoral Thesis, Maastricht University]. Datawyse / Universitaire Pers Maastricht. https://doi.org/10.26481/dis.20120308tt

Document status and date:

Published: 01/01/2012

DOI:

10.26481/dis.20120308tt

Document Version:

Publisher's PDF, also known as Version of record

\section{Please check the document version of this publication:}

- A submitted manuscript is the version of the article upon submission and before peer-review. There can be important differences between the submitted version and the official published version of record.

People interested in the research are advised to contact the author for the final version of the publication, or visit the DOI to the publisher's website.

- The final author version and the galley proof are versions of the publication after peer review.

- The final published version features the final layout of the paper including the volume, issue and page numbers.

Link to publication

\footnotetext{
General rights rights.

- You may freely distribute the URL identifying the publication in the public portal. please follow below link for the End User Agreement:

www.umlib.nl/taverne-license

Take down policy

If you believe that this document breaches copyright please contact us at:

repository@maastrichtuniversity.nl

providing details and we will investigate your claim.
}

Copyright and moral rights for the publications made accessible in the public portal are retained by the authors and/or other copyright owners and it is a condition of accessing publications that users recognise and abide by the legal requirements associated with these

- Users may download and print one copy of any publication from the public portal for the purpose of private study or research.

- You may not further distribute the material or use it for any profit-making activity or commercial gain

If the publication is distributed under the terms of Article $25 \mathrm{fa}$ of the Dutch Copyright Act, indicated by the "Taverne" license above, 
Corporate Social Responsibility Disclosure:

Management, Commitment, and Stakeholder Influence. 
(C) Copyright T. Thijssens, Maastricht 2012 Universitaire Pers Maastricht

ISBN 9789461591227 


\title{
Corporate Social Responsibility Disclosure: Management, Commitment, and Stakeholder Influence.
}

\author{
PROEFSCHRIFT \\ ter verkrijging van de graad van doctor aan de Universiteit Maastricht, \\ op gezag van de Rector Magnificus, Prof. Mr. G. P. M. F. Mols, volgens het besluit \\ van het College van Decanen in het openbaar te verdedigen op \\ donderdag 8 maart 2012 om 14:00 uur \\ door \\ Thomas Jean Gertrude Ignace Thijssens
}

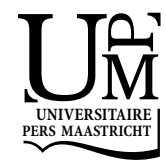




\section{Promotor}

Prof. dr. Harold Hassink

\section{Copromotor}

Dr. Laury Bollen

Beoordelingscommissie

Prof. dr. Ann Vanstraelen (voorzitter)

Prof. dr. Harry Hummels

Prof. dr. Robin Roberts (University of Central Florida)

Dit onderzoeksproject is gefinancierd door de Executive Master of Finance and Control (EMFC) van Maastricht University School of Business and Economics. 


\title{
Acknowledgements - Dankwoord
}

\author{
"Life on other planets is difficult" (Blixa Bargeld, 2004).
}

Deze 'ouwe Aio' heeft het gered: het boekje is klaar. Dat ging niet vanzelf. Het was de afgelopen jaren flink aanpakken. Maar flink genieten was het zeker ook: ik heb veel geleerd, mensen ontmoet, gereisd en ook gelachen. Ik ben blij dat ik het heb mogen meemaken. Toch ben ik nu zeker niet minder blij dat het proefschrift afgerond is.

Velen hebben aan deze onvergetelijke ervaring bijgedragen door hun ondersteuning, inspiratie en belangstelling. Graag wil ik op deze plaats een kort woord van dank wijden aan enkele van deze personen.

Allereerst wil ik Harold Hassink bedanken voor het in mij gestelde vertrouwen; het onder de hoede nemen van een promovendus met een onderzoeksterrein waarvoor eigen verkenning nodig is, vereist durf en vertrouwen. Ik hoop dat ik dit vertrouwen niet geschaad heb. Ook Laury Bollen heeft in zijn rol als copromotor veel voor mij betekend. Nimmer stond ik voor een gesloten deur in het geval van vragen en stukken werden prompt gelezen en van nuttig commentaar voorzien. De vele uren overleg met promotor en copromotor heb ik, ook als de boodschap soms minder plezierig was, als zeer plezierig ervaren. Next I would like to thank the members of the assessment committee, Ann Vanstraelen, Harry Hummels and Robin Roberts for their evaluation of my dissertation. Daarnaast wil ik Eddy Vaassen bedanken die me op het onderzoekspoor heeft gezet.

Many thanks go to all colleagues and friends who helped me in many ways. I would like to thank Dorothea Baur, Cynthia Clark Williams, Rogier Deumes, Christopher Humphrey, Frank Moers, Mette Morsing, Brendan O'Dwyer, and Michael Russo for their valuable comments on research ideas and working papers. Ook ben ik mijn collega's van Accounting \& Information Management, waar ik het grootste deel van mijn promotie werkzaam was, erkentelijk voor de vele diepzinnige gang- en koffiemachinegesprekken. In het bijzonder hebben mijn mede-discipelen van het Botte Bijl genootschap -Caren, Jos, Laury, Roger- mijn tijd bij AIM niet alleen veraangenaamd door het delen van de lachwekkende motivaties voor hun belabberde muzikale smaak, maar ook mijn statistische kennis verrijkt met enkele nuttige analyses. Ook de drijvende kracht achter dit genootschap, Mark, dank ik voor vele, vele uren aangename verstrooiing, waarbij ook de volgende personen een belangrijke rol speelden: Jessica Simpson, Ernest Hemmingway, Apichatpong Weerasethakul, Caruso, de Zuid-Italiaan, Honey, Mark Smeets, Joke Bruis, Blanco en Christoffel. Anant, my roommate, I really enjoyed your presence, Maastricht slang, and Indian dishes. I 
thank Rebecca Ries for her valuable research assistance. Special thanks go to the 'St Andrews crew', who, more than constituting a highly relevant and inspiring CSEAR research conference community, made me feel like joining a reunion of old friends every year. Next to the organisers, Rob and Sue Gray, I would like to thank Brendan, Charles, Den, Mattias, Mia, Michelle, Robin and many others for their yearly help and good company, which gave me the necessary energy and inspiration to continue with my PhD project.

Tot slot wil ik allen in mijn persoonlijke kring bedanken die me hebben gesteund in de afgelopen jaren. Om te beginnen is dat mijn mecenas die met zijn gulle gift heeft mogelijk gemaakt dat $u$ dit proefschrift ingebonden en in gedrukte vorm in handen heeft. Daarnaast zijn dat mijn familie en vrienden, die immer belangstellend en bereid waren om zo nu en dan mijn klaagzang aan te horen en bovendien (deden alsof ze) bleven geloven in de goede afloop van dit proefschrift, ook naarmate de periode van 4 jaar verder overschreden werd. Bedankt voor jullie luisterende oor en belangstelling. Papa en mama, bedankt voor jullie onvoorwaardelijke steun, interesse en logistieke hulp.

Lieve Eline, Miel, Sofie, en Juliette, de laatste, belangrijkste woorden zijn natuurlijk voor jullie. Jullie hebben de afgelopen jaren wel eens wat gemerkt van mijn werk aan het boekje. Zo gingen we een jaar niet met vakantie; of deed ik soms irritant omdat ik moe was; of was ik er gewoon niet. En toch bleven jullie me steunen en dat vind ik heel bijzonder. Zonder jullie liefde, geduld en oneetbare eten had ik dit boekje echt nooit kunnen schrijven. Bedankt!

Thomas Thijssens

Maastricht, januari 2012. 


\section{Contents}

Chapter 1: Introduction 9

Chapter 2: Managing CSR reporting: The various ways to publish exemplary reports

Chapter 3: The relation between environmental performance and environmental disclosure: The role of environmental commitment

Chapter 4: Secondary stakeholder influence on Corporate Social Responsibility Disclosure: An empirical test of stakeholder salience theory

Chapter 5: Summary and conclusion

References

Appendix A

Appendix B

Appendix C

Summary in Dutch

Curriculum vitae 



\section{Chapter 1}

\section{Introduction}

\subsection{Corporate Social Responsibility Disclosure}

The innovating power of companies is widely considered to be among the main drivers of the progress Western industrialised societies have experienced since the 18th century Enlightenment. Nevertheless, next to prosperity, progress has likewise resulted in major environmental, social and economic challenges. Hence, there is a growing belief that companies also have a key role in addressing these challenges, i.e. in stimulating sustainable development. Corresponding to this belief, companies increasingly seem to take into account social and environmental aspects of corporate conduct, rather than focusing exclusively on financial performance. This orientation is captured by terms such as Corporate Sustainability or Corporate Social Responsibility (CSR).

As part of these CSR developments, since the 1970s companies have become engaged in CSR disclosure ${ }^{1}$. Currently, CSR disclosure is proliferating, both in terms of the number of companies engaging in this activity, and the comprehensiveness of the information included in the disclosures (Deegan \& Rankin, 1996; Gray, Kouhy, \& Lavers, 1995; Kolk, 2003; KPMG, 2008). A number of developments in recent years are illustrative for this increasing importance of CSR disclosure in society, particularly for large companies. First, the adoption of the Sustainability Reporting Guidelines published by the Global Reporting Initiative (GRI) ${ }^{2}$ has grown significantly since its first release in 2000 (www.globalreporting.org). Second, Socially Responsible Investment (SRI), in which CSR disclosure plays a key role, in recent years has ev-

\footnotetext{
${ }^{1}$ Some researchers prefer to use other terms such as Corporate Social and Environmental Reporting (CSER), Corporate Social and Environmental Disclosure (CSED), Social and Ethical Accounting, Auditing and Reporting (SEAAR) or Sustainability Reporting. I use the term CSR disclosure for pragmatic reasons: CSR is a term that is understood in many academic fields and consequently seems to be the term most widely used. I use 'disclosure' instead of 'reporting', because this term reflects the fact that companies can disseminate information in several ways, not just via reports.

${ }^{2}$ The GRI was launched in the late 1990s by CERES and UNEP, originating from the desire for more transparency and accountability by providing a standard with which companies could structure their CSR reporting (www.globalreporting.org).
} 
olved to become an important economic activity. SRI assets currently represent more than $17 \%$ of total assets managed in Europe (Eurosif, 2008) ${ }^{3}$ and approximately $12 \%$ in the U.S. (US SIF, 2010). The importance of SRI is also witnessed by the success of the United Nations' Principles for Responsible Investment (PRI), which were devised to stimulate incorporation of environmental, social and corporate governance items into investment decision-making and have been signed by more than 900 investment institutions, representing more than US\$ 30 trillion in assets under management (www.unpri.org). Third, governments (and institutions such as the European Union) have become involved in this development and have started to establish standards for CSR reporting (KPMG/UNEP, 2006).

Despite its overall increased importance, CSR disclosure is still a largely voluntary activity. Besides, research indicates that in this context supplies are yet far from matching demand (e.g., Cho \& Patten, 2007; Clarkson, Li, Richardson, \& Vasvari, 2008; Tilt, 1994). In addition, variations in CSR disclosure between companies remain to exist. These observations give rise to a number of questions. One of the main questions in the field of CSR disclosure is: why do managers voluntary engage in this activity? That is: is CSR disclosure inspired by e.g. reputation or accountability motives? And more interestingly, what are the specific factors that inspire the management of one company to engage in extensive CSR disclosure, and the management of another company to disclose only minimally? Answering these questions is important in the light of the usefulness of CSR disclosures. If it appears that CSR disclosure is principally motivated by managers' desire to avoid adverse stakeholder reactions or enhance the company's reputation, the quality of the information in the reports may be suboptimal, as will be the decisions that are made by stakeholders upon this information. However, when CSR disclosure is mainly a reflection of managers' drive to provide a truthful and complete picture of the company, stakeholders could be more confident in the effectiveness of their decision-making based on this disclosure.

\footnotetext{
${ }^{3}$ More recent figures of SRI market shares in Europe are only provided for one particular kind of SRI assets (core assets, which means: best of class and advanced exclusionary screenings), the market share of which has rapidly increased to approximately $10 \%$ of the total of assets under management in Europe (Eurosif, 2010). Figures for the market share of broad assets (i.e., limited exclusionary screenings and engagement), which type of SRI is much more common, have not been provided by Eurosif recently and consequently no overall market share figures for 2010 can be provided. Therefore the most recent figures (2008) are provided. Nevertheless it should be kept in mind that this market share figure may have increased significantly over the past three years.
} 


\subsection{Theoretical framework}

Over the years researchers have offered various theoretical insights for answering the above questions. The majority of these insights can be either categorised under economic theory or socio-political theories.

Economic theory starts from the idea that due to the separation of ownership and control, by which the governance of many companies is characterised, disclosure is essential for providing external parties with information that enables them to monitor management. Traditionally, this notion of external parties has been primarily directed towards shareholders (Parker, 2007). Managers have a contractual obligation to provide information to the shareholders -as the owners of the company- about the way in which they managed their equity investments. This is referred to as 'accountability'. However, empirical evidence indicates that despite this duty, managers exploit the information asymmetry between themselves and external parties (i.e., shareholders) to act in their self-interest, which is known as the 'agency conflict'. In these settings, voluntary disclosure occurs only when management assesses that the benefits, i.e., lowering the costs of capital, outweigh the proprietary costs involved (Verrecchia, 1983). Application of these theories, in particular agency- and voluntary disclosure theory, has also been suggested in the context of CSR disclosure. This type of research is based on the idea that companies disclose truthful CSR information ${ }^{4}$, which shareholders and other investors use in their investment decisions. Nevertheless, in these instances the application of agency theory has its limitations. That is, its focus on actors with monetary considerations limits its applicability in the context of (largely non-financial) CSR disclosure (Cormier, Magnan, \& Velthoven, 2005). For example, understanding CSR disclosure to stakeholders other than shareholders, such as environmental stakeholders, on the basis of agency theory may be problematic, as they operate mostly outside capital markets (Cormier, et al., 2005), their relationships with the company are not stipulated in contracts and they may focus on other than monetary considerations. This line of argumentation is supported by the mixed evidence provided by empirical studies on the usefulness of CSR information for investors based on economic theory (for a review of the literature, see: Holm \& Rikhardsson, 2008).

Therefore, it has been suggested that more pluralistic relationships, considering management-society or management-stakeholder interactions, are more appropriate. Pluralistic relationships are the basis of socio-political theories such as legitimacy and stakeholder theory. Both theories are regarded to provide "a more complete view" on CSR disclosures (Cormier, et al., 2005) and to be "of more promising

\footnotetext{
${ }^{4}$ Previous empirical studies (e.g., Healy and Palepu, 2001, Van de Poel and Vanstraelen, 2011) have indicated that the levels of credibility of (financial) voluntary disclosures are contingent upon factors such as public oversight and regulatory regimes. Likewise, such factors may affect the degree to which CSR disclosures are truthful.
} 
descriptive power" (Gray, Owen, \& Adams, 1996) than e.g. agency theory, since they acknowledge the variety of interests in corporate disclosures.

As for stakeholder theory, Freeman's (1984) stakeholder definition is most widely used, defining a stakeholder as "any group or individual who can affect or is affected by the achievement of the firm's objectives". Many researchers consider stakeholder theory to be inherently normative (Clarkson, 1995; Donaldson \& Preston, 1995; Freeman, 1984), giving prescriptions about how companies should behave. Many researchers refer to this normative notion when applying this theory, asserting that management should take into account the demands of all stakeholders instead of only those of shareholders; or, as Donaldson and Preston (1995) put it: "The interests of all stakeholders are of intrinsic value. That is, each group of stakeholders merits consideration for its own sake and not merely because of its ability to further the interests of some other group, such as the shareholders".

Corresponding to the normative nature of stakeholder theory, legitimacy theorists have also underlined a company's duty to act in accordance with societal norms and values (Gray, et al., 1996; Hasnas, 1998). Legitimacy theory is normatively based on the idea that companies do not have an inherent right to exist, yet should adhere to norms and values of society in order to 'deserve' this right (Deegan, 2002). Often legitimacy is referred to in terms of a 'social contract' between a company and society; a contract the company should not breach.

Within the context of CSR disclosures, the normative view introduces the concept of 'social accountability' (Gray, et al., 1996), referring to "the duty to provide an account (by no means necessarily a financial account) or reckoning of the actions for which one is held responsible". Consequently, the traditional explicit contractbased relationship between principal and agent is extended to become a relationship between 'accountor' and 'accountee' based on a social contract (Gray, et al., 1996). This social contract can be legal or non-legal, the latter meaning moral contracts as governed by values and principles of society. The idea is that companies owe accountability to all of their stakeholders. Information provision is regarded as a key element in this accountability model. All in all, the normative view claims that companies have the duty to inform society about the extent to which they have complied with the 'social contract' by means of addressing the interests of its stakeholders. From a normative point of view stakeholder and legitimacy theory are positioned as the counterparts of agency theory.

Despite their important position in the socio-political research tradition, normative views have only limited explanatory or descriptive power in predicting managerial behaviour. Researchers in this field have also raised doubts about whether voluntary CSR disclosure has anything to do with accountability (Cooper \& Owen, 2007; Gray, et al., 1996; Hopwood, 2009; O’Dwyer, 2003; O’Dwyer, Unerman, \& Hession, 2005b; Owen, Swift, Humphrey, \& Bowerman, 2000). This belief is supported by 
empirical research, including studies that report a negative, or lack of, association between CSR reporting and actual CSR performance. In order to study what effectively determines CSR disclosure in practice, managerial behaviour is important. That is why 'descriptive views' are needed. A descriptive stakeholder model starts from the idea that theory corresponds to observed reality (Donaldson \& Preston, 1995). It acknowledges that stakeholders need to be managed not only because of their intrinsic interests but also because they might be able to influence a company's 'going concern'. Following a similar line of thought, the descriptive view on legitimacy theory recognises that, next to the duty to comply with the social contract, a company's going concern might be in danger when that company perceivably breaches its social contract. Taking into account CSR disclosures, the descriptive view does not consider CSR disclosures as a reflection of accountability, yet as a reflection of the perceived importance of legitimate claims from society as embodied by the corresponding stakeholders. Gray et al. (2001) indicate in this context: "Information ( . . . ) is a major element that can be employed by the organisation to manage (or manipulate) the stakeholders in order to gain their support and approval, or to distract their opposition and disapproval“.

Each of the previously discussed, and in some cases opposing, theoretical views is associated with a number of research endeavours for empirical substantiation, typically by focusing on the conditions under which companies engage in CSR disclosure. Most empirical studies either relate CSR disclosure to a wide range of external company characteristics or investigate the association between CSR disclosure and some publicly available CSR performance metrics. These studies provide contradictory results. As a consequence, a comprehensive theoretical framework for studying CSR disclosure is still missing.

Although so far each of the theories applied to researching CSR disclosure has been able to only partially explain the phenomenon (Adams, 2002), in this dissertation I nevertheless propose that socio-political theories (i.e., stakeholder and legitimacy theory) constitute the most appropriate theoretical starting point for researching CSR disclosure. These theories are increasingly considered to be the most complete perspective for enlightening the topic empirically (Cormier, et al., 2005; Gray, et al., 1996). Moreover, in each of the chapters I will provide more extensive arguments for the appropriateness of socio-political theory in the context of the specific topics addressed. Although stakeholder and legitimacy theory may be formally considered to be separate theories, from what has been said so far it appears that they are much intertwined constructs. Consequently, they are often treated as overlapping constructs (see e.g.: Deegan \& Blomquist, 2006; Gray, et al., 1995). This dissertation follows a similar approach. 


\subsection{Objectives of this dissertation}

There are various potential explanations for the inconsistency in outcomes of previous empirical research and the resulting absence of a comprehensive theoretical framework.

First, CSR measurement is a complicated issue (Wood, 2010). In order to evade this complexity, empirical researchers tend to avoid introducing new performance metrics. They rather rely on broadly accepted than on more appropriate measures.

Second, the research field of CSR (disclosure) is characterised by a general scarcity of appropriate research data. A practical absence of CSR disclosure regulation and the sensitive nature of the topics involved have contributed to this scarcity. Hence, in their attempts to frame the conditions under which companies engage in CSR disclosure, many studies rely on common company characteristics (i.e., size, industry and country), or financial accounting figures (i.e., profitability, leverage), as well as public non-financial information (such as performance information from CSR reports). Their reliance is mainly motivated by the prompt availability of this type of information. However, there are some disadvantages associated with the sole reliance on these external characteristics. First, commonly used company characteristics and accounting figures are broad measures and therefore it is difficult to pinpoint the extent to which observed variances for these measures are related to variances in specific CSR related measures. As a result, certain empirical observations related to these measures may be explained from various theoretical points of view. Likewise, different theories hypothesise similar associations between CSR disclosure and these characteristics. Second, the drawback of public non-financial information is that companies, due to the voluntary nature of most non-financial disclosure, can be selective in, and may positively bias the disclosed information. As will be discussed in a later chapter, socio-political theory, the theoretical point of reference for this dissertation, actually states that managers have incentives to provide CSR disclosures that are positively biased. These incentives stem from a felt need to avoid societal perceptions of illegitimacy due to negative CSR performance information and resulting adverse reactions by stakeholders. Consequently reported CSR performance will likely deviate from the actual (internal) performance.

From the previous it appears that the current body of knowledge on CSR reporting would benefit from empirical studies based on 'richer' company information; i.e., data better capturing the distinctive (CSR) characteristics of a particular company. One way to accomplish this is to use company information that is initiated and developed by other than managerial actors and therefore less 'coloured', such as researchers' direct observations or other stakeholders' investigations. Another way is by concentrating on internal company factors that are more unique to a particular company than common external characteristics or accounting figures. 
Hence, the aim of this dissertation is to contribute to the development of a more inclusive theoretical framework for CSR disclosure. Overall it puts forward that stakeholder needs, and particularly their ability to influence company management, are important determinants of CSR disclosure. In addition, the ability of companies to effectively respond to these needs is an important factor. It seeks to accomplish this contribution by empirically taking into account precisely these richer data.

First, an important focus in this thesis is on the way in which CSR disclosure is internally managed. Two empirical studies concentrate on these internal factors. In the first study (Chapter 2) I explore the internal management of CSR reporting by means of an in-depth investigation on what internal factors are associated with CSR reporting and how. In the second study (Chapter 3) I investigate the relation between environmental performance, which is a sub-set of CSR performance, and environmental disclosure, proposing a performance dimension that is closely related to internal managerial processes, i.e., a company's environmental commitment.

Next, the third study (Chapter 4) takes into account external factors, by concentrating on the way in which external stakeholders influence CSR disclosures. However, contrary to most previous research this influence is not considered from a management point of view. The use of a proprietary database containing information from various sources -including the media, NGOs, internal company documents and company interviews by researchers- enables a more detailed investigation of other stakeholders' influence on CSR disclosure.

The previous is illustrated in figure 1 , in which the solid arrows represent associations that have been established in previous empirical research, whereas the dotted arrows represent the associations that are the subject of this thesis. 


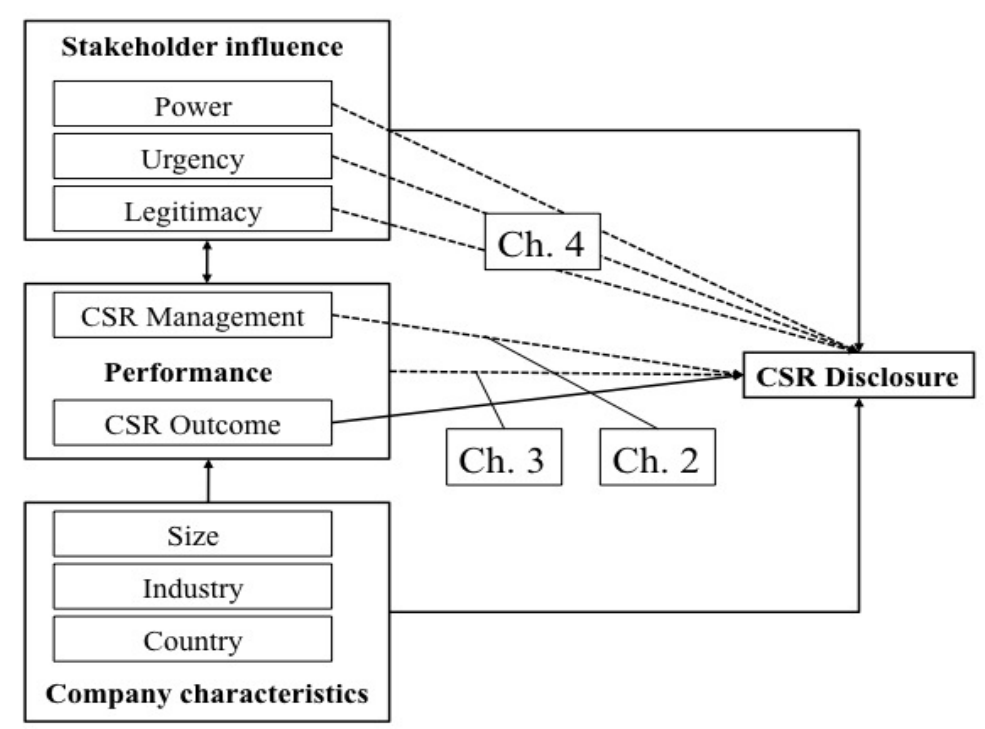

Figure 1.1: Overview of researched relations and corresponding chapters in this thesis, and their relation to established relations from previous empirical research

\subsection{Research methods}

The three studies vary with regards to their research approach.

For the first study, an inductive approach was considered to be most appropriate, given its exploratory nature (Babbie, 2008). This approach is operationalised through a multiple-case design, in combination with a data collection process via semi-structured interviews.

The second and third study are based on deductive approaches, in line with the more explanatory nature of their research questions (Babbie, 2008). Both studies are based on relatively large and comparable samples, which are drawn from a proprietary database, and for both studies quantitative data are used in the analysis. As was mentioned earlier, socio-political theories are used for the hypothesis development of these studies. They are often treated as overlapping constructs (see e.g.: Deegan \& Blomquist, 2006; Gray, et al., 1995). In fact, as put forward by Deegan (2002) many researchers switch from legitimacy to a stakeholder framework when concretising the blurred constructs of 'society' or 'relevant publics' and their corresponding needs for their empirical research designs. This dissertation follows a similar approach. That is, the two quantitative studies follow the logic of socio-political theories in developing their hypotheses. Yet, in line with the previous one of the quantitative studies (Chapter 3) starts from legitimacy theory, whereas the second (Chapter 4) is framed within stakeholder theory. 
For these two quantitative studies, sufficiently large samples were needed in order to test the hypothesised relations. The database use, data coding process and construction of the dependent variable, which were similar for both studies, will now be described. Both studies focus on a subset of CSR disclosure, i.e. environmental disclosure.

\subsubsection{Database}

The samples for both studies (Chapter 3 and 4) consist of companies that are included in a proprietary database. A cross-sectional research design is used, based on company data for the year $2004^{5}$. I use the 2004 SiRi (Sustainable Investment Research International) database with its sustainability profiles of companies included in the MSCl World Index. As this index includes the 1500 largest (by market capitalisation) equities in the world, the sample represents large companies from developed markets. SiRi is an international network of Socially Responsible Investment (SRI) research organisations collecting a wide range of CSR information of companies for their customers, which are mainly institutional investors ${ }^{6}$. The network members use the collected information also for their local databases and other investment services. The SiRi data have been used in prior research (Nimwegen, Bollen, Hassink, \& Thijssens, 2008; Prior, Surroca, \& Tribó, 2008; Surroca, Tribó, \& Waddock, 2010). The SiRi database, and the data provided by some of the individual members - among which: Kinder Lydenberg Domini (KLD), Michael Jantzi Research Associates (MJRA), and Pensions \& Investment Research Consultants (PIRC) - are widely considered a reliable and high quality information source.

The SiRi global profiles that were used, contain over 350 data points and are structured according to the following research themes: Community, Corporate Governance, Customers, Employees, Environment, Contractors/Human Rights, and Business Ethics. The themes correspond to the following stakeholder groups: the community, shareholders, customers, employees, environmental groups, and human rights groups. Due to this stakeholder orientation the database is considered to be the appropriate tool for the purpose of this study. The sources, on which the profile content is based, are not limited to annual reports, but include a multitude

\footnotetext{
${ }^{5}$ The SiRi database contained only the latest up-to-date company profiles; at the time this study was conducted profiles from prior years were not systematically kept. Nevertheless, two years (2002 and 2004) of historic data were available, next to the up-to-date profiles from the year in which this study was conducted. Hence, the initial aim of this study was to use panel data. However, analysis of the profiles learnt that in $\mathbf{2 0 0 5}$ the profiles had undergone major changes, which made comparison across years impossible. Moreover, during the coding process it appeared that in the 2002 database many of the variables of interest for this study were missing, which would seriously negatively affect the sample size. Consequently it was decided to use a cross-sectional design by only including the 2004 data.

${ }^{6}$ In September 2008 SiRi announced that it would cease the current organisation of its operations and continue its services under the name 'Sustainalytics' as from 2009.
} 
of sources, such as special-purpose reports (environmental reports, sustainability reports, and personnel reports), NGOs and governments, the media, one-to-one meetings with company representatives, and questionnaires. An extensive sample profile can be downloaded from http://dl.dropbox.com/u/20631923/sample\%20company\%20profile\%20siri.pdf.

Due to the large amount of data that had to be coded for each company, it was not feasible to analyse all companies in the database. Hence, a sample was taken that, in line with prior research, provided an equal spread over two country types: shareholder versus stakeholder-oriented countries (Holder-Webb, Cohen, Nath, \& Wood, 2008; Simnett, Vanstraelen, \& Chua, 2009; Smith, Adhikari, \& Tondkar, 2005). This differentiation is based on differences between, and similarities in corporate governance across countries as a result of institutional and legal settings. To accomplish this I first selected per country type the corresponding countries with sufficient numbers of company observations, resulting in: U.S., U.K., Australia, Canada, and Hong Kong for shareholder-oriented, and Germany, France, Belgium, Denmark, Finland, and the Netherlands for stakeholder-oriented countries. Next, $100 \mathrm{com}$ panies were selected from each of these two country-types. The resulting 200 companies accounted for slightly more than $50 \%$ of the companies in the dataset and thus formed a good representation ${ }^{7}$. After taking care of duplicates and adjusting for the fact that companies in the database were geographically ordered according to country of their main stock listing, whereas my country classification was based on the country in which the company was headquartered, the final sample consisted of 199 companies, of which 101 from shareholder and 98 from stakeholderoriented countries.

\subsubsection{Data coding}

Given that both quantitative studies focus on environmental disclosure, this measure was constructed using the previously mentioned SiRi company profiles, by taking into consideration 47 items under the theme 'environment'. The profiles divide these items between three broad categories of 'principles and policies', 'management systems', and 'performance'. An overview of the environmental information items included in the profile as well as the corresponding category for each item can be found in Appendix A. As indicated before, these items are considered to represent the information needs of the environmental stakeholders. For each information piece presented under each of the 47 items, SiRi mentions the exact source from which it was taken. Based on these sources two researchers independently

\footnotetext{
${ }^{7}$ Given the previously mentioned initial aim of using panel data, companies included in both the 2002 and 2004 database were selected, resulting in a dataset of 397 companies.
} 
scrutinised whether the majority of the information pieces provided was publicly disclosed or not, resulting in a score of 1 or 0 for each item. For this purpose, they made use of a detailed coding protocol in which all company-initiated information disclosures via public media (e.g., annual and special-purpose reports, website) were considered to be public disclosure (see Appendix B). They then compared their outcomes; in case the opinions contradicted, the results were discussed until agreement was reached. After coding, the individual scores per company were aggregated assuming equal weights, and expressed as a proportion of the total number (i.e., 47) of information items. The resulting disclosure index, labelled ENVDISC, represented the level of environmental disclosure as expressed by the extent and type of information, reflecting a company's overall disclosure strategy (Brammer \& Pavelin, 2006). To illustrate the previous, a company profile with information on 35 environmental items (and consequently no information for 12 items), of which 27 items were sourced from a company's public disclosure and 6 items from other sources (such as the media or a questionnaire), would result in an index-score of $27 / 47=0.57$. This method is similar to the one applied by Brammer \& Pavelin (2006: 1176), which the authors present as an improvement over previously used measures, as it enables judging the quality of disclosure by type rather than by volume of disclosures (e.g., the number of words or sentences).

\subsection{Contributions}

This dissertation contributes to the existing literature in a number of ways.

To start, it initiates answering the call for including internal factors in CSR disclosure research. This is achieved in three ways. First, it provides an exploration into the way in which CSR disclosure is internally managed. This was enabled by rich data on a wide variety of internal management factors, which were collected through semi-structured interviews. In addition, it shows how differences in internal management relate to differences in the extent of CSR disclosure. Third, it provides evidence on how internal management affects (external) CSR performance, as well as the relation between CSR performance and CSR disclosure.

In addition, it provides evidence that outside stakeholders are influential with regards to CSR disclosure. More importantly it is also one of the first studies to provide evidence on why this is the case by showing how stakeholder characteristics are related to management choices regarding CSR disclosure. As such it contributes to the literature by showing that not only external company characteristics but also external stakeholder characteristics are related to CSR disclosure.

The contributions made by the quantitative studies can be attributed to the use of a proprietary database, which made it possible to create a unique dataset. 
Overall, the above contributions are valuable complements to the inconclusive empirical evidence that has informed theory-building in CSR disclosure so far.

\subsection{Outline of the dissertation}

The remainder of this dissertation is organised as follows. Chapter 2 presents a qualitative study exploring the way in which CSR reporting is internally managed. Chapter 3 describes a quantitative study on the link between environmental performance and environmental disclosure, focusing on the role of internal company factors. Chapter 4 shifts the focus to external factors related to CSR disclosure, presenting a quantitative study on the extent to which secondary stakeholders can influence CSR disclosure. Chapter 5 concludes and summarises this dissertation. 


\section{Chapter 2}

\section{Managing CSR reporting: The various ways to publish exemplary reports ${ }^{8}$}

\subsection{Introduction}

A colourful group of institutions such as governments, rating agencies, the accounting profession and other interest groups has responded to the popularity of CSR reporting by establishing awards and benchmarking schemes. The focus of these schemes is CSR reporting rather than CSR performance, as expressed in the following statement: 'The purpose of the awards program is to acknowledge and publicize best practice in reporting on sustainability performance and to provide leadership to those companies that are publishing or intend to publish sustainability reports. The awards are not intended to endorse or reward company performance, but rather to acknowledge exemplary disclosure (...) (www.ceres.org $\left.{ }^{9}\right)$.

Academics acknowledge the importance of CSR reporting by focusing on its ability to effectively respond to the information needs of various stakeholders (e.g., Cormier, Magnan, \& Velthoven, 2005; Gray, Owen, \& Adams, 1996). These stakeholder information needs relate to the extent to which the management of a company has addressed their respective interests, which is reflected in a company's CSR performance. CSR performance is usually specified with the term 'Corporate Social Performance (CSP)'. Wood (1991) defines CSP as 'a business organisation's configuration of principles of social responsibility, processes of social responsiveness, and policies, programs, and observable outcomes as they relate to the firm's societal relationships'. Given that most stakeholders are external to the company, they cannot directly observe these principles, processes, policies and programs, resulting in

\footnotetext{
${ }^{8}$ I would like to thank the interview participants for their time and cooperation; also comments by Brendan O'Dwyer, Christopher Humphrey, as well as the participants of the $21^{\text {st }}$ CSEAR Conference in St Andrews are gratefully acknowledged. Special thanks go to Rebecca Ries for her valuable research assistance.

${ }^{9}$ CERES, a stakeholder network addressing sustainability issues in capital markets, co-founded the CERESACCA North American awards for Sustainability Reporting.
} 
information asymmetry between managers and stakeholders. CSR reporting potentially is the appropriate tool for reducing this asymmetry. A necessary condition for a successful reduction in asymmetry is that the CSR information is of high quality, i.e. a genuine reflection of accountability. However, as was discussed in the previous chapter, researchers have expressed their doubts on the correctness of this condition, and as a result have sought for alternative theoretical explanations. Typically, these researchers have empirically tested the various theoretical frameworks by focusing on the conditions under which companies engage in CSR reporting. Consequently, most empirical studies relate to an association between CSR reporting and a wide range of external (accounting) company characteristics. This focus on external factors has largely precluded research attention for internal determinants of CSR reporting.

Yet, as was discussed in the previous chapter, studying internal determinants is of equal importance since these factors are better able to capture the unique (CSR) characteristics of a particular company. Some observations underline the importance of internal factors.

First, company practice reveals that managers increasingly are convinced of the importance of the proper internal management of CSR reporting, as indicated by a $100 \%$ increase in the use of the $\mathrm{AA} 1000^{10}$ standard by large companies between 2005 and 2007 (KPMG, 2008); this scheme is concerned with the internal processes related to CSR reporting quality.

Next, in the only study to date that explicitly focuses on internal determinants Adams (2002) finds that CSR reporting is subject to internal contextual variables. This implies that variance in CSR reporting, next to external determinants, may be attributed to variance in internal company factors as well. She suggests: "There would, I think, be great value in more case study work examining the processes of social and ethical reporting ( . . . )".

In response to the previous suggestion, this study aims at determining these internal factors through exploring internal management of CSR reporting by means of a multiple-case study. Building on interview data from the case companies and on the limited discussion from prior work a typology of management of CSR reporting is developed. I find that two important factors in the management of CSR reporting are the level of formalisation of CSR reporting and the level of integration of CSR into the day-to-day CSR management.

In focusing on the internal management of CSR reporting, the following contributions to the literature are made. First, this study initiates answering the call to include internal factors in CSR disclosure research (Adams, 2002). Second, following

\footnotetext{
${ }^{10}$ The AA1000 is a framework developed by the Institute for Social and Ethical Accountability, focusing on internal processes for reporting and auditing (Adams, 2002).
} 
the limited empirical evidence on what internal factors influence CSR reporting, it is a first exploration of how CSR reports are internally managed. Third, the suggested typology may serve as a useful tool to understand the different ways in which companies internally manage CSR reporting, to explore the relationships between the various types of internal management, and to frame future research. With these contributions this study aims to inform theory building in the field of CSR reporting at large.

The remainder of this paper is structured as follows. Section 2 gives an overview of the existing literature related to the factors that determine CSR reporting. The third section describes the data collection process and describes how the interviews were conducted. Further, it elaborates on the research method and the instruments that are used. Section 4 presents the empirical results, focusing on a typology of ways in which companies internally manage CSR reporting and how the related internal organisational factors fit into existing models of CSR reporting. Finally, a conclusion is drawn and the implications for future research and the limitations of this study are discussed.

\subsection{Literature Review}

Researchers have tried to explain dissimilarities in CSR reporting by offering various theories. Mostly these theories have been tested by focusing on the factors that influence CSR reporting. Empirical research on the determinants of CSR reporting has typically addressed external factors, using a wide variety of theories.

\subsubsection{External factors influencing CSR reporting}

Adams (2002) provides a review of the literature that uses socio-political theories ${ }^{11}$ in researching the determinants of CSR reporting. She concludes that there is general consensus regarding an established link between CSR reporting and size, industry affiliation and country, where the influence of the latter factor can be attributed to institutional settings (economic and political contexts) and culture (Adams, 2002).

Although socio-political theories are frequently regarded to be the most promising avenue for enlightening the topic (Cormier, et al., 2005; Gray, et al., 1996), researchers have suggested alternative theoretical perspectives. Whereas some of these researchers suggest the same characteristics as previously mentioned, others come up with alternative factors that are associated with CSR reporting, such as:

\footnotetext{
${ }^{11}$ 'Socio-political theories' is the umbrella term for the following theories: legitimacy theory, stakeholder theory, and political economy theory.
} 
profit (Bowman, 1973; Bowman \& Haire, 1975; Gray, et al., 1996), cost of capital (Belkaoui \& Karpik, 1989; Blacconiere \& Patten, 1994), financial condition, information costs, and imitation and routine (Cormier, et al., 2005). Since no one theory among this multitude of theoretical viewpoints has received consistent support, a comprehensive theoretical framework for studying CSR reporting is still lacking. Each of the theories used in researching the determinants of CSR reporting can only partially explain the phenomenon (Adams, 2002). That is why Adams (2002: 1) stresses the need for "a more inclusive model of corporate social reporting", which includes also internal contexts.

\subsubsection{Internal factors influencing CSR reporting}

The focus on external factors has largely precluded research attention for internal determinants of CSR reporting. The difficulty in observing these factors may add to this lack of attention. And even in the limited amount of cases where internal factors are mentioned, such is mostly done as an aside or in passing. Nevertheless, this section presents this limited body of research on internal factors.

Some studies discuss internal factors that relate to styles and attitudes of top managers, such as the influence of the number of outside non-business directors (Bowman \& Haire, 1975), the presence of a CSR committee (Cowen, Ferreri, \& Parker, 1987) and changes in the company chairman (Campbell, 2000). Delfgaauw (2000: 70) stresses the importance, particularly for large companies, of 'a proper structure' for sustainability reporting, based on shared values and translating into policies, processes, procedures and systems. One of the latest contributions is a study by Adams and Frost (2008) on companies' development of sustainability key performance indicators (KPIs) and the degree to which they are integrated in decision-making and performance management. One of the many management practices they considered in this study for a sample of 7 Australian and British companies (all with best-practice CSR reporting) was sustainability reporting. They found considerable variation in the extent to which reporting functions were integrated into management decision making, motivations for reporting and the functions, departments and numbers of staff involved in, and formalisation of the KPI development process. Adams (2002), in the only study to date with the explicit purpose of determining the internal organisational factors influencing CSR reporting ${ }^{12}$, suggests that CSR reporting is subject to reporting structures and processes and the attitudes of the ones involved in it. Based on interviews with companies in two countries, she finds that the degree of formality of the process, the departments involved and the level of stakeholder involvement have an impact on CSR reporting.

\footnotetext{
${ }^{12}$ The study actually focuses on health safety \& Environment (HSE) report, which limits the comparability with studies on CSR reporting, since the latter type of reporting is much broader.
} 
Also the views and attitudes of the ones involved in reporting towards: past and future reporting, reporting bad news, costs and benefits of reporting and regulation and verification appear to have an influence. She argues that these process factors in turn are dependent on company size, country of origin and corporate culture. From the previous discussion, it becomes clear that knowledge about the internal factors affecting CSR reporting is still largely fragmented.

Given that CSR reporting can be considered as a subset of CSR performance (Wood, 1991), this literature review will also include studies on the potential influence of internal organisational factors on CSR performance from (strategic) management literature. Notwithstanding the fact that this research is limited too (Adams \& Frost, 2008), it may be helpful in determining internal organisational factors that also influence CSR reporting.

In line with Adams' (2002) literature review, management literature on internal determinants of CSR performance also can be broadly divided into studies focusing on the influence of personal traits on the one hand and organisational structures and processes on the other hand. As regards the former stream of literature, studies have suggested a relationship between CSR performance and managerial (Carroll, 1979; Weaver, Trevino, \& Cochran, 1999; Wood, 1991) and employee (Collier \& Esteban, 2007) commitment or values (Agle, Mitchell, \& Sonnenfeld, 1999; Hemingway \& Maclagan, 2004; Quaak, Aalbers, \& Goedee, 2007). Studies in the latter stream of research have provided evidence for a link between organisational strategies, structures and CSR performance. Husted (2000) provides a summary of the literature, which suggests widely differing organisational factors such as: publicaffairs management structures, the implementation of permanent versus temporary departments dealing with social decisions, or the degree to which companies use planning, evaluation and compensation systems. Based on this literature and using a definition of Lorange et al. (1986), he suggests that CSR performance is dependent upon "the overall mechanism in the organisation that impacts the flow of information, the process of decision making, and the delineation of responsibility". Husted (2000) states that this body of literature is driven by the well-established strategystructure-performance relationship developed in the strategy literature. Finally, a handful of papers discuss how organisational processes and structures may influence commitment and values of the persons involved in CSR. Quazi (2003) finds that managerial skills, obtained by formal education and management training, determine managers' commitment to CSR. Delmas and Toffel (2004) indicate that organisational structure moderates the relationship between external pressures and management perception with regard to environmental practices. Albelda-Pérez, CorreaRuiz and Carrasco-Fenech (2007) put forward that both personal characteristics and organisational structures and processes - which they label 'intangible assets'- are essential for enhancing environmental performance; they suggest the following factors: employee awareness, knowledge, skills and expertise of employees, inte- 
gration of environmental issues in strategic planning, the use of management accounting practices, management commitment, and cross-functional coordination and communication.

The above discussion leads to the following research questions: What are the organisational structures, systems and processes with which companies manage their reporting process? What types of CSR reporting management are there and how do they relate to existing models of CSR reporting? What are the underlying dimensions of managing CSR reporting?

\subsection{Research method}

The principal aim of this study is to respond to Adams' (2002) call for "a more inclusive model of corporate social reporting" by exploring the under-researched topic of internal organisational factors. Given this lack of empirical research, and the consequent exploratory nature of this study, an inductive approach was considered to be most appropriate (Mintzberg, 1979). A multiple-case design was chosen as this allows detailed exploration of several cases in an iterative process, which potentially produces more robust outcomes (Yin, 1994). The data collection process was based on semi-structured interviews with knowledgeable managers and secondary data sources, the latter of which were used to corroborate the findings from the interviews.

Rooted in the idea that most understanding is gained from focusing on the companies that have already achieved high-quality reporting (Adams, 2002) this research focuses on companies that are generally recognised ${ }^{13}$ for their exemplary CSR reporting.

In order to select companies with high-quality CSR reports, two criteria were specified. The first selection criterion was whether a company over the last three years reported in line with the Sustainability Reporting Guidelines (G3) ${ }^{14}$ provided by the Global Reporting Initiative (GRI). The second criterion was whether the company over the last three years was included in the top 20 of the Transparency Benchmark by Pricewaterhouse Coopers (PWC) and the Dutch Ministry of Economic Affairs, one of the previously mentioned benchmarking award schemes in the Netherlands. ${ }^{15}$

\footnotetext{
13 'Generally recognised' refers to the fact that these companies are frequently listed in reward and benchmarking schemes among the top companies in terms of CSR reporting.

${ }^{14}$ As from October 2006 the Sustainability Reporting Guidelines are abbreviated as G3. Before, they were labelled $\mathrm{G} 2$ and based on guidelines from 2002.

${ }^{15}$ At the time of conducting this study (July 2008), I used the latest three available benchmarks, i.e. the Transparency Benchmarks of years 2005, 2006 and 2007 (based on respectively fiscal years 2004, 2005 and 2006) and the GRI application benchmarks of fiscal year 2005, 2006 and 2007 reports.
} 
The GRI is a reputable institution and the application of its guidelines has grown significantly in recent years. Because the guidelines mention: "The Sustainability Reporting Guidelines (...) consist of Principles for defining report content and ensuring quality of reported information" (GRI, 2006: 3), application of the guidelines was regarded as a signal for high-quality CSR reporting ${ }^{16}$. The Transparency Benchmark is a scheme initiated by the Dutch Ministry of Economic Affairs and performed by Pricewaterhouse Coopers. It analyses the transparency with regard to CSR of the annual (CSR) reports of 171 Dutch companies. Companies are ranked on the basis of a set of 47 CSR reporting criteria for which a maximum amount of 100 credits are granted (PWC, 2007) ${ }^{17}$. The report mentions that the total amount of credits that a company is granted, expresses the quality of its CSR report (PWC, 2007: 15). The top 20 companies in this scheme are considered to be the 'leading group' with regards to the level of transparency in their CSR reports (PWC, 2007: 32).

For the selection of case companies theoretical sampling was used (Eisenhardt, 1989; Yin, 1994); that is, companies were purposefully chosen, in order to ensure that they were illustrative for the issues of concern. The purpose of this sampling was to choose both cases producing similar results and cases producing contrasting results for reasons that were expected, according to the logic of respectively literal and theoretical replication (Yin, 1994). So as to meet the conditions of literal replication, sampling was done through selecting only large publicly listed companies from one country: The Netherlands. This choice was based on previous research indicating that company size and country of ultimate ownership affect CSR reporting. Since previous studies also found an industry effect on CSR reporting, in line with the need for contrasting case results, companies from different industries were chosen. If possible, given the limited number of companies that satisfied the previous selection criteria, two companies per industry were selected. The final sample consists of six companies from four industries (Table 2.1).

\footnotetext{
${ }^{16} \mathrm{GRI}$ also recognises various adherence levels of the $\mathrm{G} 3$; dependent on the number of indicators that are covered in the reports, GRI distinguishes between C-, B-, and A-level, where A is the highest level. In addition, these levels can be with or without external assurance, which is symbolised with a ' + '. The initial aim of the sample selection procedure was to include only companies with a GRI adherence level of A+. However, it turned out that, given the other selection criteria, the number of companies would be too small. At the time of conducting the research the application levels of the latest available reports (i.e., from 2007) of the companies included in the study varied from C to A+. Nevertheless, the 2008 reports, which refer to companies' actions during the year in which the interviews were held, all had an $A+$ adherence level, except for company $C$ who did not declare this level.

${ }^{17}$ A detailed overview of the criteria can be retrieved from: www.transparantiebenchmark.nl.
} 
Table 2.1: Sample descriptives

\begin{tabular}{|c|c|c|c|c|c|c|c|c|}
\hline \multirow[t]{2}{*}{ Company } & \multirow[t]{2}{*}{ Interviewee(s) } & \multirow[t]{2}{*}{ Industry } & \multirow{2}{*}{$\begin{array}{c}2004 \\
\text { TB }\end{array}$} & \multicolumn{2}{|c|}{2005} & \multicolumn{2}{|c|}{2006} & \multirow{2}{*}{$\begin{array}{c}2007 \\
\text { G3 }\end{array}$} \\
\hline & & & & G3 & TB & G3 & TB & \\
\hline A & $\begin{array}{l}\text { Manager corporate com- } \\
\text { munications \& Coordinator } \\
\text { CR }\end{array}$ & Financials & Top 20 & $\mathrm{G} 2$ & Top 20 & yes & Top 20 & yes \\
\hline B & Corporate director CSR & Chemicals & Top 20 & $\mathrm{G} 2$ & Top 20 & yes & Top 20 & yes \\
\hline C & $\begin{array}{l}\text { Manager corporate com- } \\
\text { munications }\end{array}$ & Nutrition & Top 20 & $\mathrm{G} 2$ & Top 20 & yes & Top 20 & yes \\
\hline D & $\begin{array}{l}\text { Project manager sustaina- } \\
\text { bility reporting }\end{array}$ & Financials & Top 20 & $\mathrm{G} 2$ & Top 20 & yes & Top 20 & yes \\
\hline$E$ & Issue manager & Energy & Top 20 & yes & Top 20 & yes & Top 20 & yes \\
\hline $\mathrm{F}$ & $\begin{array}{l}\text { Associate corporate secre- } \\
\text { tary }\end{array}$ & Chemicals & Top 20 & $\mathrm{G} 2$ & Top 20 & yes & Top 20 & yes \\
\hline
\end{tabular}

For each of the selected companies the names and positions of the responsible managers for CSR reporting, as well as their e-mail addresses were retrieved. All of these company representatives were contacted to explain the purpose, method and planning of the research. It was also stressed that the study aimed at interviewing the person that was 'most knowledgeable' about CSR reporting within the company, which is not necessarily the one that is the ultimate responsible. Three respondents consequently suggested other, more knowledgeable, company representatives for the interviews. All of the interviewees were managers having extensive knowledge about CSR reporting, which was gained through their active participation in the decision-making process regarding CSR reporting. Company names have been exchanged with alphabetical characters, since confidentiality was guaranteed to the participating companies. The interviews were carried out in July 2008 on the premises of the companies. They lasted between 55 to 75 minutes and were all taperecorded.

Prior literature formed the starting point of the data collection process. Given the broad range of potential organisational factors that came up in the literature review, I used one model to structure these internal drivers: the 7-S framework (Pascale \& Athos, 1981; Waterman, Peters, \& Philips, 1980). This model systematically takes into account the breadth of the potential factors that may influence CSR reporting, by addressing seven elements that have been associated with management process optimisation in the strategy literature (Waterman, et al., 1980). This model encompasses most of the factors that were suggested in prior literature. Although this model has not been used before with regard to CSR research, it has proven to be a successful tool for similar types of studies. Previous studies have shown that the 7-S framework enables a structured analysis of organisational variables driving 
various management processes (Bollen, Hassink, Lange, \& Buijl, 2008; Galliers \& Sutherland, 1991; Levy, Powell, \& Yetton, 2002; Lin, 2002; Mehta \& Tambe, 1997). The 7-S framework composes seven variables: structure, strategy, systems, style, skills, staff and shared values.

The element of 'Structure' relates to the way in which the entity is organised; it provides coordination and task division (Waterman, et al., 1980). 'Strategy' refers to the "actions that a company plans in response to or in anticipation of changes in its external environment, its customers, and its competitors" (Waterman, et al., 1980). 'Systems' encompasses all formal and informal procedures that a company uses in its day-to-day operations (Waterman, et al., 1980).

The element of 'Style' is a reflection of a company's culture and its ability to change (Waterman, et al., 1980). 'Skills' refers to the attributes or capabilities of a company (Waterman, et al., 1980), whereas 'Staff' relates to the employees of the company in the sense of: "people as a pool of resources to be nurtured, developed, guarded, and allocated" (Waterman, et al., 1980). Finally 'shared values' expresses the idea that every organisation is constructed of fundamental ideas (Waterman, et al., 1980). Based on the literature, for each of the seven elements a number of corresponding themes were addressed, serving as a guide for the data collection process. Whenever appropriate, during the interviews I deviated from these themes. Table 2.2 provides a summary of the themes under each of the elements of the 7-S model that informed our conversations.

Table 2.2: 7 themes and associated interview topics and questions

\begin{tabular}{|c|c|c|c|}
\hline $7-S$ & Reference & Topics & Questions \\
\hline \multirow[t]{2}{*}{ Structure } & $\begin{array}{l}\text { Delfgaauw, 2000; Adams, } \\
\text { 2002; Delmas \& Toffel, } \\
\text { 2004; Adams \& Frost, } 2008\end{array}$ & $\begin{array}{l}\text { Position } \\
\text { within com- } \\
\text { pany }\end{array}$ & $\begin{array}{l}\text { How is CSR reporting represented in company? } \\
\text { Do affiliated employees devote } 100 \% \text { of time? } \\
\text { How many FTE? } \\
\text { What is the estimated annual budget for CSR } \\
\text { Reporting? }\end{array}$ \\
\hline & $\begin{array}{l}\text { Wood, 1991; Carroll, 1997; } \\
\text { Weaver et al., 1999; } \\
\text { Husted, 2000; Adams, } \\
\text { 2002; Campbell, 2002; } \\
\text { Delmas \& Toffel, 2004; } \\
\text { Albelda-Pérez et al., 2007; } \\
\text { Adams \& Frost, } 2008\end{array}$ & $\begin{array}{l}\text { Concentration } \\
\text { of authority }\end{array}$ & $\begin{array}{l}\text { How many management layers are involved in } \\
\text { CSR reporting? } \\
\text { Who is responsible for what? } \\
\text { Is there final approval? } \\
\text { Who decides on the budget? }\end{array}$ \\
\hline Strategy & $\begin{array}{l}\text { Adams, 2002; Albelda- } \\
\text { Pérez et al., 2007; Adams } \\
\text { \& Frost, } 2008\end{array}$ & $\begin{array}{l}\text { Intended vs. } \\
\text { emergent }\end{array}$ & $\begin{array}{l}\text { Is there a formal CSR reporting strategy? } \\
\text { Is it written down? } \\
\text { Has this document been published to the } \\
\text { employees/public? } \\
\text { Who formulates the strategy? } \\
\text { How many years ahead is it formulated? }\end{array}$ \\
\hline
\end{tabular}


Delfgaauw, 2000; Adams, Stakeholder 2002

Systems

Husted, 2000; Adams, 2002

Delfgaauw, 2000; AlbeldaPérez et al, 2007

Delfgaauw, 2000; Adams, Verification 2002 Cowen et al., 1987; Wood, coordination 1991; Carroll, 1997;

Weaver et al., 1999;

Campbell, 2002; Albelda-

Pérez et al., 2007

Husted, 2000; Albelda-

Pérez et al. 2007;

Adams \& Frost, 2008

Skills

Quazi, 2003; Albelda-Pérez et al., 2007

Delfgaauw, 2000; Adams, 2002

Staff

Shared

values

involvement

Information

systems

CSR-related certification

Level of
Means of communication

Diversity of expertise experience process?

Who are the target stakeholder groups?

Are they all equally important?

Do you have a content management system which contains all CSR reporting information? What are the 3 most important systems generating the CSR information?

Do you have any certifications relating to CSR reporting?

Is the CSR report verified by and external party? If yes: auditor or consultant? Do you have an external review committee? Who coordinates the department or reporting

How does the communication within the CSR department take place? What is the frequency of meetings?

What is the professional background of the members of the CSR team?

Any members with an NGO background?

What kinds of training opportunities exist for group members?

Expertise and Which of your company skills would you call superior with regard to CSR reporting? What is the most important document regarding CSR reporting? When was it first published?

Adams, 2002; Albelda-

Pérez et al., 2007; Adams

\& Frost, 2008

Group composition

Creation of awareness gaauw, 2000; Adams, 2002; Hemingway \& Maclagan, 2004; Collier \& Esteban, 2007; Quaak et al., 2007

Adams, 2002; Adams \& Frost, 2008 reporting
How many employees are currently working for the CSR reporting department?

What are the job description and responsibilities of each team member? In case of a matrix structure: which departments do members come from?

Are there any groupings within the team? On what are they based?

How do you create awareness about CSR reporting? E.g.: how are CSR reporting award winnings communicated to employees? How do you encourage your employees to contribute to CSR reporting?

Motivation of What is the most important reason for your company to engage in CSR reporting? 
For the data analysis I largely followed protocols set out by Miles \& Huberman (1994) and Yin (1994). The data analysis process consisted of three main stages. First, an initial analysis was carried out after each interview, which included the immediate review of handwritten notes and transcription of the tape-recorded interviews, corroboration of the primary with secondary data, familiarisation of the cases and reflection on the content. Second, after completion of all interviews a more detailed coding was undertaken, in which codes were assigned to constructs that were drawn from the literature, as well as emerging constructs. The last step was the identification of major themes that appeared across multiple companies. Moving back and forth between the data, the literature and the set of common themes, two broad dimensions of managing CSR reporting emerged, with which a typology was constructed.

\subsection{Analysis and Results}

This section starts with a discussion of the main findings per each of the seven elements of the 7-S framework and the associated topics. Next, it is described how the two dimensions and the resulting typology for managing CSR reporting emerged from these findings. The final part of this section will give a detailed description of each of the types of internal CSR reporting management.

With regard to the element of structure the following observations are relevant. Four companies have extensive $\mathrm{CSR}^{18}$ reports, next to dedicated websites for CSR issues. Two companies mention as their most important CSR documents the 'CSR brochure' and website. Consequently, the printed reports of the individual companies vary widely in their length between 7 and 70 pages. The two companies publishing brochures ( $A$ and $D$ ) state that their websites are most important. With the exception of company $E$ that published its first sustainability report in the 1990s, all companies in the sample published their first CSR report after 2000. However, four companies ( $B, D, E, F)$ make mention of prior formal publishing of HSE (Health, Safety, and Environment), Environmental or Social reports before, one even dating back more than 30 years.

For all companies the CSR reporting is incorporated as a matrix structure. Next to a CSR report team, all companies, except company $\mathrm{C}$ have CSR representatives or focal points in each business unit and function (HR, finance, technology, compliance, etc.) that deliver the content for the report. The positioning of the CSR reporting team differs. In some companies it is integrated in the corporate communications

\footnotetext{
${ }^{18}$ Some companies have Sustainability Reports instead of CSR reports. In the remainder of this paper, whenever I use the term CSR reporting, I implicitly also refer to Sustainability Reporting.
} 
department ( $C, D$, and $F$ ) and in others into the sustainability department ( $B$ and $E$ ). The management layers that are involved vary considerably between the companies. In company A the CSR coordinator and communications manager jointly coordinate CSR reporting, with a hierarchical relation to the commercial director of one of the divisions, who in turn reports to the CEO. Company B has one layer less: the director of CSR coordinates the team and reports directly to the CEO. In company $C$ and $D$ the CSR manager coordinating the reporting team hierarchically links to the responsible manager for corporate communications, which reports to the CEO. The team of company $E$ is coordinated by a senior editor, reporting to the vice president CSR, which reports to the CEO. Finally, company $F$ also has a joint responsibility for the CSR reporting function: the department is coordinated by the associate secretary, and communication manager, reporting to the secretary of the Board, which ultimately reports to the CEO. Notwithstanding these differences, all companies reported on an additional function related to CSR reporting, that has an advisory role to the board and the reporting team. This function, often so called steering committees, sustainability councils, or non-executive directors, is a small body of representatives of key business areas that is also involved in setting objectives.

As for the element of strategy the relevant findings are as follows. While four companies $(B, D, E, F)$ reported on a formal, intended strategy, the other two companies ( $A$ and $C$ ) exhibit a more emergent strategy. In terms of the formulation of the strategy, three companies $(B, E, F)$ mention that the CSR reporting strategy is very much embedded within the overall strategy and therefore under the responsibility of the board or a strategy group. Within the other companies, the reporting team, or senior management formulate the strategy. Moreover, the analysis revealed that hardly any of the entities publishes the strategy to its employees or the public directly. In fact, the companies mention the CSR report as a reflection of their CSR strategy.

The observations for the element of systems will be presented here. None of the companies uses a content management system that contains all information that is related to the CSR reporting. One company (D) is building a database from the information that is retrieved from the business units by means of a digital questionnaire. The companies revealed that most of the CSR content originates from the business units and functions (such as HR, finance, compliance, etc.). These business units and functions typically have a number of separate databases.

With regard to the certifications, only the companies in high-impact industries $(B, E, F)$ are engaging in certification such as the European Union's voluntary Eco- 
Management and Audit Scheme (EMAS) and Social Accountability (SA) $8000^{19}$. However, with the exception of company $E$, which is compliant to or following SA8000 and some EMAS, the companies focus on ISO14001, which has no explicit requirement regarding reporting. The other companies, that are active in industries that have less impact, do not have any certification at all.

All companies, with the exception of one $(A)$, engage in a form of external verification of their reports. Whereas companies $B, C, D$ and $F$ have their reports verified by a big four auditor, company $E$ had installed an external review committee, consisting of five independent international experts, each in its own field, such as human rights, environment, social, and transparency. Their role is to give advice on the appropriate subjects and dilemmas to include in the report, as well as the way in which they are described. As a final section of the report, the external review committee gives a separate independent written commentary with recommendations for the next year. Companies $\mathrm{C}$ and $\mathrm{F}$ are discussing the installation of a review committee. Two companies ( $B$ and $F$ ) have, next to an audited report, also more informal review mechanisms, such as meetings with NGOs and shareholders, whereas company $A$ is considering a platform for discussion with stakeholders.

As for the element of style, there was a clear divide in the level of coordination, in that companies $B, E$ and $F$ replied that sustainability is integrated into the day-today business practices and can hardly be differentiated as an individual process, whereas the others did not.

Moreover, the same companies responded that CSR reporting is also very much integrated into general CSR management.

Focusing on the topics related to the element of skills, the following responses were relevant. All companies reported on a diverse set of backgrounds of their reporting team members, varying from accounting, communications, customer contact, law, and economics. In addition, many companies reported on environmental specialists, persons with technical backgrounds and members with NGO working experience. Personal affinity with CSR seems to be another important background of the CSR reporting team members.

Three companies hired external expertise: company $C$ and $F$ hire external writers, whereas company A hired a sustainability consultant for the development of the website and the CSR brochure, particularly for aligning it with GRI guidelines.

\footnotetext{
${ }^{19}$ EMAS and SA8000 both explicitly include requirements with regards to communication. EMAS requires participating company sites to produce an environmental report at site level (Kolk, Walhain, \& Wateringen, 2001). Article 9.13 of the SA8000 standard states: 'The company shall establish and maintain procedures to communicate regularly to all interested parties' (SAI, 2008). ISO 14001 does not explicitly contain reporting requirements (Kolk, et al., 2001).
} 
Apart from one company (E) that has sustainability courses for all employees, no formal training programs have been established in the sample companies.

When the participants were asked to indicate the unique company skills with regard to CSR reporting they mentioned various, ranging from: historical ties to the labour unions (A), a dedicated CEO (C) and the level of professionalism as a result of its embedded position within corporate communications (D). Some companies also mention their long-term experience (B, C, D, F). The three companies from highimpact industries $(B, E, F)$ bring up the fact that their CSR reporting reflects actual CSR: the way in which the company deals with critical CSR issues, in terms of how these issues are embedded in the organisation and the solutions the company has found.

In the context of the element of staff, I found basically one difference between companies, relating to the size of the reporting function. That is, the numbers of employees in the reporting teams range from 3 to 10. These numbers refers to the employees that are mainly responsible for the information collection, the writing and the publishing of the report. Small CSR reporting functions either reflected that CSR reporting was considered a specialised part of the overall CSR function or was the result of the fact that a number of individuals dedicated only a small fraction of their time to CSR (reporting) related issues. Yet, more employees are involved when it comes to the content of the CSR report. All companies indicate that employees in the business units and staff departments (such as CSR, HR, quality, R\&D) are contacted by the CSR report team for content information.

Under the heading of the element of shared values the following issues were brought up during the interviews. When asked about how awareness on CSR reporting is created within the organisation, most respondents mentioned that employees are informed about a newly published CSR report. However, whereas half of the companies (A, C, D) inform employees without sending the actual CSR report, two companies ( $B$ and $E$ ) do so, and one company (F) sends the CSR report to selected employees.

The decision to publish a CSR report can be basically ascribed to two major reasons: outside expectations and a need to structure CSR. Some companies give the most attention to the first motivation (C, D, F) and state that stakeholders express a need for CSR information. Regarding the second motive, most companies (B, C, D, E, F) articulate the importance of CSR reporting in structuring CSR management, yet companies $B$ and $E$ consider it to be the most important motivation. In contrast, company A stated that CSR has become mainstream and that CSR reporting is inevitable if companies wish to retain their license to operate. 
Focusing on potential commonalities in the constellations of the factors from the previous findings, I intended to distinguish between different types of internal management of CSR reporting. Moving back and forth between the data, the literature and the set of common themes, two broad dimensions of managing CSR reporting emerged. The first dimension was a distinction between formal versus informal CSR reporting management. Whether CSR is an activity that is integrated in, or separated from everyday organisational activities emerged as a second dimension. With regard to the latter, Weaver, Trevino \& Cochran (1999) developed the concepts of 'integrated' versus 'decoupled CSR', which terms will also be used in this study. Table 2.3 provides an overview of a number of selected topics from the previous findings on the basis of which companies were clustered. Besides, this Table illustrates what commonalities in the constellation of these topics led to the emergence of the two dimensions.

Table 2.3: Differences in CSR management between companies and the underlying dimensions

\begin{tabular}{|c|c|c|c|c|c|c|c|}
\hline \multirow[b]{2}{*}{ ELEMENT } & \multirow[b]{2}{*}{ TOPIC } & \multicolumn{6}{|l|}{ COMPANY } \\
\hline & & $A$ & B & C & $\mathrm{D}$ & $E$ & $F$ \\
\hline \multirow[t]{3}{*}{ Structure } & $\begin{array}{l}\text { Coordination } \\
\text { CSR depart- } \\
\text { ment }\end{array}$ & $\begin{array}{l}\text { CSR coordina- } \\
\text { tor, reports to } \\
\text { commercial } \\
\text { director division } \\
+ \text { individuals } \\
\text { important }\end{array}$ & $\begin{array}{l}\text { director } \\
\text { sustaina- } \\
\text { bility, re- } \\
\text { ports to CEO }\end{array}$ & $\begin{array}{l}\text { head of } C R \text {, } \\
\text { reports to } \\
\text { director com- } \\
\text { munications }\end{array}$ & $\begin{array}{l}\text { director com- } \\
\text { munications, } \\
\text { reports to CEO }\end{array}$ & $\begin{array}{l}\text { VP sustaina- } \\
\text { bility, re- } \\
\text { ports to } \\
\text { executive } \\
\text { board }\end{array}$ & $\begin{array}{l}\text { manager } \\
\text { CSR, reports } \\
\text { to board }\end{array}$ \\
\hline & $\begin{array}{l}\text { Highest CSR } \\
\text { officer }\end{array}$ & $\begin{array}{l}\text { commercial } \\
\text { director division }\end{array}$ & $\begin{array}{l}\text { CEO (as } \\
\text { member of } \\
\text { sustainability } \\
\text { council) }\end{array}$ & $\begin{array}{l}\text { same as previ- } \\
\text { ous, advisory } \\
\text { role for top } \\
\text { managers }\end{array}$ & $\begin{array}{l}\text { corporate } \\
\text { director, reports } \\
\text { to CEO }\end{array}$ & $\begin{array}{l}\text { member of } \\
\text { executive } \\
\text { board }\end{array}$ & $\begin{array}{l}\text { member of } \\
\text { managing } \\
\text { board }\end{array}$ \\
\hline & $\begin{array}{l}\text { Coordination } \\
\text { CSR report- } \\
\text { ing depart- } \\
\text { ment/team }\end{array}$ & $\begin{array}{l}\text { CSR coordinator } \\
+ \text { communica- } \\
\text { tions manager, } \\
\text { report to com- } \\
\text { mercial director } \\
\text { division }\end{array}$ & $\begin{array}{l}\text { head of } \\
\text { sustainability } \\
\text { communica- } \\
\text { tion, reports } \\
\text { to director } \\
\text { sustainability } \\
\text { and director } \\
\text { communica- } \\
\text { tions }\end{array}$ & $\begin{array}{l}\text { CR manager, } \\
\text { reports to head } \\
\text { of } C R\end{array}$ & $\begin{array}{l}\text { CSR manager, } \\
\text { reports to } \\
\text { director com- } \\
\text { munications }\end{array}$ & $\begin{array}{l}\text { senior edi- } \\
\text { tor, reports } \\
\text { to VP sus- } \\
\text { tainability }\end{array}$ & $\begin{array}{l}\text { associate } \\
\text { secretary of } \\
\text { the board + } \\
\text { communica- } \\
\text { tion man- } \\
\text { ager, report } \\
\text { to secretary } \\
\text { of the } \\
\text { board/ } \\
\text { director } \\
\text { communica- } \\
\text { tions }\end{array}$ \\
\hline Strategy & $\begin{array}{l}\text { Formal CSR } \\
\text { strategy }\end{array}$ & no, in future & yes & $\begin{array}{l}\text { no, annual } \\
\text { presentation to } \\
\text { employees }\end{array}$ & no, next year & $\begin{array}{l}\text { yes + inte- } \\
\text { grated in } \\
\text { overall } \\
\text { strategy }\end{array}$ & $\begin{array}{l}\text { yes + inte- } \\
\text { grated in } \\
\text { overall } \\
\text { strategy }\end{array}$ \\
\hline
\end{tabular}




\begin{tabular}{|c|c|c|c|c|c|c|c|}
\hline \multirow[b]{2}{*}{ ELEMENT } & \multirow[b]{2}{*}{ TOPIC } & \multicolumn{6}{|l|}{ COMPANY } \\
\hline & & A & B & C & D & $E$ & $\mathrm{~F}$ \\
\hline & $\begin{array}{l}\text { Formulated } \\
\text { by }\end{array}$ & $\begin{array}{l}\text { will be done by } \\
\text { commercial } \\
\text { director division } \\
\text { (in future) }\end{array}$ & $\begin{array}{l}\text { sustainability } \\
\text { council } \\
\text { (including } \\
\text { board) }\end{array}$ & CSR team & $\begin{array}{l}\text { will be done by } \\
\text { CSR manager (in } \\
\text { future) }\end{array}$ & $\begin{array}{l}\text { strategy } \\
\text { group (in- } \\
\text { cluding top } \\
\text { manage- } \\
\text { ment) }\end{array}$ & $\begin{array}{l}\text { managing } \\
\text { board }\end{array}$ \\
\hline \multirow[t]{2}{*}{ Systems } & $\begin{array}{l}\text { Formal } \\
\text { external } \\
\text { review } \\
\text { committee }\end{array}$ & no & $\begin{array}{l}\text { no, informal } \\
\text { committee }\end{array}$ & no & no, in future & yes & $\begin{array}{l}\text { no, informal } \\
\text { committee }\end{array}$ \\
\hline & $\begin{array}{l}\text { Verification } \\
\text { of report }\end{array}$ & no & yes & yes & yes & no & yes \\
\hline Style & $\begin{array}{l}\text { CSR Termi- } \\
\text { nology used }\end{array}$ & CR & Sustainability & CR & CSR & Sustainability & Sustainability \\
\hline Skills & $\begin{array}{l}\text { Background } \\
\text { of CSR } \\
\text { reporting } \\
\text { officers }\end{array}$ & $\begin{array}{l}\text { diverse (some } \\
\text { compliance/risk) }\end{array}$ & diverse & $\begin{array}{l}\text { many legal }+ \\
\text { communications }\end{array}$ & $\begin{array}{l}\text { many legal + } \\
\text { communications }\end{array}$ & accounting & diverse \\
\hline \multirow[t]{2}{*}{ Staff } & $\begin{array}{l}\text { Number of } \\
\text { officers in } \\
\text { CSR }\end{array}$ & $\begin{array}{l}7 \text { (all part-time, } \\
\text { in total } 1,2 \text { FTE) }\end{array}$ & $\begin{array}{l}10 \text { in } \\
\text { sustainability } \\
\text { council + } 17 \\
\text { focal points } \\
\text { in BSU (not } \\
\text { full-time) }\end{array}$ & $\begin{array}{l}16 \text { (full time) + } \\
80 \text { (not full- } \\
\text { time) in BSU } \\
\text { only for report- } \\
\text { ing }\end{array}$ & $\begin{array}{l}6 \text { people (all } \\
\text { part-time for } 2 \% \\
\text { of time) }\end{array}$ & $\begin{array}{l}\text { BSU has } \\
\text { most power, } \\
\text { but unknown } \\
\text { how many + } \\
12 \text { in sus- } \\
\text { tainability } \\
\text { department }\end{array}$ & $\begin{array}{l}8 \text { in sustain- } \\
\text { ability }+ \\
\text { unknown } \\
\text { number in } \\
\text { BSU }\end{array}$ \\
\hline & $\begin{array}{l}\text { Number of } \\
\text { officers in } \\
\text { CSR report- } \\
\text { ing }\end{array}$ & $\begin{array}{l}\text { same as previ- } \\
\text { ous }\end{array}$ & $\begin{array}{l}\text { no separate } \\
\text { department, } \\
\text { but } 1 \text { head } \\
\text { and } 6 \text { from } \\
\text { functional } \\
\text { areas }\end{array}$ & 4 & $\begin{array}{l}3+1 \text { external } \\
\text { (total } 1 \text { FTE) }\end{array}$ & $\begin{array}{l}4 \text { (full-time), } \\
\text { but only } \\
\text { facilitating } \\
\text { CSR report- } \\
\text { ing in BSU }\end{array}$ & $\begin{array}{l}10 \text { in work- } \\
\text { ing group } \\
\text { (none full- } \\
\text { time)+ } \\
\text { 1external }\end{array}$ \\
\hline $\begin{array}{l}\text { Shared } \\
\text { values }\end{array}$ & $\begin{array}{l}\text { Main moti- } \\
\text { vation }\end{array}$ & $\begin{array}{l}\text { CSR is main- } \\
\text { stream so you } \\
\text { have to do it }\end{array}$ & $\begin{array}{l}\text { various other } \\
\text { than outside } \\
\text { pressure, } \\
\text { such as CEO } \\
\text { dedication, } \\
\text { way to } \\
\text { structure } \\
\text { CSR }\end{array}$ & $\begin{array}{l}\text { outside pres- } \\
\text { sure }\end{array}$ & $\begin{array}{l}\text { outside pres- } \\
\text { sure }\end{array}$ & $\begin{array}{l}\text { various other } \\
\text { than outside } \\
\text { pressure, } \\
\text { such as CEO } \\
\text { dedication, } \\
\text { way to } \\
\text { structure } \\
\text { CSR }\end{array}$ & $\begin{array}{l}\text { various other } \\
\text { than outside } \\
\text { pressure, } \\
\text { such as CEO } \\
\text { dedication, } \\
\text { way to } \\
\text { structure } \\
\text { CSR }\end{array}$ \\
\hline
\end{tabular}

bold = underlying dimension 1: formal versus informal CSR Reporting management italic = underlying dimension 2: integrated versus decoupled CSR

bold and italic $=$ underlying both dimension $1+2$ 
The two suggested dimensions correspond to factors that have been associated with practices related to CSR reporting in earlier studies (Adams, 2002; Adams \& Frost, 2008). For example, Adams and Frost (2008) state that important factors in the development of key performance indicators for measuring sustainability performance are the "( . . . ) extent to which sustainability accounting and reporting functions are integrated into the planning, performance management and risk management operations of organisations' and the 'degree of formality versus informality in the data collection, reporting and performance management process". With the two dimensions a typology was constructed.

The first type of companies, which I labelled Improvisers, is characterised by a lack of formal organisation with regard to its management of CSR reporting, and no systematic integration of CSR in business operations, i.e.: decoupled CSR. Improvisers in general show an inclination toward informal and implicit CSR, yet acknowledge the importance of (explicit) CSR reporting for contemporary companies in order to retain legitimacy and therefore seek to publish reports in accordance with up to date standards. Since the formal structures for composing the report are largely absent, external expertise is acquired. The second type consists of companies that combine decoupled CSR with formalised CSR reporting. These companies have developed and installed formal structures, systems and processes for CSR. However, CSR is regarded separate from everyday business and besides it is considered to be mainly a communication issue. Therefore CSR reporting forms the foundation of overall CSR management and formalisation mainly applies to CSR reporting. This company type has been labelled Reporters. The third type Performers- involves companies that show a high level of formalisation of managing CSR reporting together with an integrated approach to CSR. Performers demonstrate a business orientation that integrates social and environmental goals into their economic objective function; CSR is integrated in everyday decision-making. With regard to CSR the ultimate performance is important; CSR reporting is only the logical consequence of this orientation, that is: informing stakeholders is part of this orientation. The last quadrant represents companies combining integrated CSR with informal structures, strategies and systems of CSR reporting management. Companies that may suit this description are 'social entrepreneurs'. Social entrepreneurs are companies that "combine the passion of a social mission with an image of business-like discipline, innovation, and determination" (Dees, 1998). Instead of balancing their profit oriented business model by integrating social and environmental goals, this company type basically reforms this business model by considering CSR as the core of it. Hence, I've labelled these companies as Reformers. In terms of formalisation of the CSR reporting process, social entrepreneurs are characterised by innovative reporting practices that are "emergent and dynamic" and "are consistent with the bricolage evident in social entrepreneurs' attitude to problem-solving 
more generally" (Nicholls, 2009: 756). This implies that their management of CSR reporting tends to be more informal. The latter is also supported by the observation that social entrepreneurs are typically small and medium sized enterprises (SMEs) combined with research evidence that Dutch SMEs are more informally managed with regard to CSR than large companies (Graafland, Ven, \& Stoffele, 2003).

Table 2.4 summarises the different types. There were no companies in the sample matching the characteristics of the Reformer type. This may be the result of my focus on large public companies.

I will discuss each of the three other types in further detail in the following.

Table 2.4 Typology of CSR reporting

\begin{tabular}{|c|c|c|}
\hline & Informal management of CSR reporting & Formal management of CSR reporting \\
\hline \multirow[b]{2}{*}{ Integrated CSR } & REFORMERS & PERFORMERS \\
\hline & $\begin{array}{l}\text { - } \quad \text { CSR performance inherent to } \\
\text { business model } \\
\text { CSR reporting is logical con- } \\
\text { sequence of social mission }\end{array}$ & $\begin{array}{l}\text { - } \quad \text { Focus on CSR performance } \\
\text { CSR reporting is logical con- } \\
\text { sequence/integrated part of } \\
\text { overall CSR management }\end{array}$ \\
\hline & IMPROVISERS & REPORTERS \\
\hline Decoupled CSR & $\begin{array}{l}\text { - } \quad \text { Focus on CSR reporting } \\
\text { CSR reporting is result of con- } \\
\text { formity to reports of com- } \\
\text { petitors and benchmarks }\end{array}$ & $\begin{array}{l}\text { - } \quad \text { Focus on CSR reporting } \\
\text { CSR reporting is result of } \\
\text { formal internal manage- } \\
\text { ment }\end{array}$ \\
\hline
\end{tabular}

\subsubsection{Improvisers}

The term Improvisers signals the informal orientation of the CSR reporting management of this type of companies, to distinguish it from the more formal approaches of the other types. The same informal orientation applies to the overall CSR management of these companies. It also stands for companies for which CSR is not an integrated part of everyday operations. Nevertheless CSR reporting is important; in fact, CSR reporting is one of the very few instances in which the company's CSR management is made explicit. Company A corresponds to the Improviser type.

The informal orientation of the company's CSR reporting management is illustrated by the interviewee of company $A$, who stated: 
"There is nothing formal yet; in general the actions [i.e., with regard to CSR reporting] we did up till now, are based on common sense".

A number of observations correspond to both the informal management of CSR reporting and the decoupled CSR. First, the company's CSR (reporting) management had been built on the intrinsic motivation and 'personal affinity' of a number of individual employees, which considered themselves 'evangelists'. No formal CSR strategy was formulated. Most of the CSR was fragmented and implicit, referring to historically grown commonly held beliefs and values. The company representative labelled some parts of this CSR as 'spontaneous', in that they were initiated by the people on the work floor in the various branches. With regard to the latter, the interviewee mentioned:

“Most people probably wouldn't even give this the label ' $C R^{\prime 20 "}$.

The CSR (reporting) function was represented by seven employees, all of which were employed by different departments and had a number of hours to be devoted to CR. The amount of time jointly allocated to CSR by these employees resembled to approximately $1 \mathrm{fte}$. The main task of this CR team was to manage CR reporting. CSR reporting was the dual responsibility of a 'coordinator $C^{2}$ ' and a 'manager communications'; the CSR coordinator reported to the commercial director of one of the divisions, who in turn reported to the CEO. The interviewee mentioned with regard to this structure: "responsibilities are not yet so clear". None of the employees of the CSR (reporting) department was formally trained in CSR. The company did not engage in any formal management systems regarding CSR reporting, such as external verification, certification or the use of a management information system.

Notwithstanding the largely implicit and informal notion of CSR, relatively recently (the first report was published in 2005) the company felt an increasing need to (explicitly) communicate its CSR inclination by means of a report. This was fuelled by the growing popularity of CSR reporting among large companies together with an increased information demand by stakeholders in recent years. This need is illustrated by the interviewee's response to the question of why the company engaged in CSR reporting:

"Because everybody does it [laughter] ... no, but seriously: Corporate Responsibility has simply become mainstream; you're out of business if you don't follow. [...] Institutional shareholders -but also other stakeholders- demand CR informa-

\footnotetext{
${ }^{20} \mathrm{CR}$ stands for 'Corporate Responsibility', the term that the company preferred instead of CSR.
} 
tion. [...] If you're not transparent and [do not] show integrity, you will lose your license to operate".

The previous makes clear that the company's actions with regard to CSR are motivated by a belief that CSR is simply inevitable. From the interview it appeared that the company's initial focus was on the publication of a CSR report and the acquisition of external expertise, which seemed to be the most readily accomplishable CSR goals. The external expertise was represented by a newly appointed commercial director of one of the divisions with a background in CSR, and an external CSR consultant. The appointment of the commercial director marked the 'transition phase of formulating [CSR] policies' in which the company reportedly found itself at the time of the interview. This person can be seen as an internal CSR 'champion' (Peters \& Waterman, 1982), personifying a more formal CSR orientation ${ }^{21}$. The external consultant was hired to guide the company in producing a CSR report in line with prevailing norms of quality (particularly: the GRI guidelines). With regard to CSR reporting company $A$ exhibits a management approach that is results oriented, which boils down to the publication of a CSR report that is comparable to its competitors and in line with quality benchmarks. The means to get there (that is: the internal reporting processes) are of secondary importance.

The interview also revealed that the company preferred to use the term 'Corporate Responsibility' instead of 'Corporate Social Responsibility'. The use of this terminology was a conscious choice to stress the instrumental orientation with which the company approached CSR. This orientation is also illustrated by its business principles that emphasise the need to take care of the stakeholder interests with the aim to create value. In addition, the interviewee stated that the most important audience for its CSR report were the 'primary stakeholders', providing the resources on which the company depends for its survival.

From the previous it follows that CSR reporting is an important activity. In fact, CSR reporting represents the majority, if not: the sole expression, of the company's formal CSR actions. It also reveals the company's decoupled CSR.

In summary, this company type is a relative newcomer practically without a formal organisation of its CSR management, as well as a systematic integration of CSR in everyday business. The company's high-quality CSR report can be jointly attributed to a focus on conformity to external reporting quality benchmarks and the use of external CSR reporting expertise.

\footnotetext{
${ }^{21}$ The company's 2008 CR Report provided evidence that the company at that time was indeed in a process of change by including its policies (CR principles); besides, the company mentioned in the same report that one of its ambitions for 2009 was to integrate corporate responsibility into strategy.
} 


\subsubsection{Reporters}

Reporters are companies that have formalised their CSR reporting and general CSR management, however have not (yet) integrated CSR in the overall strategy and everyday management. CSR reporting forms the core of CSR management. Companies $C$ and $D$ have characteristics that correspond to the Reporter type.

With regard to the first dimension -formal versus informal management of CSR reporting- Reporters differ from Improvisers. The formal management structures for the Improviser company type were limited to a single combined CSR/CSR reporting function, while in the Reporter type CSR was manifested through multiple formal functions and levels. To illustrate, company C had a CSR manager that was responsible for the CSR reporting team of 3 internal and 1 external employees (representing $1 \mathrm{fte}$ in total), and also coordinated a CSR steering committee, which consisted of 6 employees (representing less than $1 \mathrm{fte}$ ) that represented key elements of CSR. Among these 6, there was a corporate director Health Safety Environment and Quality, as well as a manager Quality and Regulatory Affairs. This committee had an advisory role to the executive board. The interviewee from company $C$ (the CSR manager), who was appointed only 2 months before the interview, stated:

"[When I was appointed] I started building a management structure. In the past there was no structure. [Company name] was quite defensive at that stage [...]. Then, there was outside pressure, [examples of controversies], ${ }^{22}$ and they responded to that".

This indicates that the company only very recently had established formal CSR management structures and before it was more implicitly and reactively taking care of CSR, the latter of which applies more to the Improviser type. Another observation adds to the previous finding. That is, whereas both companies had (recently) established internal management structures in order to publish a high quality CSR report, company $\mathrm{C}$ still was hiring an external advisor for guiding the process. This finding corresponds to the Improviser type that also acquired external expertise to succeed in publishing a high quality CSR report ${ }^{23}$.

The CSR management structure in company $D$ was characterised by a head of CR that was responsible for a department of 16 employees, among which a manager $\mathrm{CR}$ that coordinated the CSR reporting function. Other functions included in this department were for example: charity, microfinance and climate. The CSR reporting

\footnotetext{
${ }^{22}$ Given that the controversies that were mentioned are very company specific, they were removed from this quote in order to safeguard confidentiality.

${ }^{23}$ Further evidence can be found in the company's 2008 CSR report, in which it is stated that in the years before 2008, the company followed a route of seeking awards for its CSR reporting but that these objectives would be put aside in the coming years.
} 
team consisted of 4 employees. The company had also installed a Corporate Responsibility Council, with representatives from various staff departments and operational business units, which had an advisory role toward the executive board. Further, there were CSR representatives in most of the 80 business units, whose task it was to provide the content for the CR report. Company D was the only company in the sample that was building a formal reporting database from the information that was retrieved from the business units by means of a digital questionnaire

Next to management structures both companies had, different from the Improviser company type, formal systems for verifying the content of the CSR report by means of external verification by a 'Big Four' audit firm, as well as formal CSR strategies that were published in the CSR report. Compared to the Improviser type, Reporters had considerable experience in CSR reporting: both companies' first CSR reports were published in 2001; before that year, company D published Safety, Health and Environment (SHE) reports.

As for the second dimension -decoupled CSR- the following findings are relevant. First, in both companies, not only the CSR reporting but also the overall CSR function was part of the communication department. In company $C$, the director of communications managed the CSR department. The manager CSR that coordinated the CSR reporting team, reported to this manager. In case of Company $D$, the CSR department was not directly under the supervision of a communications officer, but the responsible manager (the head of $\mathrm{CR}$ ) reported to the director of communications. The officer that coordinated CSR reporting reported to him. Moreover and as previously mentioned, the main task of the CSR representatives in the business units of company $D$ was to provide the content for the CSR report. All that points at a dominant position of CSR reporting in the overall CSR function. The interviewee of Company $D$, while reflecting on the company's most important skills with regard to CSR reporting, extended his answer beyond CSR reporting to CSR in general, by stating:

"[...] because Corporate Responsibility is part of corporate communications, it is at a high professional level".

The dominance of the communication function in CSR also reveals a lack of direct board involvement in the CSR departments for companies C and D. None of the representatives of the companies mentioned that CSR was integrated into the overall strategy or everyday business, which was different from other companies in the sample from which the interviewees repeatedly stressed the importance of such integration, as will be discussed under the next company type. Besides, none of the board members of the Reporter type companies had an active role in CSR and the CSR strategies were developed by the CSR departments, not the board. Notwithstanding the fact that both companies did have management structures through 
which an advisory role to the executive board was formalised (as was mentioned under the first dimension) the previous adds to the picture of a decoupled CSR of these companies ${ }^{24}$.

In company D CSR was seen as a part of the wider compliance risk management. Hence, next to key officers with a background in communications, many officers in the CSR department had a legal background. In company $C$ the background of the CSR employees was more diverse, although legal and communications were expressly represented. Finally, it is notable that the interviewees of both companies stated that CSR reporting was first and foremost motivated by strong external expectations and demand for information.

To summarise, this company type consists of companies that are considerably experienced in CSR reporting; the companies have internalised CSR reporting expertise by means of formal management structures, systems and processes in the course of many years in order to publish state-of-the-art CSR reports. The executive board is not directly and actively involved in CSR; instead CSR is closely linked to the communications department. This signals that CSR is not fully integrated into everyday business and that CSR reporting is at the heart of overall CSR management.

\subsubsection{Performers}

The term 'Performers' reflects the fact that $\mathrm{CSR}^{25}$ management is focused on the ultimate CSR performance, not CSR reporting. CSR is not an addition to, but an integrated part of the normal business processes. Consequently top management is actively and directly involved in CSR. To succeed in this integration, structures, systems and processes with regard to CSR, and hence also CSR reporting, have been highly formalised. Companies $B, E$ and $\mathrm{F}^{26}$ have been labelled Performers.

The formal management of CSR reporting can be derived from a number of observations. First, all companies had formulated formal CSR strategies. Second, all companies were engaging in a form of assurance for their CSR reports; companies $B$ and $F$ had their CSR reports verified by a Big Four auditor, while company $E$ had

\footnotetext{
${ }^{24}$ Company C's 2008 CSR report provides further evidence for a lack of integration by explicitly stating that by 2010 CSR would be made an integral part of the company's business.

${ }^{17}$ Performers have experienced a change in attitudes towards CSR. The term CSR has been replaced by the broader concept of sustainability, since the latter term better reflects the fact that the issues at hand are not limited to the company but relevant for society at large. Consequently all Performer type companies for example published sustainability reports and had sustainability departments. However, the other types used terms such as CSR or CR. For reasons of consistency I will continue using the term CSR for all types.

${ }^{26}$ Company $\mathrm{F}$ actually had a number of characteristics that could also be attributed to the Reporter type of company, as can be seen from the previous presentation of the findings per element. Nevertheless, considering the observations in the light of the two dimensions, the overall picture that emerged from these findings corresponded to the Performer type.
} 
installed an external review committee. ${ }^{27}$ Third, Performer type companies aimed at creating internal awareness for CSR by sending the CSR report to their employees (companies $B$ and $E$ to all, company $F$ to selected employees), whereas the other company types only sent a notification e-mail or included an announcement on their intranet. Next, comparable to Reporters CSR was manifested through several formal management functions and levels. In companies B, E and F the CSR department was managed by a CSR manager (for which the job titles were respectively: director, vice president and manager) with a direct reporting line to a member of the executive board; the CSR reporting function was integrated in this CSR department. In addition, in all Performer type companies board members were directly involved in CSR. Companies $E$ and $F$ had board members with explicit responsibilities in CSR, whereas in case of company B the CEO was a member of the sustainability council, which was the management body that was engaged in the formulation of the CSR strategy. Company E additionally had installed a non-executive board committee focusing on CSR (sustainability committee), which reviewed the corporate plans on a monthly, and the annual performance on an annual basis. The committee also advises on the production of the CSR report. Finally, in all companies there was a sustainability focal point in each business unit. Nevertheless, as compared to Reporters the relative importance of CSR reporting in the entire CSR structure was only modest. The emphasis was on the overall CSR function. To illustrate, the CSR function was structured in terms of small and 'semi-permanent' bodies, such as a 'project team' in company B and in company $\mathrm{F}$ as a 'working group'. The interviewee of company B stated:

"The reporting process is not as important anymore; it should not be seen as an isolated process of a corporate communications department".

The aforementioned formalisation of structures, systems and processes had been gradually established in the course of time. All companies had been active in CSR reporting for many years, although companies $B$ and $F$ published only relatively recently their first CSR reports (respectively 2004 and 2002); before, they published SHE reports for many years.

The integrated nature of CSR in Performer type companies is derived from several findings. First, each of the interviewees of companies $B, E$, and $F$ repeatedly stressed the fact that CSR was not a separate activity, yet that it was fully integrated both

\footnotetext{
${ }^{27}$ Company E actually used to have its report verified by a Big Four auditor until three years before the year in which the interview took place, but then decided to install a formal external review committee instead. The company's decision was motivated by the fact that at that time the company needed to bring its financial reporting in line with US accounting rules. As a consequence most of the environmental reporting had to be included in Form 20-F, which was already strictly audited.
} 
into the overall strategy and everyday management. To illustrate, the representative of company $B$ referred to this integrated approach, stating:

"Sustainability is embedded in the day to day practice, and I ask people to report on their progress of embedding sustainability in their day to day management. We don't want a separate CSR department ... we don't want it to be known as a corporate initiative. It is important to know that sustainability [...] is linked through in all business processes. We have moved from risk management [...] to sustainability as a means of creating business opportunities. [...] It is up to each of our business units to understand this concept and to develop the products and services that customers need and that are in balance with the resources on the planet. That concept is in our company at a very high strategic level".

The interviewee of company E likewise stated:

"[The sustainability strategy] is an overall strategy, not a separate strategy, because everything that is separate will drop off the table at the end of the day. It's no add-on, it's a main stream process ... it is part of the whole project design".

Besides, all companies mentioned the important role of the business units in their CSR management. They all had a focal point in each of the business units and shared the idea that the business units are the places where the CSR strategy becomes real, in that it is translated into everyday actions. This powerful position of the business units was best described by the interviewee of company $E$ :

“The corporate centre doesn't have much executive power; it is a facilitating position. The business units ... that is where the action is".

Another finding that contributes to the notion of an integrated CSR is that in all companies the board is involved in formulating the CSR strategy. This finding corresponds to earlier literature, stating that senior management involvement is essential for integrated CSR (Weaver, et al., 1999). This indicates that CSR is represented at the same hierarchical level as where the overall strategy is formulated. Such facilitates the integration of CSR into general management decision-making. In company $B$, the board formulated the overall strategy. It was the board's explicit task to integrate CSR into this strategy. In order to do so, the board was supported by a sustainability council. This council consisted of the CEO, the managers of the three most important business areas, and the chief staff officers for strategy, technology, 
purchasing, human resources, communications as well as the director sustainability. In company $\mathrm{F}$ the CSR strategy was decided upon directly by the board. Again, this process was integrated in the general strategy formulation process. The interviewee of company also $\mathrm{E}$ also stressed the fact that strategy formulation of CSR took place at the highest hierarchical level. The strategy group integrated CSR into the overall strategy by means of the input that is received from specialists on a wide variety of societal matters. In addition, also the supervisory board was actively involved in this process through its previously mentioned sustainability committee.

The fact that CSR reporting was not the focus of the overall CSR management was reflected by interviewees' statements that the CSR reporting process was first and foremost a way to structure and to maintain a management system and to nurture shared CSR values by communicating it to employees. Company F added that also the dedication of the CEO towards CSR was instrumental to the publication of a CSR report. The comments made by the various representatives of this type of companies illustrated that CSR reporting was a structured process that depicted each business unit what to report on, and what the next steps would be. It enabled to get an overview of the entire business processes within the organisation. The companies reportedly moved from risk management to CSR as a means of creating business opportunities. Further, they stressed that the main goal of the CSR report was to communicate the progress the company made in terms of the integration of CSR, rather than displaying nice examples and images as a means of a marketing tool. The interviewee of company $\mathrm{F}$ stated in this respect:

"The sustainability report really shows that it [i.e., sustainability] is important and fits our strategy. You can't be successful in a failing society".

With this intrinsic motivation for CSR (reporting), Performers distinguished themselves from the other types; the most important reasons for Improvisers and Reporters to engage in CSR reporting were the outside pressures and expectations. As a concluding remark, it is worth mentioning that all Performer type companies were active in high-impact sectors, being: Chemicals and Energy.

To summarise, the Performer type consists of companies with an established history in, and a high level of formalisation of CSR reporting. Given the sensitive contexts of the industries in which they operate they are tried and tested with regards to CSR issues in the course of time. CSR is integrated within the day-to-day practices and linked to all business processes. The CSR reporting process is no longer only a means for satisfying outside expectations, but a way to structure and to maintain a management system and to nurture shared CSR values by communicating it to employees. 


\subsection{Discussion and conclusions}

This paper is a first exploration of how CSR reporting is internally managed. I argue that knowledge about the management of CSR reporting is critical for our understanding of CSR reporting at large. Using a qualitative research design I examined the internal factors that are associated with CSR reporting of six Dutch companies with exemplary CSR reports. During semi-structured interviews with representatives of these companies they demonstrated that the CSR reporting function played various parts. Correspondingly the constellations of structures, systems and processes with which CSR reporting was managed, varied across companies. Despite this heterogeneity in internal factors, some notable patterns of internal management were uncovered across companies, which resulted in a typology of companies. Improvisers, the first company type, are characterised by a CSR approach that is predominantly informal and is separated from the conventional management decisions, the latter of which was labelled 'decoupled CSR'. Companies belonging to the second type (Reporters) have formalised the management of CSR reporting; comparable to the first type, CSR is of a decoupled nature. For Performers the formal management of CSR Reporting forms part of an integrated and formal overall CSR function. Hence, this third company type links formal CSR reporting management to an integrated CSR approach. Finally, Reformers combine an informal CSR reporting management with integrated CSR. However, no sample companies matched this type.

Most strikingly the findings indicated that the heterogeneous management practices led to homogeneous outcomes. No matter whether the sample companies were formally imbued with CSR in all facets of business activity, or revealed an informal approach in which CSR was limited to isolated initiatives that were separated from everyday management, the quality of their actual CSR reports was perceivably high. Hence this implies that irrespective of whether the CSR was of a decoupled or integrated nature, all sample companies published similar CSR reports. Since decoupled CSR is associated with 'window dressing' (Weaver et al., 1999: 539) and integrated CSR with accountability (p. 541), this finding implies that corporate engagement in CSR (reporting) may be motivated by varying beliefs. These results also indicate that it is difficult to say anything meaningful about a company's CSR performance on the basis of the CSR report alone.

These findings have implications for both theory and practice. Many scholars in the field regard CSR reporting as meaningless if it is not a reflection of true accountability toward all stakeholders (O'Dwyer, et al., 2005b). The results for the Improvisers and Reporters type of companies may give rise to doubts about the meaningfulness of CSR reporting. Users of these reports thus should practice prudence in the assessment of CSR performance by means of the CSR report. The internal manage- 
ment processes regarding CSR reporting may be more informative about the actual CSR than the content of the report.

Looking more in detail, it follows that companies A \& D are active in the same industry (Finance), yet they manage CSR reporting differently. This seems to go against the general consensus in the literature that companies within the same industry have comparable CSR reporting practices (for an overview of studies see e.g. Gray, et al., 2001). However, it corresponds to a recent study by Adams and Frost (2008) that also reported considerable differences in the way in which two companies from the same sector and country integrated sustainability in their management processes. This implies that the effect of determinants of CSR reporting such as size, industry and country- in cases where the disclosed CSR information is balanced with some internal organisational factors may be different from studies that only take into account the CSR disclosure.

From a practical view the results of this study have implications for award and benchmark schemes. These schemes have been found to be important drivers of CSR reporting (Hammond \& Miles, 2004). Even when some of the schemes explicitly mention that their purpose is not to reward CSR performance, the goal of most of these schemes is to augment CSP by rewarding transparency or accountability. The findings suggest that their assessment tools are not able to distinguish between the decoupled and integrated CSR type. Such raises the question as to whether the assessments by the various benchmarking and award schemes lack rigor and whether they are useful in enhancing CSP.

Therefore, the institutions behind these schemes (such as governments, rating agencies and the accounting profession) might consider other incentives for augmenting CSP than rewarding high-quality CSR reports. Alternatively, they may want to consider including internal organisational factors in their schemes to nuance rankings that are strictly based on what is reported. Stakeholders that want to use the CSR reports for assessing the extent to which companies have taken care of their interests, may also be interested in the internal organisational factors, since they give valuable context to the information in the reports. However, this internal information will be difficult to obtain. Hence, the inclusion of internal organisational factors in existing measures may serve as a valuable addition to the content in the reports, benefiting the development of a good measure for CSR reporting quality. Companies that are considering CSR reports in order to respond to public pressures, should note that a 'checkbox strategy', by which a company strictly takes into account only the reporting requirements of various benchmarking and award schemes, may lead to inclusion in such schemes in the short run, but may not be the best strategy in the long run. That is, although inclusion may lead to perceived legitimacy by the public in the short run, the company may eventually lose its legitimacy when it cannot back up its CSR reporting with evidence of a solid integration of CSR in its day-today practices. 
This study has some limitations, which should be considered when interpreting the results. First, inherent to any inductive research approach, generalising the results of this study should be done with care, for a number of reasons. First, only the most knowledgeable representative of each company was interviewed. This was motivated by the fact that most of the interview topics referred to some objectively verifiable company system or structure and hence, interviews with other company representatives were expected to generate very similar answers. Besides, all answers could be corroborated with internal company documents. Nevertheless, subjective bias cannot be completely excluded. Also, the small sample size adds to the previous. In addition, the focus of this study is on listed large companies. As a consequence, the results may not be generalisable to SMEs and non-listed companies. Another limitation is that, although the companies included are large multinational organisations of which some have cross-listings in the US, an international sample, or a sample from another country, may provide different results. That is, in the Netherlands a number of companies with major environmental impact have a legal obligation to provide environmental reports at the plant level (Kolk, et al., 2001). In addition, some mandatory CSR reporting directions are included in the Dutch Civil Code for annual reports of all listed and large non-listed companies. The code states that: "organisations should, to the extent necessary for an understanding of the company's development, performance or position as far as relevant, give some information (financial and non-financial) about the environment, employees and risks in their annual reports" (www.sustainabilityreporting.eu, 2008). Consequently some of the CSR reporting of particularly the chemical and oil companies in this sample may be influenced by these requirements. Nevertheless, these directions do not put forward any requirements for the (internal) process of CSR reporting, and hence the generalisability of the presented typology will not directly suffer from variations in CSR reporting requirements across countries or industries.

Future studies may consider testing the suggested typology, using a quantitative research design. In addition, researching the topic of internal organisational factors determining CSR reporting using a longitudinal research design may be considered in the future. Knowledge of the various stages a company goes through in the course of time will be a valuable addition to the typology presented in this study. It may also be interesting to look at the internal factors driving lower quality reporting, as well as similar research settings in other countries, or based on samples in which SMEs are also included. 



\section{Chapter 3}

\section{The relation between environmental performance and environmental disclosure: The role of environmental commitment $^{28}$}

\subsection{Introduction}

As corporate environmental disclosure is the main source of information on corporate environmental performance for investors and other stakeholders, it is essential for them to know to what extent this is a reliable source. If not, stakeholders' decisions that are based on these reports may be sub-optimal. In recent years, empirical studies have found contradicting evidence with regard to the relation between environmental performance and disclosure. That is, some have found no significant relation; other studies did find a significant relation, yet some evidence points at a positive (i.e., superior performers disclose more extensively) and other at a negative relation (i.e., inferior performers disclose more extensively).

This study is motivated by the complexity of environmental performance measurement, which may be effectually summarised by the following question: which company is the better environmental performer; an irresponsible service company or a responsible mining company? In terms of environmental impact the former will typically outperform (i.e., have less negative impact than) the latter simply because of the nature of its activities. Yet, the sole reliance on outcome measures in environmental performance measurement may be questioned.

Most recent research on the link between environmental performance and disclosure relies exclusively on outcome measures, such as the U.S. Environmental

\footnotetext{
${ }^{28} \mathrm{I}$ am indebted to Sustainalytics (the former Dutch Sustainability Research) for providing the SiRi (Sustainable Investment Research International) Global Profiles database. Comments by the Participants of the $22^{\text {nd }}$ CSEAR UK Conference and the first Accounting and Information Management PhD Colloquium at Maastricht University are greatly acknowledged.
} 
Protection Agency's (EPA) Toxic Release Inventory (TRI), as a proxy for environmental performance. However, empirical studies (Delmas \& Blass, 2010; Mattingly \& Berman, 2006) indicate that companies in the most polluting industries actually seem to have the most developed CSR management practices. Hence, inferior outcome-based performance may be accompanied by superior environmental management practices. This implies that even if companies in polluting industries have an unfavourable current outcome-based performance, they may be better fit for dealing with future environmental challenges, which would signify an improvement in future performance. Companies without such practices, probably in lesspolluting industries, may be characterised by deteriorating environmental performance in future. In these instances overall environmental performance will in fact deviate from outcome-based performance. Consequently the revealed relation between (overall) environmental performance and disclosure from the research data in previous studies may deviate from the factual relation. This may be one of the reasons for the inconclusive and contradicting evidence that these studies have provided.

Hence, in this study I suggest that investigating the relation between environmental disclosure and -performance requires environmental performance measures that, next to an outcome dimension, also include a process dimension. This suggestion is based on a distinct field of research dealing with corporate environmental performance measurement, which argues that environmental performance encompasses both the motivations for and consequences of corporate actions (Wood, 2010). Whereas outcome measures focus on the actual environmental impact of a company's business conduct, process-based measures reflect a company's efforts to mitigate this (negative) environmental impact.

By including both the outcome and process dimensions of environmental performance, this study aims to shed a new light on the association between environmental performance and disclosure. In addition, as there is a lack of empirical evidence on the above association for samples other than North American manufacturing companies, this study seeks to increase the generalisability of the body of evidence by also including e.g. service companies from other countries.

Capturing the actual environmental impact, outcome measures of environmental performance -such as emission figures or energy consumption- are fundamentally negative. In contrast, process-based measures are inherently positive, as they reflect a company's efforts to mitigate its (negative) environmental impact. Legitimacy theory assumes that companies have incentives to provide "positive or mitigating environmental disclosures" to legitimate their behaviours (Cho, 2009: 36). This implies that positive performance information (i.e., processbased performance) tends to be disclosed. Hence, the more superior a company's process-based performance, the more extensive its environmental disclosure will be. This also implies that companies do not have incentives to disclose negative 
performance information, and thus will minimise the disclosure of (negative) outcome-based performance. However, legitimacy theory suggests that companies under greater pressure engage in more extensive disclosures to influence the public's perception and mitigate potential stakeholder actions that jeopardise their 'going concern' (e.g., Cho, 2009; Gray, et al., 1995; Lindblom, 1994; Patten, 1991; Walden \& Schwartz, 1997). Companies with inferior outcome-based performance, such as companies in environmentally sensitive industries, are more visible due to greater public scrutiny and hence will face greater exposure to public pressure (Walden \& Schwartz, 1997). Therefore, from legitimacy theory point of view, inferior outcome-based performance is expected to lead to more extensive, rather than less extensive disclosure.

Drawing on legitimacy theory, I thus expect outcome-based environmental performance to be negatively related and process-based performance to be positively related to environmental disclosure.

To empirically specify the hypothesised relations, two environmental performance constructs and one variable measuring the extensiveness of discretionary environmental disclosure are developed for an international sample of 138 large companies. The outcome-based performance measure is captured by sales-adjusted greenhouse gas (GHG) emissions. Process-based performance is measured by a company's environmental commitment, data for which are retrieved from a proprietary database.

The results show that environmental disclosure is first and foremost related to positive performance, i.e. environmental commitment. In line with expectations, it appears to be consistently positively associated with environmental disclosure. The results for GHG emissions (outcome-based performance) are less consistent. As expected they show that this measure in itself is significantly positively related to environmental disclosure, both across and within industries. However, this relation disappears in models that include GHG emissions and environmental commitment simultaneously. Besides, more in-depth analysis shows that the positive relation between GHG-emission and disclosure is only applicable in two conditions. First, it reflects that manufacturing companies have overall more extensive disclosures than non-manufacturing companies. Second, it reveals that non-manufacturing companies with higher GHG emissions have more extensive disclosures than their lower GHG emissions industry peers. A further important result is that the positive relation between environmental commitment and disclosure may occur due to inferior outcome-based performance. The significant positive association between GHG emission and environmental commitment reflects this. This points at the importance of visibility. Companies with greater environmental impact face greater exposure to public pressure, since they are more intensely scrutinised, and hence need to make more extensive mitigating disclosures. However, given the scrutiny they 
face, they need to provide evidence of their environmental commitment. For manufacturing companies providing only disclosure, without evidence of actual commitment, will not pass this 'scrutiny test'. For non-manufacturing companies this is less of a problem, as evidenced by the significant negative relations between outcomebased performance and disclosure, while the correlation between process-based and outcome-based performance is non-significant. These conclusions are in line with the expectations from legitimacy theory.

This study contributes to the literature by showing how process-based performance adds to a better understanding of the complex relation between (different expressions of) environmental performance and disclosure. It also demonstrates that studies based on legitimacy theory will benefit from nuancing the commonly used hypothesis that inferior performance is associated with more extensive disclosure, as this relation is dependent on which performance dimension is used. As inferior outcome-based performance may be associated with superior process-based performance and vice versa, it is important to distinguish between these two dimensions. Relating disclosure to company visibility, rather than performance, may be a more successful path for explaining variations in environmental disclosures across companies. Practically it shows that assessing a company's environmental performance on the basis of its voluntary environmental disclosures is questionable, as these disclosures are mainly motivated by a company's positive performance and hence give an overly optimistic picture.

The remainder of this paper is organised as follows. First I review the literature on the link between environmental performance and environmental disclosure, as well as on corporate environmental performance measurement. After this, the hypothesis development is presented. In the next section I describe the sample selection, data collection, empirical specification and variable measurement. The final sections consist of a presentation and discussion of the empirical results, and a conclusion.

\subsection{Literature review}

(Accounting) literature on the relation between environmental performance and environmental disclosure basically distinguishes between two competing theories: voluntary disclosure theory and legitimacy theory.

Voluntary disclosure theory (Dye, 1985; Verrecchia, 1983) provides an economic rationale for companies to engage in voluntary disclosure. This theory posits that companies with unobservable superior performance have incentives to signal this by means of voluntary disclosure, since the perceived benefits (i.e., avoiding adverse selection) outweigh the proprietary costs associated with the disclosures 
(Verrecchia, 1983). In contrast, inferior performers lack these incentives due to a less favourable benefits-to-costs ratio. Voluntary disclosure theory has been applied to environmental disclosure (Bewley \& Li, 2000; Li, Richardson, \& Thornton, 1997) based on the idea that environmental disclosure is largely voluntary. In an environmental disclosure context, voluntary disclosure theory argues that companies with superior environmental performance, which cannot be observed by external stakeholders, have an incentive to disclose this performance. However, disclosure by inferior environmental performers may result in substantial proprietary costs due to subsequent adverse reactions by regulators or other stakeholders ( $\mathrm{Li}$, et al., 1997). This means that superior environmental performers are associated with more extensive environmental disclosure, whereas inferior performers will resort in less or no disclosure on their performance (Clarkson, et al., 2008). One of the assumptions of voluntary disclosure theory is that company disclosures are 'truthful'. Besides, companies with superior performance are expected to disclose 'hard' environmental information (e.g., actual emission figures) that is difficult to mimic by inferior performers (Clarkson, et al., 2008).

At this place it is important to consider the basic assumptions of voluntary disclosure theory in the context of recent environmental disclosure research. The assumption that managers disclose environmental information that is hard to mimic when their companies' performance is superior relative to other companies implies that managers also know the performance (such as emission figures) of the other companies. Yet, it is questionable whether this assumption holds. ${ }^{29}$ In order to make this assessment, managers will have to use other companies' disclosures, as this is still the main source for environmental information. However, recent empirical evidence shows that companies mostly refrain from disclosing environmental outcomes and that companies that do make these disclosures mainly accentuate performance trends related to their own performance, rather than impact data relative to peers (Clarkson, Fang, Li, \& Richardson, 2010; Clarkson, et al., 2008). ${ }^{30}$ Due to the previous, comparison of environmental impact from disclosures across companies is hardly possible (Delmas \& Doctori Blass, 2010). And even if it would be possible for

\footnotetext{
${ }^{29}$ Apart from the broad 'common sense' idea that e.g. the emission of a company in the chemical industry will be higher than a professional service company.

${ }^{30}$ This lack of information supply is in contrast with an increased demand for environmental performance information by stakeholders. For that reason, some stakeholder groups have joined forces and have developed initiatives for systematically collecting and publishing environmental impact data per company, such as the frequently used U.S. Environmental Protection Agency's (EPA) Toxic Release Inventory (TRI). Nevertheless, these data also suffer from a number of drawbacks (Ilinitch, Soderstrom, \& Thomas, 1998). First, similar to company disclosures on environmental impact, they vary with regard to scope, and consequently global comparability will be negatively affected (Wood, 2010). Second, TRI is only available for U.S. facilities with emission levels above a certain threshold (Delmas \& Blass, 2010), and thus companywide emissions for large multinational companies cannot be measured reliably (Sullivan \& Gouldson, 2007). This lack of objective and comparable environmental performance data (at least: data that could be obtained with reasonable effort) was also experienced during the data collection for this study.
} 
managers to collect and analyse this performance information (e.g., based on the data sources used in this study) it is arguable whether this is a viable assumption, given the considerable costs associated with the collection and analysis of the information (Schaltegger, 1997). Hence, it is disputable whether voluntary disclosure theory is able to provide an explanation for the results of some of previous studies in this field, particularly for those relying on outcome measures.

Consequently this study relies on legitimacy theory, on which an increasing number of recent environmental disclosure studies are based. Legitimacy is defined as: "A generalized perception or assumption that the actions of an entity are desirable, proper, or appropriate within some socially constructed system of norms, values, beliefs, and definitions" (Suchman, 1995). Legitimacy will be maintained when companies act in congruence with the generalised norms and values of the ones with which it interacts, i.e. its stakeholders, or more broadly, society. The appropriateness of company actions with respect to the environment is derived from the perceived environmental performance of the company. This public perception may be based on its own observations or information provided by other parties, such as the media or the company. When a company's actions are perceivably not congruent with the norms and values of society, which may occur due to inferior environmental performance, this company will face greater exposure to public pressure (Walden \& Schwartz, 1997). Disclosure is an important tool for companies in maintaining or repairing their legitimacy. Legitimacy theory suggests that companies under greater pressure engage in more extensive disclosures to influence the public's perception and mitigate potential stakeholder actions that jeopardise their 'going concern' (e.g., Cho, 2009; Gray, et al., 1995; Lindblom, 1994; Patten, 1991; Walden \& Schwartz, 1997). This implies that companies with inferior environmental performance have no incentives to disclose this negative performance information; however, they do have incentives to disclose positive performance information to offset any negative perceptions. Consequently, inferior performance will lead to more extensive, rather than less extensive disclosure.

In the following the results of prior empirical research on the link between environmental performance and -disclosure will be discussed. Next to studies that explicitly address this link, also some studies that have related environmental performance to disclosure measures for other purposes have been considered.

The earliest empirical studies on the link between environmental performance and environmental disclosure failed to establish any significant relation. Of these early contributors, Ingram and Frazier (1980) were the first and they were also the first in a row to use the environmental performance measures provided by the Council on Economic Priorities (CEP). This non-profit organisation provided measures for environmental performance for a limited number of companies in highly environmentally sensitive industries. These measures, ranging from environmental 
policies and impact to political donations, were expressed as a rating on a 0 to 10 scale. Subsequent studies by Wiseman (1982) and Freedman and Wasley (1990) corresponded to Ingram and Frazier in using the CEP data, small sample sizes (26 and 49 respectively) and in their conclusion that no relation between the two constructs existed. Fekrat, Inclan and Petroni (1996) introduced environmental performance measurement based explicitly on the U.S. Environmental Protection Agency's (EPA) Toxic Release Inventory (TRI) ${ }^{31}$, which was created earlier as part of the Superfund legislation. For a subsample of 26 U.S. companies they find no significant relation between annual report environmental disclosures and performance rankings based on TRI (total releases per $\$ 1000$ sales), the number of Superfund sites for which the company had been identified as a potentially responsible party, and the average of both measures. Patten (2002) suggests that the insignificant findings of the aforementioned studies are associated with problems in the research design. That is, the studies fail to control for company size and industry affiliation, the samples are limited with regard to industry diversification and size, and the CEP ratings as a measure for environmental performance cannot be compared between industries. Other studies around that time, which were not reviewed by Patten, mostly suffer from similar limitations. Hughes, Sander and Reier (2000), for a sample of 20 companies from various industries, find that 'environmental laggards' (based on Fortune rankings) have more mandatory disclosure. Yet, no significant differences in voluntary disclosures were found. Hughes, Anderson and Golden (2001) study 51 U.S. companies, using a disclosure index based on Wiseman and performance rankings by the CEP, finding no differences between mixed and poor performers, but significant higher mandatory disclosures for poor performers. An exception is the study by Bewley and Li (2000), in which they take into account a relatively large sample of 188 Canadian manufacturing companies and proxy environmental performance ('pollution propensity') by industry affiliation and whether the company participates in a governmental pollution program. The authors find that companies with higher pollution propensity and more media and political exposure have a higher tendency to disclose general (as compared to financial) environmental information.

In response to the limitations of the previously mentioned studies, Patten (Patten, 2002) furthers Fekrat et al.'s (1996) research design by also using the TRI data (total releases per $\$ 1000$ sales) as a proxy for environmental performance for a large U.S. sample ( $n=131$ ) of both companies from 'environmentally sensitive' (ESI) and 'non-environmentally sensitive' (non-ESI) industries, controlling for company size. He finds a significant negative relation between performance and an environmental reporting measure, based on the Wiseman index of annual report disclosures, from which litigation-related disclosures were excluded. Al-Tuwaijri, Chris-

\footnotetext{
${ }^{31}$ Nevertheless, these data were obtained from CEP.
} 
tensen and Hughes (2004) proxy environmental performance by the total toxic waste recycled divided by total toxic waste generated, based on the TRI. In their multivariate analysis they also control for 'environmental exposure' (i.e., total waste generated adjusted by revenue), 'environmental concern' (i.e., the presence or absence of an environmental committee, frequency of reporting and the number of voluntary EPA programs in which the company is participating). For a sample of 198 US manufacturing companies the results of a three-stage least squares regression, through which the relation between environmental performance, environmental disclosure and economic performance is jointly estimated, indicate that disclosure is positively associated with performance, which also holds for environmental concern. The authors conclude that their findings are consistent with voluntary disclosure theory. However, for a comparable -yet smaller- sample, Cho and Patten (2007) show that companies that received environmental concerns by the Kinder Lydenberg \& Domini (KLD) rating scheme, as well as companies from environmentally sensitive industries (ESI) have significantly higher levels of environmental disclosure than companies without KLD concern and from non-ESI industries respectively. This corresponds to legitimacy theory predictions. In contrast to all previous studies Clarkson et al. (2008) investigate the link between performance and disclosure focusing entirely on environmental disclosure outside the annual report. They use a measure capturing the toxic waste recycled (similar to Al-Tuwaijri et al. (2004)) supplemented by another measure: the ratio of toxic waste to total sales (which is similar to the performance measure of Patten (Patten, 2002) and the environmental exposure measure by Al-Tuwaijri et al. (2004). They find that the amount of toxic waste recycled is positively related to disclosure, both within and between industries. In contrast with Al-Tuwaijri et al. (2004) and Patten (2002) their results indicate that the amount of sales-adjusted toxic waste is negatively related to disclosure, also within and between industries. Their explanation for this contrasting finding is that they consider only disclosures outside the annual report ${ }^{32}$. In a subsequent study by Cho, Patten and Freedman (2009) the disclosure measure is limited to environmental capital expenditure. Performance is measured by sales adjusted and raw TRI emissions, as well as a differentiation between ESI and non-ESI (Cho \& Patten, 2007) companies and the interaction of industry and sales adjusted TRI emissions. Based on their findings that the majority of spending amounts disclosed are not material, and both disclosing and non-disclosing companies show patterns of improving performance over time, they find no evidence for voluntary disclosure theory. Subsequent regression analysis shows that all performance measures, except for the interaction term, are positively related with environmental capital expenditure disclosure, which leads them to conclude that legitimacy theory explains

\footnotetext{
${ }^{32}$ Nevertheless, Clarkson et al. (2008) also find that toxic waste emitted is negatively associated with toxic waste recycled. This correlation is exactly opposite that of Al-Tuwaijri et al. (2004) while they use similar samples.
} 
the relation between performance and disclosure. Finally Delmas and Doctori Blass (2010) in a case study comprising 15 U.S. chemical companies, assess the association between a range of performance measures, one of which is environmental disclosure in special purpose reports and websites. They report that disclosures are significantly positively associated to only raw TRI emissions, the quarters of noncompliance of company facilities with environmental legislation, and KLD strengths and concerns. The majority of the measures are also significantly positively associated with one another. The previous review is summarised in Appendix C.

Appendix $C$ reveals that there is a wide variety in corporate environmental performance constructs used. Nevertheless, most studies, particularly the most recent (i.e., Al-Tuwaijri, et al., 2004; Bewley \& Li, 2000; Cho, et al., 2009; Clarkson, et al., 2008; Fekrat, et al., 1996; Patten, 2002) exclusively rely on outcome measures for environmental performance measurement. Yet, these studies find both positive and negative associations. The studies that rely on aggregate measures of performance, in which constructs such as environmental policies and impact data are combined into a rating scale (e.g., the CEP rating), for the most part fail to find any significant relation. However, this does not necessarily mean that these measures are inappropriate; the lack of significant results may be attributed to small sample sizes and the incomparability across industries (see Patten, 2002). So far, studies have not explicitly used measures based on environmental policies and programs separately. ${ }^{33}$ To conclude, the various measures used in previous research have not resolved the ambiguity as to what motivates companies to engage in environmental disclosure. The aim of this study is to consider the relation between environmental performance and disclosure, using an environmental performance measure that is conceptually (more) appropriate. Therefore, in the next section a performance measure will be introduced that seeks to capture the attributes of conceptually sound performance measures, as suggested by environmental performance measurement literature.

\subsubsection{Corporate environmental performance measurement}

In environmental performance measurement literature, it is widely acknowledged that corporate environmental performance measurement is a complicated issue (Azzone, Nocci, Manzini, \& Welford, 1996; Ilinitch, et al., 1998; Semenova \& Hassel,

\footnotetext{
${ }^{33}$ The previously discussed KLD measure may be an exception, as KLD distinguishes between environmental strengths and concerns. Strengths mainly relate to environmental policies and programs that a company has in place, whereas concerns relate to problematic environmental outcomes. KLD measures are used in the study by Cho and Patten (2007). Yet, the particular way in which the authors operationalise their study (i.e., only taking into account the absence or presence of environmental concerns) practically means that their measure is also mainly limited to (negative) environmental outcomes. Delmas and Doctori Blass (2010) show that both KLD environmental strengths and concerns are significantly positively related to disclosure.
} 
2008). Hence it is characterised as "controversial, fluid, ambiguous and difficult to research" (Wood, 2010: 50). As will be discussed below, contrary to (accounting) literature on the link between environmental performance and -disclosure, most contributions in this field recognise the existence of at least two dimensions, i.e., process- and outcome-dimensions.

Wood (1991) puts forward that corporate social performance (CSP), of which environmental performance is a sub-set, encompasses both the motivations and consequences of the actions of a company and consequently distinguishes between process- and outcome- related dimensions. Based on Wood's suggestions llinitch et al. (1998: 388-389) state that the process-related dimension of environmental performance is a reflection of "structural and programmatic characteristics of the company" and outcome dimensions relate to "more observable and quantifiable results achieved by the company". Xie and Hayase (2007) in their review of studies on the development of environmental performance measurement, conclude that almost all models for environmental performance measurement include an 'environmental management processes' dimension and an 'environmental results' dimension. Moreover, they conclude that the two dimensions are independent from each other, implying that proactive environmental management not necessarily leads to good outcomes. In the same vein, Gouldson and Sullivan (2007) distinguish between 'procedural' (i.e., policies and processes) and 'substantive' (i.e., outcomes) dimensions of 'corporate environmentalism'.

In the context of the relation between environmental performance and environmental disclosure the process-based dimension is of particular importance. That is, outcome measures reflect a company's actual environmental impact (such as toxic and greenhouse gas releases, or energy usage), and are consequently inherently negative. On the contrary, process-based measures reflect a company's efforts to avoid or mitigate its environmental impact, which are of a more positive character. Since companies tend to disclose information that reflects good performance (i.e., positive information) and withhold negative environmental information (e.g., Cho, 2009; Deegan, 2002; Deegan \& Gordon, 1996; Deegan \& Rankin, 1996; Dye, 1985; Guthrie \& Parker, 1989; Patten, 1992, 2002; Verrecchia, 1983; Walden \& Schwartz, 1997), these measures are an important factor to consider in the light of companies' motives for environmental disclosure.

\subsection{Hypotheses development}

The first part of the literature review pointed out that previous research on the environmental performance-disclosure link has not distinguished between the process and outcome dimensions of environmental performance. In the subsequent part of the review, it nevertheless became clear that conceptually appropriate 
measures of corporate environmental performance do include these two dimensions. In order to bring the distinction between process-based and outcome-based environmental performance into the research design, I develop separate hypotheses for each of the two dimensions.

Capturing the actual environmental impact, outcome measures of environmental performance -such as emission figures or energy consumption- are fundamentally negative. In contrast, process-based measures are inherently positive, as they reflect a company's efforts to mitigate its (negative) environmental impact. Legitimacy theory assumes that companies have incentives to provide "positive or mitigating environmental disclosures" to legitimate their behaviours (Cho, 2009: 36). This implies that positive performance information (i.e., processbased performance) tends to be disclosed. Hence, the more superior a company's process-based performance, the more extensive its environmental disclosure will be. This also implies that companies do not have incentives to disclose negative performance information, and thus will minimise the disclosure of (negative) outcome-based performance. However, legitimacy theory suggests that companies under greater pressure engage in more extensive disclosures to influence the public's perception and mitigate potential stakeholder actions that jeopardise their 'going concern' (e.g., Cho, 2009; Gray, et al., 1995; Lindblom, 1994; Patten, 1991; Walden \& Schwartz, 1997). Companies with inferior outcome-based performance, such as companies in environmentally sensitive industries, are more visible due to greater public scrutiny and hence will face greater exposure to public pressure (Walden \& Schwartz, 1997). Therefore, from legitimacy theory point of view, inferior outcome-based performance is expected to lead to more extensive, rather than less extensive disclosure.

The previous is in line with the scarce empirical evidence from prior literature. As was discussed in the literature review, Delmas and Doctori Blass (2010) show that both KLD environmental strengths (mainly relating to process-based performance) and concerns (mainly relating to outcome-based performance) are significantly positively related to disclosure; this implies that superior process-based performance and inferior outcome-based performance both are associated with more extensive disclosure.

Drawing on legitimacy theory, I thus expect outcome-based environmental performance to be negatively related and process-based performance to be positively related to environmental disclosure.

H1a: $\quad$ Outcome-based environmental performance and the extensiveness of environmental disclosure are negatively associated.

H1b: $\quad$ Process-based environmental performance and the extensiveness of environmental disclosure are positively associated. 


\subsection{Research method}

\subsubsection{Sample}

As described in Chapter 1, the sample for this study consists of companies that were included in 2004 SiRi (Sustainable Investment Research International) database. This resulted in an initial sample of 199 companies

For the particular purpose of this study, for this initial sample of 199 companies it was checked whether GHG-emission figures were available from the website of the Carbon Disclosure Project (CDP) and/or from the GHG-emission fact sheets of the U.S. Environmental Protection Agency's (EPA) 'Climate Leaders' program. The CDP database for the year 2004 resulted in GHG emission figures for only 114 of the companies in the sample. This number was increased by 24 U.S. companies through inclusion of GHG-emission figures provided by the EPA. The final sample consisted of 138 companies.

\subsubsection{Statistical analysis}

The following function is employed to test the hypotheses:

$E N V D I S C=f($ OUTC_PERF, PROC_PERF, control variables)

In this function ENVDISC represents the environmental disclosure measure, OUTC_PERF the outcome dimension of environmental performance, and PROC_PERF the process dimension of environmental performance. OLS regressions are used to test these models.

Next to regressions based on the absolute numbers for each of the variables included in the model (referred to as 'between industries analysis'), I also ran regressions based on industry ranks to account for within-industry variation (referred to as 'within industries analysis'). For this purpose I ranked all continuous variables within each industry, expressed these ranks as a fraction of the maximum ranks of the corresponding industry and then pooled these fractional ranks across industries. This circumvents potential violations of normality assumptions, which may occur due to limited numbers of observations per industry and different sample sizes between industries (e.g., Clarkson, et al., 2008). In this way it is also possible to distinguish between a company's environmental impact as a result of the nature of its commercial activities (King \& Lenox, 2001; Semenova \& Hassel, 2008), and the impact as a result of its own environmental actions. The former type of environmental impact, referred to as the 'base-level exposure' of a company (Cho \& 
Patten, 2007), will be particularly important to consider in this study, as both manufacturing and service companies are included in the sample. ${ }^{34}$

\subsubsection{Measures for dependent variable}

The construction of the dependent variable was described in Chapter 1. Next to scrutinising for each of the 47 items whether the majority of the information pieces provided was publicly disclosed or not, it was possible to further refine this measure to only take into account the 'truly discretionary public disclosure'. In line with suggestions by Clarkson et al. (2008), for this purpose only the public disclosures that were not included in the annual reports or 10-Ks were included, as these disclosures are "largely non-discretionary". This measure differs from the studies as presented in Appendix C, which are all based on annual report and $10-\mathrm{K}$ reports ${ }^{35}$.

\subsubsection{Measures for explanatory variables}

As indicated earlier, this study differs from previous (accounting) studies on the relation between environmental performance and-disclosure in two ways.

First, next to the frequently used outcome measures, it also seeks to include process-based measures. Given that (external) outcome measures are more easily observable than (internal) process-based measures they have been most intensively used in empirical research (Mitnick, 2000). Nevertheless, from the previous review of corporate environmental performance literature it appeared that conceptually sound performance measures include both.

Another difference between the current and previous studies is the sample, as was discussed before. Prior research has investigated the association between environmental performance and environmental disclosure only for North-American manufacturing companies. Consequently, there is a lack of evidence on the relation between environmental performance and disclosure for e.g. service companies and for companies in other countries. Since there is evidence that managers' attitudes toward, and actions related to environmental performance and disclosure differ between countries (Bansal \& Roth, 2000; Buysse \& Verbeke, 2002; Delmas, 2002; Hofstede, Deusen, Mueller, \& Charles, 2002; Holder-Webb, et al., 2008) and industries (Fineman \& Clarke, 1996; Gray, et al., 2001; Halme \& Huse, 1997; HolderWebb, et al., 2008) an additional aim of this study is to increase the generalisability

\footnotetext{
${ }^{34}$ To illustrate, irrespective of how proactive the environmental strategy of a chemical company, its performance in terms of impact (e.g. GHG emissions per unit of sales) will be inferior than a service company without any environmental strategy. However, its future performance might be superior due to the proactive strategy, whereas the service company's future performance may be inferior. This example illustrates that lower emission figures are not necessarily associated with a proactive environmental strategy.

${ }^{35}$ Exceptions are: Clarkson et al. (2008) and Delmas and Doctori Blass (2010)
} 
of the evidence by also including other than North-American manufacturing companies in the sample.

The previous has a number of consequences for the research design. First, a measure for the process dimension of environmental performance is needed. Second, as the frequently used TRI-emissions are only available for North-American manufacturing companies, other data were needed to capture the outcome dimension of a multi-country and multi-industry sample.

\section{Environmental Commitment}

In contrast with the stated importance of the process dimension for environmental disclosure, there is hardly any research using performance constructs based on process dimensions (for an extensive literature review of environmental performance studies and the constructs used, see Wood, 2010). In the specific context of the relation between performance and disclosure, Clarkson et al. (2008) suggest that a company's 'type' of environmental performance is reflected by its 'commitment to protect the environment'. This environmental commitment can be captured by 'hard data' such as the existence of an environmental board committee or implementation of ISO 14001 (Clarkson, et al., 2008: 310). As these company actions are examples of what llinitch et al. (1998) call "structural and programmatic characteristics of the company", which they refer to as reflections of process-based performance, environmental commitment can be seen as an appropriate construct to measure process-based performance.

Henriques and Sadorsky (1999: 88) define environmental commitment as: "What a company is actually doing or has done with reference to environmental issues" and state that environmental practices such as the development, formalisation and communication of an environmental plan, and the establishment of an ESH unit and environmental board committee are examples of this. Stanwick and Stanwick's (2000) definition -"the environmental activities that the organization is currently involved in"- largely corresponds to the previous. Roy, Boiral and Lagacé (2001) mention that environmental commitment is captured by ISO's (International Organization for Standardization) description of an EMS: “organizational structure, planning activities, responsibilities, practices, procedures, processes and resources for developing, implementing, achieving reviewing and maintaining the environmental policy". Polonsky, Zeffane and Medley (1992), with reference to environmental commitment, mention the existence of environmental policies, and the implementation thereof by means of structural provisions, audits, and inclusion in performance evaluation and investment decisions. Other studies have used similar constructs, yet have labelled them differently, such as: 'environmental responsiveness' (e.g., Elsayed, 2006; Staden \& Hooks, 2007) or 'environmental proactiveness' (e.g., González-Benito \& González-Benito, 2006; Murillo-Luna, Garcés-Ayerbe, \& Rivera-Torres, 2008). Based on the previous, for the purpose of this study envi- 
ronmental commitment will be defined as the internal formal provisions that companies make to take into account their environmental impact.

In order to capture these internal provisions, for each company it was checked whether it had a number of environmental structures, management systems and formal programs in place that require substantial resources in terms of labour and money. Examples of these include: board level responsibility for the environment, a dedicated environmental department, an environmental management system, third party audits, and the implementation of programs for reduction of water, waste or GHG. To do this, the previously mentioned SiRi global profiles were used. Under the 'environmental management systems' heading of these profiles information on the presence and absence of 20 environmental provisions is given (see Appendix A). Environmental commitment was measured by quantifying the absence (value ' 0 ') or presence (value ' 1 ') of these 20 internal environmental provisions. The idea is that the more provisions a company has made, the more resources it has used, the less informal its environmental management; a company will only spend these resources when it is committed to the environment. ${ }^{36}$ This measure was labelled 'COMMIT'.

\section{GHG emissions}

This study's outcome measure for environmental performance is based on the company's Greenhouse Gas (GHG) emissions, as this type of environmental impact is relevant for all companies, including companies in services industries. For each company the total annual direct and indirect ${ }^{37}$ emissions of the six main GHGs in tonnes $\mathrm{CO}_{2}$ equivalents were taken ${ }^{38}$. More precisely, the ratio of $\mathrm{GHG}$ emissions to total sales is used. This results in a measure comprising total tons of GHG emissions per ten thousand dollars of sales, labelled 'EMISS'. The main source for these emission figures was the website of the Carbon Disclosure Project (CDP). This is a not-

\footnotetext{
${ }^{36}$ The dependent variable (ENDISC) also includes these 20 environmental items, in the sense that 20 of the total of 47 environmental items included the disclosure index refer to whether a company publicly discloses information on its 'management systems' (see appendix A), which category includes things such as the existence of environmental programs and an environmental department. However, the dependent variable measures disclosure about these 20 items, whereas COMMIT measures whether these 20 items are actually in place. Nevertheless, in order to exclude the possibility that any potential relation between COMMIT and ENVDISC would be simply driven by this, I also developed an alternative disclosure measure from which these 20 items were excluded. Except for a slight decrease in explanatory power of the regression models, the results were very similar for the two measures. Hence, only the results for the original ENVDISC measure will be reported.

${ }^{37}$ Direct GHG emissions are emissions from sources that are owned or controlled by the company and indirect GHG emissions are those from sources that are not owned or controlled, but nevertheless occur due to the activities of the company. Examples of indirect emissions are those related to business travel, or the consumption of energy that was purchased.

${ }^{38}$ These GHGs included Carbon Dioxide $\left(\mathrm{CO}_{2}\right)$, Methane $\left(\mathrm{CH}_{4}\right)$, Nitrous Oxide $\left(\mathrm{N}_{2} \mathrm{O}\right)$, Hydroflurocarbons (HFCs), Perfluorcarbons (PFCs) and Sulphur Hexafluoride $\left(\mathrm{SF}_{6}\right)$.
} 
for-profit organisation, acting on behalf of hundreds of institutional investors around the world with the aim "to accelerate solutions to climate change by putting relevant information at the heart of business, policy and investment decisions" (www.cdproject.net). Using its investor power, one of the main tasks of the CDP is to urge companies to disclose relevant information of their performance with regard to climate change, for inclusion in their database. Data are not limited to manufacturing companies or particular countries. The retrieved GHG emission data were verified with the GHG emission figures from companies' reports of the corresponding year if available. In case these figures did not correspond, the higher figure of the two was taken. This resulted in GHG data for only 114 companies in the sample. Hence, an additional data source was used. This data source, the GHG-emission fact sheets of the U.S. Environmental Protection Agency's (EPA) 'Climate Leaders' program, resulted in data for another 24 U.S. companies. Where possible, the same verification procedure was applied as described before. This measure was labelled 'EMISS'.

\subsubsection{Control variables}

In prior literature three factors that have been consistently associated with environmental disclosure: company size, industry affiliation, and country of ultimate ownership (Hibbitt, 2004).

First, I control for size by taking the market value of common equity of the companies. Company data on size (SIZE) were taken from the Datastream financial statistical database. Legitimacy theory assumes that larger companies are more visible than smaller companies, and therefore are scrutinised more intensively by stakeholders, which requires more active disclosure (Belkaoui \& Karpik, 1989; Brammer \& Pavelin, 2004). Hence, larger companies have greater incentives to disclose environmental information. Whilst the specific sample for this study -the largest companies in the world- may limit the variance in size, I nevertheless predict a positive sign of the coefficient for SIZE.

Second, industry affiliation is controlled for. Based on the GICS two-digit industry classification the companies in the sample are divided into ten industries ${ }^{39}$. As I run separate within industry regressions, in which the base-level exposure of an industry will already be controlled for, no dummy variables will be included in the between industries regressions to control for industry fixed effects. Besides, a number of studies (Cho, et al., 2009; Cho \& Patten, 2007; Patten, 2002) consider industry affiliation (i.e., environmentally sensitive versus non-environmentally sensi-

\footnotetext{
${ }^{39}$ The Global Industry Classification Standard (GICS) is the product of the cooperation between Standard \& Poor's and Morgan Stanley Capital International and distinguishes the following two-digit industries: Energy (10), Materials (15), Industrials (20), Consumer Discretionary (25), Consumer Staples (30), Health Care (35), Financials (40), Information technology (45), Telecommunication Services (50), Utilities (55).
} 
tive industries) as a measure for environmental performance. This implies that the environmental performance of a company to a certain extent will be determined by its industry affiliation.

Third, in the specific context of CSR prior studies report on the unique position of the U.S., not only in comparison to stakeholder-oriented countries, but also to other shareholder-oriented countries (Aguilera, Williams, Conley, \& Rupp, 2006; Buhr \& Freedman, 2001; Cormier \& Magnan, 1999; Holder-Webb, et al., 2008; Thijssens, Bollen, \& Hassink, 2010). The underlying rationale for these differences is the high litigation risk that characterises the specific legal environment of the U.S. As a result U.S. companies are inclined to provide mandatory CSR disclosure, but will abstain from disclosing voluntary CSR information (Buhr \& Freedman, 2001). In line with prior studies (Meek, Roberts, \& Gray, 1995; Thijssens, et al., 2010) this study will therefore distinguish between three country clusters: STAK (stakeholderoriented), SHR_N_US (shareholder-oriented non-US) and SHR_US (shareholderoriented US).

\subsection{Results}

\subsubsection{Descriptives}

Table 3.1 shows the descriptive statistics.

Panel A illustrates that on average only $31 \%$ of the environmental items, which are of interest to stakeholders, are publicly disclosed by companies outside their annual report. This Table also shows that the average environmental commitment (COMMIT), expressed as a percentage, is $63 \%$. This signifies that on average companies have made two third of the 20 environmental provisions measured. ${ }^{40}$ The other performance measure, EMISS, reveals that companies vary considerably in their average emission figures. This high variance reflects the fact that both manufacturing and non-manufacturing companies are included in the sample. As further descriptive analysis ${ }^{41}$ revealed that both SIZE and EMISS were peaked, these measures were log-transformed. Descriptives for the resulting measures (not tabulated) indi-

\footnotetext{
${ }^{40}$ The mean commitment for the sample $(n=199)$ including also companies that did not participate in one of the GHG disclosure projects (and for which consequently no GHG data were available) was exactly $50 \%$. This indicates that the sample is somewhat biased toward more committed companies.

${ }^{41}$ For all variables of interest, in order to test for potential violations of the normality assumptions, medians were calculated and compared to the means, and skewness and kurtosis statistics were analysed. This revealed that for EMISS (4062 versus 60566), SIZE (19787 versus 414880 and to some extent COMMIT ( 0.71 versus 0.63$)$ medians deviated considerably from the means; nevertheless, further analysis showed that only SIZE and EMISS had Kurtosis levels outside the -3 to +3 range.
} 
cated that kurtosis problems were resolved. Consequently, the log of these measures will be used for further analysis.

Table 3.1: Descriptive statistics

\begin{tabular}{|c|c|c|c|c|c|c|}
\hline \multicolumn{7}{|c|}{ Panel A: Continuous variables } \\
\hline Variable & Description & $\mathrm{N}$ & Min & Max & Mean & S.D. \\
\hline \multicolumn{7}{|c|}{ 1.Dependent/explanatory variables } \\
\hline Public disclosure & ENVDISC & 138 & .00 & .72 & .31 & .19 \\
\hline $\begin{array}{l}\text { Environmental commit- } \\
\text { ment }\end{array}$ & COMMIT & 138 & .00 & 1.00 & .63 & .26 \\
\hline GHG emissions & EMISS & 138 & 2 & 1787699 & 60566 & 196877 \\
\hline \multicolumn{7}{|c|}{ 2. Control variables } \\
\hline Size & SIZE & 138 & 1521 & 319848 & 41488 & 59206 \\
\hline \multicolumn{3}{|c|}{ Panel B: Dichotomous/category variables } & \multicolumn{2}{|c|}{ Value $=1$} & \multicolumn{2}{|c|}{ Value $=0$} \\
\hline Variable & Description & $\mathrm{N}$ & Freq & $(\%)$ & Freq & $(\%)$ \\
\hline \multicolumn{7}{|c|}{ 1.Control variables } \\
\hline \multirow[t]{3}{*}{ Country } & STAK & 138 & 73 & (52.9) & 65 & $(47.1)$ \\
\hline & SHR_N_US & 138 & 25 & $(18.1)$ & 113 & (81.9) \\
\hline & SHR_US & 138 & 40 & $(29.0)$ & 98 & $(71.0)$ \\
\hline \multirow[t]{10}{*}{ Industry } & ENERGY & 138 & 7 & (5.1) & 131 & (94.9) \\
\hline & MATERIALS & 138 & 20 & $(14.5)$ & 118 & $(85.5)$ \\
\hline & INDUSTRIAL & 138 & 16 & $(11.6)$ & 122 & $(88.4)$ \\
\hline & CONS_DISCR & 138 & 16 & $(11.6)$ & 122 & (88.4) \\
\hline & CONS_STAPL & 138 & 14 & $(10.1)$ & 124 & (89.9) \\
\hline & HEALTH & 138 & 9 & $(6.5)$ & 129 & (93.5) \\
\hline & FINANCIALS & 138 & 26 & $(18.8)$ & 112 & $(81.2)$ \\
\hline & IT & 138 & 13 & $(9.4)$ & 125 & (90.6) \\
\hline & TELECOM & 138 & 9 & $(6.5)$ & 129 & (93.5) \\
\hline & UTILITIES & 138 & 8 & $(5.8)$ & 130 & $(94.2)$ \\
\hline
\end{tabular}

In panel B the frequencies of the dichotomous variables are given. These figures indicate that all country and industry categories are fairly represented.

\subsubsection{Univariate analysis}

Table 3.2 provides the correlation statistics for dependent, explanatory, and control variables, both between and within industries. 
Table 3.2: Correlations statistics

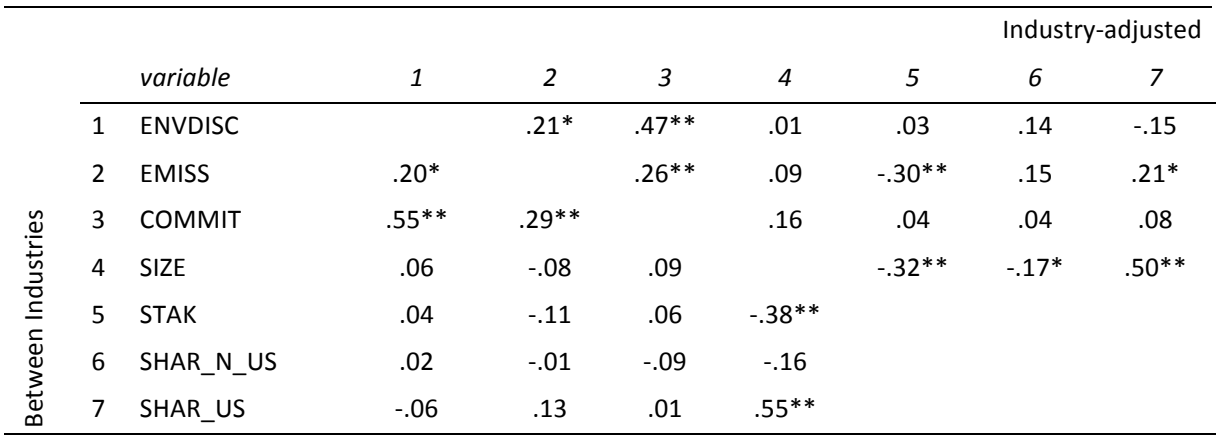

Upper-right part provides the Spearman rank correlations between industry-adjusted variables based on industry fractional ranks for all continuous variables ${ }^{42}$.

Lower-left part provides regular Pearson correlations between the absolute values of the variables.

Formal Mann-Whitney U-tests and t-test for the dichotomous variables (STAK, SHAR_N_US, and SHAR_US) confirm these associations.

$* p<.05 * * p<.01$

These correlation statistics show that EMISS is positively and significantly associated with environmental disclosure. This signifies that companies with inferior outcomebased performance (i.e., high levels of GHG emissions) tend to have more extensive environmental disclosure. This is in line with the expectations from hypothesis $1 \mathrm{a}$. The correlation between the level of environmental commitment (COMMIT) and environmental disclosure is also positive and highly significant. This implies that companies with superior process-based performance (i.e., a high level of environmental commitment) have more extensive disclosure, which is in line with hypothesis $1 \mathrm{~b}$. Hence, the univariate results so far are in line with expectations.

From Table 3.2 it can also be concluded that EMISS and COMMIT are significantly positively associated. This suggests that companies with higher GHG emissions (i.e., inferior outcome-based performance) tend to have higher levels of environmental commitment (i.e., superior process-based performance). Hence,

\footnotetext{
${ }^{42}$ Rank 1 represents companies with the most extensive disclosure (ENVDISC), greatest environmental commitment (COMMIT) and size (SIZE), but the lowest GHG emissions (EMISS). The inverse ranking for EMISS was motivated by the logic that lower GHG emissions represented better (outcome-based) performance, and hence, in line with process-based performance (COMMIT), deserved better ranks. So in contrast with the other continuous variables, companies with lower GHG emission (lower values of EMISS) received better ranks. As a consequence, the negative Spearman rank correlations between EMISS and other continuous variables (ENVDISC and SIZE) that are listed in Table 3.2 were in fact positive. Nevertheless, to facilitate the interpretation of the results, as well as the comparability with the between industries Pearson correlations, it was chosen not to include the inverse ranking in the Table. For the same reason the signs of the correlations for the dichotomous variables (STAK, SHAR_N_US, and SHR_US) were also reversed.
} 
ronmental commitment (i.e., superior process-based performance). Hence, processbased- and outcome-based performance are negatively correlated. Such corresponds to earlier research findings by Mattingly and Berman (2006). All this implies that companies with inferior outcome-based performance (higher levels of GHG emissions) on average put more effort in mitigating their environmental impact (as reflected by higher COMMIT) and communicating this (as reflected by higher ENVDISC).

As for the country clusters, none of them is significantly associated with ENVDISC; however, the within industries analysis illustrates that the country cluster in which a company is located is associated with its level of GHG emissions. Companies from stakeholder-oriented countries tend to be the companies that have the lowest emissions (most superior outcome-based performance) in their industry and U.S. companies the ones with the highest emissions (most inferior outcome-based performance) in their industries.

The previous results indicate that the effects of the two dimensions of environmental performance on disclosure work in opposite directions. That is, processbased performance (COMMIT) is positively related, and outcome-based performance (EMISS) is negatively related with environmental disclosure. To develop some preliminary insight into the way in which this affects overall environmental performance (i.e., based on both the process and outcome dimension) I analysed the extent of environmental disclosure for four categories of overall performance, based on combinations of the two performance dimensions. Table 3.3 gives the results of this analysis.

These results illustrate that companies are reasonably evenly distributed across the categories of environmental performance, except for the high outcome-based and high process-based, as well as the high outcome-based and low process-based performance quadrants, which companies seem to be respectively relatively under- ( $\mathrm{n}$ $=22$ ) and over-represented $(n=47)$. This reflects the positive correlation between EMISS and COMMIT that was presented in Table 3.2. 
Table 3.3: Mean environmental disclosures and significance of differences between high and low performance of two performance dimensions

\begin{tabular}{|c|c|c|c|c|c|c|c|c|}
\hline \multirow{3}{*}{ 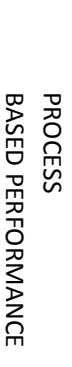 } & \multicolumn{4}{|c|}{$\begin{array}{l}\text { Between industries }^{\mathrm{a}} \\
\text { a higher numbers indicate more extensive disclosure }\end{array}$} & \multicolumn{4}{|c|}{$\begin{array}{l}\text { Within industries (fractional ranks) } \\
\text { b higher numbers indicate less extensive disclosure }\end{array}$} \\
\hline & \multicolumn{8}{|c|}{ OUTCOME-BASED PERFORMANCE } \\
\hline & High & & Low & total & High & & Low & total \\
\hline \multirow[t]{2}{*}{ High } & $\begin{array}{c}18.68 \\
(n=22)\end{array}$ & $t=0.24$ & $\begin{array}{c}19.22 \\
(n=36)\end{array}$ & $\begin{array}{l}19.02 \\
(n=58)\end{array}$ & $\begin{array}{c}46.55 \\
(n=36)\end{array}$ & $t=-1.30$ & $\begin{array}{c}38.64 \\
(n=37)\end{array}$ & $\begin{array}{c}42.54 \\
(n=73)\end{array}$ \\
\hline & $\mathrm{t}=4.14 * * *$ & & $\mathrm{t}=2.84^{* *}$ & $\mathrm{t}=5.37 * * *$ & $\mathrm{t}=-4.10^{* * *}$ & & $\mathrm{t}=-3.29 * *$ & $\mathrm{t}=-5.22 * * *$ \\
\hline Low & $\begin{array}{c}9.94 \\
(n=47)\end{array}$ & $\mathrm{t}=2.42^{*}$ & $\begin{array}{c}14.03 \\
(n=33)\end{array}$ & $\begin{array}{c}11.63 \\
(n=80)\end{array}$ & $\begin{array}{c}73.58 \\
(n=34)\end{array}$ & $\mathrm{t}=-2.48^{*}$ & $\begin{array}{c}57.84 \\
(n=31)\end{array}$ & $\begin{array}{c}66.07 \\
(n=65)\end{array}$ \\
\hline total & $\begin{array}{c}12.73 \\
(n=69)\end{array}$ & $\mathrm{t}=2.76^{* *}$ & $\begin{array}{c}16.74 \\
(n=69)\end{array}$ & $(n=138)$ & $\begin{array}{l}59.68 \\
(n=70)\end{array}$ & $\mathrm{t}=-2.55^{*}$ & $\begin{array}{c}47.39 \\
(n=68)\end{array}$ & $(n=138)$ \\
\hline
\end{tabular}

$* p<.05 ; * * p<0.01 ; * * *<0.001$ (two-tailed).

To facilitate comparison and interpretation of the outcomes, for both 'between industries' and 'within industries' analyses t-tests are provided. Given that the 'within industries' analysis builds on fractional ranks, also Mann-Whitney U-tests were calculated; the results were very similar.

For the 'between industries' analysis, the inclusion of companies in the 'High' or 'Low' category is based on whether a company has GHG emissions (in case of outcome-based performance) or environmental commitment (in case of process-based performance) above or below the sample median. In case of the 'within industries' analysis assigning companies to any of the categories is based on whether companies perform below or above the industry median, which was effectuated through the use of industry fractional ranks of EMISS and COMMIT.

More importantly Table 3.3 shows that the quadrants with the highest and lowest average levels of environmental disclosure do not correspond with the quadrants with the highest or lowest overall performance. It shows that the highest and lowest levels of disclosure are associated with intermediate levels of environmental performance (respectively, the upper right and lower left quadrant), although the dif- 
ferences in the mean disclosure levels between the upper right and upper left quadrant are not significantly different.

Overall, the fact that vertical comparison results in more-significant differences between disclosures than horizontal comparison is a preliminary indicator that differences in environmental disclosure may be more associated with differences in process-based performance (environmental commitment) than differences in outcome-based performance (GHG emissions). This analysis also confirms that the effects of the two dimensions of environmental performance on disclosure work in opposite directions. When aggregating the two dimensions into one performance measure, some of the effect of the one dimension is cancelled out by the opposite effect of the other. From this, it appears that including the two performance dimensions separately will be more informative.

\subsubsection{Multivariate analysis}

Table 3.4 presents the multivariate results of the $\mathrm{OLS}^{43}$ regression analyses for the model specified in equation (1), both for the 'between industries' and 'within industries' analyses ${ }^{44}$.

The basic models (Model 1 ) include only the explanatory variables of primary interest, i.e., the two measures for environmental performance. This model explains approximately $29 \%$ of total environmental disclosure between industries and $21 \%$

\footnotetext{
${ }^{43}$ Given the rather low mean environmental disclosure score (0.31) as was shown under the descriptives, I assessed the number of cases for which this variable equals zero; this turned out to be six cases. To take away any potential bias in the OLS regression results due to potential truncation at zero of the dependent variable I also ran Tobit regressions; the results were the same.

${ }^{44}$ Due to the fact that this study's industry-classification was based on the two-digit GCIS classification, the resulting ten industries -as presented earlier- are rather broad. Hence, they may contain companies, of which the activities have different environmental impacts. E.g. the sector Consumer Discretionary (20) contains companies employing economic activities ranging from manufacturing cars to hotel services. This is an inherent problem for any industry classification based on economic activities (rather than on environmental impact). In order to check for any potential bias from this, I did an additional 'within industries analysis'. This analysis was based on a sample $(n=59)$, including only four groups of companies. Each of the groups was composed of companies carrying out activities with similar environmental impacts. Three of these groups were the same as the two-digit GCIS sector. In one group I combined companies from two six-digit GCIS industries in order to get a sufficient number of companies. The resulting four groups are: 1: Pharmaceuticals (151010) combined with Chemicals (352020), 2: All Financials (i.e., two-digit GCIS sector 40), 3: Telecommunication (i.e., two-digit GCIS sector 50), and 4: All Utilities (i.e., two-digit GCIS sector 55). The regression outcomes are the same as the ones presented in Table 8, except for a slight increase in $\mathrm{R}^{2}$ by $2 \%$. For the two largest groups (Pharmaceuticals/Chemicals and Financials) I also ran separate regressions per industry (only for the basic model), from which it appears that the results remain unchanged, but that the $\mathrm{R}^{2}$ for Chemicals/Pharmaceuticals is almost $50 \%$ and for Financials only13\%.
} 
when adjusted for industry-affiliation. As compared to Table 3.2, Table 3.4 shows that the effect of EMISS becomes non-significant; this corresponds to the univariate results indicating that the correlation between COMMIT and ENVDISC was significantly higher than that between EMISS and ENVDISC.

Table 3.4: Between and within industries OLS regression results

\begin{tabular}{|c|c|c|c|c|c|c|c|c|}
\hline \multirow[b]{4}{*}{ Model } & \multicolumn{4}{|c|}{ Between industries } & \multicolumn{4}{|c|}{ Within industries } \\
\hline & \multicolumn{8}{|c|}{ Dependent variable } \\
\hline & \multicolumn{8}{|c|}{ Total discretionary environmental disclosures } \\
\hline & 1 & 2 & 3 & 4 & 1 & 2 & 3 & 4 \\
\hline (intercept) & $(2.02)$ & $(-6.55)$ & $(-10.38)$ & $(-3.34)$ & $(35.54)^{* * *}$ & $(44.46)^{* * *}$ & $(72.37)^{* * *}$ & $(35.42)^{* * *}$ \\
\hline COMMIT & $18.06 * * *$ & $17.67 * * *$ & & $18.42^{* * *}$ & $0.44 * * *$ & $0.42 * * *$ & & $0.45^{* * *}$ \\
\hline EMISS & 0.15 & 0.24 & $0.84 * *$ & & 0.10 & 0.12 & $0.24 * *$ & \\
\hline SIZE & & 0.65 & $1.51 \dagger$ & 0.51 & & 0.08 & 0.12 & -0.00 \\
\hline SHR_US & & baseline & baseline & baseline & & baseline & baseline & baseline \\
\hline SHR_N_US & & 3.03 & 3.83 & 2.73 & & $13.46+$ & $19.88 * * *$ & $13.03+$ \\
\hline STAK & & 2.02 & $4.06^{\dagger}$ & 1.62 & & 8.64 & $16.41 * *$ & 1.05 \\
\hline $\operatorname{Adj} R^{2}$ & 0.289 & 0.283 & 0.046 & 0.284 & 0.212 & 0.217 & 0.072 & 0.210 \\
\hline F-value & $28.81^{* * *}$ & $11.72 * * *$ & $2.62^{*}$ & $14.49 * * *$ & $19.45^{* * *}$ & $8.53 * * *$ & $3.63 * *$ & $10.06 * * *$ \\
\hline$N$ & 138 & 137 & 137 & 137 & 138 & 137 & 137 & 137 \\
\hline
\end{tabular}

Model 1: basic model

Model 2: full model including both performance measures, and control variables Model 3: model including only outcome-based performance, and control variables Model 4: model including only process-based performance, and control variables $+\mathrm{p}<0.10$; $^{*} \mathrm{p}<.05$; $^{* *} \mathrm{p}<0.01$ * $^{* * *} \mathrm{p}<0.001$ (two-tailed)

When the control variables are added to the model (Model 2), the explanatory power does not really improve. None of the control variables is significantly related to environmental disclosure for any of the two full models, except for a modest significance of the coefficient for one of the country variables. This implies that the variance in disclosure that is explained by the model can be attributed to differences in the level of environmental commitment.

As for the models including only one of the performance measures (Models 3 and 4) it appears that there is a notable difference in explanatory power. The explanatory power for the model including only process-based performance (Model 4) is between 21 and $28 \%$ while the model based on only outcome performance (Model 3, which corresponds to models used in prior studies) only explains about $5-7 \%$ of the dependent variable. Whereas the limited amount of explained variance $(5 \%)$ in the between industries regression can be mainly attributed to EMISS, for the within regression the country variables also add to the explained variance in disclosure. 
Overall the results indicate that process-based environmental performance (COMMIT) is the main driver of environmental disclosure since all results consistently show evidence of a significant positive relation. Hypothesis $1 \mathrm{~b}$ therefore can be accepted.

The results for the outcome-based performance measure (EMISS) are mixed. Only for the model in which EMISS is singly included (Model 3 ), the results are supportive of hypothesis $1 \mathrm{a}$. This is the model that corresponds to the research design of much of recent studies in the field. The coefficients for EMISS in models that include EMISS and COMMIT simultaneously (i.e., Models 1 and 2) are nonsignificant. One of the reasons for this may be the significant positive correlation between EMISS and COMMIT (see Table 3.2), which points at the fact that (part of) the positive relation between COMMIT and disclosure in fact may occur due to inferior outcome-based performance (i.e., higher GHG emissions). Although the effect of EMISS on environmental disclosure is overall positive (signifying a negative association between outcome-based performance and disclosure, as was hypothesised) hypothesis 1a cannot be accepted due to a lack of consistent significance.

In order to see if the use of a broader sample in this study has led to differences in the results compared to previous studies, a number of sensitivity analyses were carried out, which will be reported in the next section.

\subsection{Sensitivity analysis}

This study advances prior research by using a sample that consists of companies from various countries and industries. This is different from previous studies that included only North American manufacturing companies. As was discussed earlier, there is growing evidence that managers' environmental attitudes and actions differ between countries and industries. Hence, I performed a sensitivity analysis to investigate the extent to which the results for a sample based on the typical industry settings in prior empirical studies deviate from those based on the sample that is used in this study.

First, I analysed the t-statistics for the differences in mean values between a sample containing only manufacturing companies (corresponding to prior studies) and another containing non-manufacturing companies, by splitting up the total sample. ${ }^{45}$ These (non-tabulated) statistics reveal that manufacturing companies on average have higher disclosure levels (ENVDISC: 0.35 vs. 0.25 ) and process-based

\footnotetext{
${ }^{45}$ As a split in the overall sample into North-American manufacturing versus other companies resulted in one of the two subsample containing only 12 observations, the sensitivity analysis is limited to a split in manufacturing ( $n=87$ ) versus non-manufacturing $(n=51)$ companies.
} 
performance (COMMIT: 0.73 vs. 0.47), but lower outcome-based performance (i.e., higher GHG emissions; EMISS: 9.33 vs. 7.11). All differences are statistically significant $(p<0.001)$.

Second, the associations between the variables for a split sample of manufacturing versus non-manufacturing companies (non-tabulated) show some notable differences as compared to those presented in Table 3.2. In a between industries context the Pearson correlations illustrate that outcome-based performance (EMISS) is no longer significantly associated with disclosure or process-based performance (COMMIT) for both split samples. Apparently, the positive significant correlations both between COMMIT and EMISS, and EMISS and ENVDISC in the full sample were caused by the differences between manufacturing (overall higher emissions and higher commitment) and non-manufacturing companies (overall lower emissions and lower commitment). This corresponds to the results of the $t$ tests. In line with Table 3.2, COMMIT remains significantly positively associated with disclosure. When considering the within industry Spearman rank correlations for this split sample, it turns out that the significant correlation between EMISS and ENVDISC is only applicable to the sample containing non-manufacturing companies only, whereas the correlation between EMISS and COMMIT is only significant for the manufacturing companies. This implies that non-manufacturing companies with the most inferior outcome-based performance (highest GHG emissions) in their industry have more extensive disclosures. This also signifies that manufacturing companies with the most inferior outcome-based performance in their industry have a higher environmental commitment. Again, the significantly positive relation between environmental commitment and disclosure remains unchanged.

Third, the results of the regression analysis for the split sample are presented in Table 3.5. 
Table 3.5: OLS regression results for a split sample of manufacturing vs. non-manufacturing companies

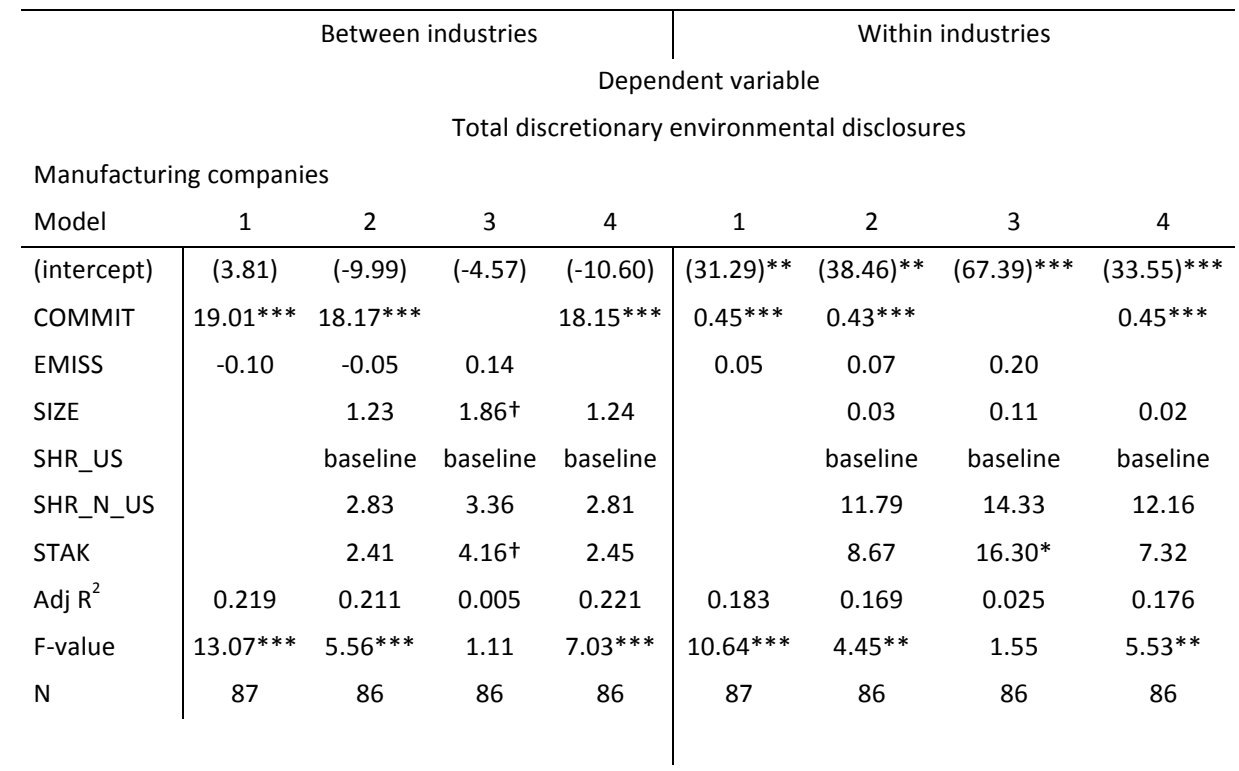

Non-Manufacturing companies

\begin{tabular}{|c|c|c|c|c|c|c|c|c|}
\hline Model & 1 & 2 & 3 & 4 & 1 & 2 & 3 & 4 \\
\hline (intercept) & $(-0.74)$ & $(-5.99)$ & $(-16.70)$ & (7.67) & $(42.03)^{* *}$ & $(58.49)^{* *}$ & $(84.08)^{* * *}$ & $(43.23)^{* *}$ \\
\hline COMMIT & $14.76^{* *}$ & $12.79 *$ & & $15.27 * *$ & $0.41 * *$ & $0.35^{* *}$ & & $0.41^{* *}$ \\
\hline EMISS & 0.74 & 0.88 & $1.37^{*}$ & & 0.18 & 0.20 & $0.28^{*}$ & \\
\hline SIZE & & 0.17 & 1.21 & -0.55 & & 0.00 & 0.15 & -.02 \\
\hline SHR_US & & baseline & baseline & baseline & & baseline & baseline & baseline \\
\hline SHR_N_US & & 5.62 & $9.29 *$ & 3.75 & & 20.25 & $32.72 *$ & 17.74 \\
\hline STAK & & 3.59 & $6.98+$ & 1.66 & & 11.98 & $21.73+$ & 7.51 \\
\hline Adj $R^{2}$ & 0.207 & 0.202 & 0.104 & 0.179 & 0.214 & 0.220 & 0.130 & 0.195 \\
\hline F-value & $7.52^{* *}$ & $3.53^{* *}$ & $2.45^{*}$ & $3.72 *$ & $7.82^{* *}$ & $3.82^{* *}$ & $2.87^{*}$ & $4.02^{* *}$ \\
\hline $\mathrm{N}$ & 51 & 51 & 51 & 51 & 51 & 51 & 51 & 51 \\
\hline
\end{tabular}

Model 1: basic model

Model 2: full model including both performance measures, control variables Model 3: model including only outcome-based performance, control variables Model 4: model including only process-based performance, control variables $+\mathrm{p}<0.10 ;{ }^{*} \mathrm{p}<.05 ; * * \mathrm{p}<0.01 ; * * \mathrm{p}<0.001$ (two-tailed)

Comparison of the results between manufacturing and non-manufacturing companies, as well as between Table 3.4 and 3.5 indicates that they are largely similar. The only distinction relates to Model 3, in which solely the outcome-based performance is included. It appears that the significance of Model 3 for the full sample (Table 3.4) can be mainly attributed to non-manufacturing companies. In case of manufacturing companies only, the Models 3 are non-significant. 
The above sensitivity analysis shows that prior studies -focusing on manufacturing companies- are based on samples with an overall superior process-based performance and inferior outcome-based performance relative to this study. This analysis also shows that in sample settings comparable to prior studies, outcomebased performance is not associated with environmental disclosure. From these findings it also appears that the found association between disclosure and processbased performance is substantially robust.

\subsection{Discussion}

This study analyses the relation between environmental performance and environmental disclosure. Based on prior literature it suggests that environmental performance measures, next to an outcome dimension, should also encompass a process dimension. Drawing on legitimacy theory, it was firstly expected that outcomebased performance is negatively associated with the extensiveness of environmental disclosure. The hypothesised association between process-based performance and disclosure was positive.

The results can be divided into three main findings. First, they show that environmental commitment (process-based performance) is the main factor related to environmental disclosure. In line with expectations, it appears to be consistently positively associated with environmental disclosure, a result that holds irrespective of industry and other controls included, or the sample used. Second, the results for GHG emissions (outcome-based performance) are less consistent. As expected they show that this measure in itself is significantly positively related to environmental disclosure, both across and within industries. However, this relation disappears in models that include GHG emissions and environmental commitment simultaneously. Besides, more in-depth analysis shows that the supposed positive relation between GHG-emission and disclosure is actually less generally applicable. This relation holds only to the extent that manufacturing companies have overall more extensive disclosures than non-manufacturing companies, and non-manufacturing companies with higher GHG emissions have more extensive disclosures than their lower GHG emissions industry peers. Third, GHG emissions and environmental commitment are significantly positively correlated, indicating that outcome-based and process-based environmental performance are negatively related. The latter mainly holds for manufacturing companies. That is, the results indicate that manufacturing companies have higher commitment than non-manufacturing companies, and the same holds for manufacturing companies with inferior outcome-based performance (higher GHG emissions) as compared to industry peers with superior performance. 
From these results I conclude that environmental disclosure is first and foremost related to positive performance, i.e. environmental commitment. Yet, the positive relation between environmental commitment and disclosure may occur due to inferior outcome-based performance. This points at the importance of visibility. Companies with greater environmental impact face greater exposure to public pressure, since they are more intensely scrutinised, and hence need to make more extensive mitigating disclosures. However, given the scrutiny they face, they need to provide evidence of their environmental commitment. Manufacturing companies providing only disclosure, without evidence of actual commitment, will not 'pass the test'. For non-manufacturing companies this is less of a problem, as evidenced by the significant negative relations between outcome-based performance and disclosure, while the correlation between process-based and outcome-based performance is non-significant. To conclude, company visibility is the main factor associated with environmental disclosure; environmental performance is an explanatory factor to the degree that it reflects this visibility.

The previous corresponds to prior research showing that company affiliation to environmentally sensitive industries is associated with greater public pressure due to increased visibility and consequently with more extensive environmental disclosures. Despite the lack of consistency in the results for outcome-based performance with respect to the hypothesis, I therefore conclude that environmental disclosure can be explained by legitimacy theory.

A potential explanation for the previous might be that perceptions of the public are largely based on negative expressions of performance, as these are most observable. ${ }^{46}$ Given the many environmental controversies that have appeared in the media in some industries over the last decades (e.g., the Exxon Valdez and Erika oil tanker spills in the oil industry, the Bhopal tragedy in the Chemical industry) affiliation to an (manufacturing) industry will already result in extensive public scrutiny, independent of the actual environmental outcomes. On the contrary, performance examples such as the implementation of an environmental management system or a reduction in toxic waste by a certain percentage lack both observability and appeal. Consequently, in absence of corporate communication, stakeholder actions would be based on perceptions that could be informed by incomplete, (overly) negative information. Given that these actions (among which, disinvestment by investors, consumer boycotts or employee turnover) may, to a wider or lesser extent, negatively affect their 'going concern', companies have an incentive to balance this perception with positive performance information. This can be effectuated by

\footnotetext{
${ }^{46}$ E.g., seabirds covered with oil and factory chimneys belching out heavy smoke, are both directly observable and appealing (for the media).
} 
communicating about the way in which they (claim to) mitigate their negative environmental impact, i.e. process-based performance.

These results have both academic and practical implications. The academic implications mainly refer to research on the relation between performance and disclosure. First, the results show that the effect of the two dimensions of environmental performance on disclosure work in opposite directions. Hence, when aggregating the two dimensions into one performance measure, some of the effect of the one dimension may be cancelled out by the opposite effect of the other. Including the two performance dimensions separately will be more informative. Secondly, analysis of the results for the effect of GHG emissions in isolation, which corresponds to prior studies' research designs that have included only outcome-based performance measures, reveals that this measure is only related to disclosure to the extent that manufacturing companies have more extensive disclosures than non-manufacturing companies. When limiting the sample to manufacturing companies only, the relation between GHG emissions and disclosure even disappears. This implies that the relation between outcome-based performance and environmental disclosure is contingent upon the sample. These two observations may explain some of the lack of significance and inconsistencies in the results of previous studies using aggregate environmental performance measures (e.g., the CEP index), or only outcome-based performance. Adding process-based performance to the empirical model increases the explanatory power significantly and contributes to a better understanding of the complex relation between different expressions of environmental performance and disclosure. Consequently, studies based on legitimacy theory will benefit from nuancing the commonly used hypothesis that inferior performance is associated with more extensive disclosure, as this relation is dependent on which performance dimension is used. As inferior outcome-based performance may be associated with superior process-based performance and vice versa, it is important to distinguish between these two dimensions. Relating disclosure to visibility, rather than performance, may be a more successful path for explaining environmental disclosures.

From practice point of view, assessing a company's environmental performance based on its voluntary environmental disclosure may give an overly positive picture, as these disclosures appear to be primarily inspired by positive performance, i.e., environmental commitment. Besides, more extensive disclosures may be a signal for inferior rather than superior performance in terms of actual environmental impact. This suggestion is fuelled by the observations that more polluting industries have on average more extensive environmental disclosures and higher environmental commitment is associated with higher GHG emissions.

This study also has a number of limitations. First it is important to stress that this study does not claim that the resulting performance measures are fully capturing the nuances and complexities associated with environmental performance. 
Nevertheless, the added value of the suggested measures lies in the inclusion of the process dimension next to the outcome dimension, and the resulting differences in the relation with disclosure, as compared to previous performance measures, based on only the outcome dimension. Second, due to the former, this study uses outcome-based performance measures that have not been used before, i.e. salesadjusted GHG emission figures. However, the nature of the GHG-emission data and the sources from which they were retrieved are similar to some of the previously used measures (such as the EPA's TRI figures). Yet, this also implies that, even if these data may be the best available for the purpose of this study, they may suffer from the same inconsistencies in scope. Third, despite the lower likelihood of annual report and Form 10-K disclosures containing non-mandatory environmental information, it may be the case, especially outside the U.S., that discretionary environmental information items are disclosed via these reports. By excluding disclosure in these reports some discretionary environmental disclosures and consequently some variance in disclosure may have been missed.

Future research may take into account the mandatory and voluntary disclosures per country in order to come to a more sophisticated voluntary disclosure measure. Future studies may also focus more on disclosure content, in that they do not only use the extensiveness of disclosure as the dependent variable, yet also study how the two performance dimensions are disclosed. E.g., to what extent are outcome measures disclosed only in positive terms (e.g., only focusing on the improvements)? 


\title{
Chapter 4
}

\section{Secondary stakeholder influence on Corporate Social Responsibility Disclosure: An empirical test of stakeholder salience theory. ${ }^{47}$}

\begin{abstract}
"One of the major responsibilities of the board of directors is to ensure that shareholders and stakeholders are provided with high-quality disclosures ( . . )" (UNCTAD, 2006)
\end{abstract}

\subsection{Introduction}

A look at the major corporate governance codes around the world shows that disclosure is considered an important aspect of corporate governance. Next to financial disclosure, most codes recommend boards to engage in non-financial - such as social and environmental - disclosure, thus reflecting society's changing expectations on corporate objectives (UNCTAD, 2006). Consequently, boards nowadays are increasingly involved in Corporate Social Responsibility (CSR) disclosure (Gray, et al., 2001; Knox, Maklan, \& French, 2005; KPMG, 2008). Despite the overall increase in this largely voluntary activity, decisions on CSR disclosure differ among companies. The aim of this study is to analyse how companies' stakeholders influence managerial decision-making regarding CSR disclosure. I do so by investigating whether dif-

\footnotetext{
${ }^{47}$ This chapter is based on a working paper co-authored with Laury Bollen and Harold Hassink. I gratefully acknowledge Dutch Sustainability Research (DSR, currently active under the name: Sustainalytics) for providing the SiRi (Sustainable Investment Research International) Global Profiles database. Comments by Dorothea Baur, Rogier Deumes, Frank Moers, Robin Roberts, Ann Vanstraelen and Mark Vluggen on earlier versions of this paper, as well as the participants of the European Business Ethics Network (EBEN) Annual Conference 2007, the European Group for Organizational Studies (EGOS) Annual Conference 2008, the Next Generation ESG Workshop, Bentley University 2009 and the participants of the Accounting and Information Management research colloquium at Maastricht University are also gratefully acknowledged.
} 
ferences in CSR disclosure between companies are systematically related to key stakeholder attributes.

The corporate governance literature on disclosure traditionally has adopted an agency perspective (Parker, 2007); and consequently observed differences would be analysed within the context of investor-board relationships. Agency theory is still the basis of much current corporate governance research (e.g., two very recent examples are: Hertzberg, Liberti, \& Paravisini, 2010; Hoi \& Robin, 2010), yet there have been calls for complementary theoretical perspectives (e.g., Judge, 2009). Stakeholder theory has increasingly been suggested as an appropriate complementary perspective for studying CSR disclosure (Cormier, et al., 2005; Gray, et al., 1996) and corporate control in general (Heath \& Norman, 2004; Kacperczyk, 2009; Slinger \& Deakin, 1999; Stoney \& Winstanley, 2001). Furthermore, stakeholders form the core in the development of the $\mathrm{G} 3$ guidelines issued by the Global Reporting Initiative (GRI), which have become the leading standard for CSR reporting (KPMG, 2008): "The GRI's multi-stakeholder consensus-seeking approach has proven the most valuable way to produce reporting guidance that is universally applicable and appropriately responds to stakeholders' needs" (GRI, 2009).

Whereas stakeholder theory posits that each stakeholder claim has merit in itself (Donaldson \& Preston, 1995), one nevertheless cannot ignore the practical reality that companies have limited resources and may consequently make tradeoffs among, and prioritise stakeholder claims. Continuing on the same line of thought, the level of priority of a stakeholder claim will depend on the level of influence of that stakeholder. Hence it is necessary to know whether and how stakeholders influence CSR disclosure decisions.

Mitchell, Agle and Wood's (1997) theory of stakeholder identification and salience (in short: 'stakeholder salience theory') provides a consistent framework for analysing the extent to which stakeholder characteristics influence managerial decision-making with respect to stakeholder claims. The theory states that managers ascribe salience to stakeholder claims on the basis of the degree to which these stakeholders possess one or more of the following key attributes: power, legitimacy and urgency. Salience is reflected by manager's stakeholder prioritisation, conditional upon which resources are allocated to respond to their claims (Mitchell, et al., 1997). In the context of CSR disclosures, claims represent stakeholders' needs for CSR information that enables them to assess the degree to which the company has addressed their interests.

Empirical CSR disclosure studies investigating how stakeholders affect managerial decision-making are scarce (e.g., Boesso \& Kumar, 2009; Cormier, Gordon, \& Magnan, 2004; Deegan \& Blomquist, 2006; Neu, Warsame, \& Pedwell, 1998) and have so far not provided specific insight on the extent to which stakeholders' characteristics are influential in this respect. This study operationalises stakeholders' influence on CSR disclosure by focusing on environmental non-governmental or- 
ganisations (NGOs), since their potential influence is generally presumed but rarely empirically addressed (Deegan \& Blomquist, 2006). Environmental NGOs are referred to as secondary stakeholders (Clarkson, 1995: 107); this term reflects the fact that they are not engaging in transactions directly relating to the company's going concern and that they lack the formal contractual relationships typical for primary stakeholders, such as investors. Contrary to previous empirical studies that are based on self-administered management surveys, which introduces the limitation of managers' self-reporting bias, in this study stakeholder attributes as well as salience are operationalised using observable measures. These measures are based on archival data, retrieved from a proprietary database and complemented by publicly available data sources. Following prior research (Eesley \& Lenox, 2006) salience is measured as the degree to which a company responds positively to an environmental stakeholder's request, i.e., the degree to which environmental stakeholders' information needs are satisfied. Arguing that companies respond to the information needs of environmental stakeholders by means of environmental disclosure, I hypothesise that the level of environmental disclosure is determined by the stakeholder attributes power, urgency and legitimacy.

The results for a sample of 199 large listed companies in various countries provide evidence that the three stakeholder attributes are individually associated with environmental disclosure. Multivariate analysis reveals that stakeholder legitimacy is directly associated with environmental disclosure, and that the influences of power and urgency are of an indirect nature, in that they are mediated by legitimacy.

Although environmental stakeholders have not been a major concern in existing corporate governance literature in general and disclosure literature in particular, corporate governance research on environmental stakeholders (e.g., Jones \& Goldberg, 1982) and their role in environmental disclosure (Halme \& Huse, 1997; O’Dwyer, Unerman, \& Bradley, 2005a; Wheeler \& Elkington, 2001) are nevertheless expanding fields. This study contributes to both streams by demonstrating that stakeholders (other than investors) influence managerial decision-making regarding an important CG phenomenon, i.e., CSR disclosure. Besides, it provides evidence that next to the well-documented effect of company characteristics, stakeholder characteristics influence the extent of CSR disclosure too. It further advances the CSR disclosure literature by giving specific insight into why some stakeholders are better able to influence management decisions on CSR disclosure than others.

The remainder of the paper is organised as follows. The next section reviews previous literature. Section 3 develops the hypotheses. Section 4 elaborates on the research method, including a discussion of the sample, the measures for dependent variables, independent variables, control variables, and the statistical analysis. The results of the statistical tests, along with a discussion and limitations are presented in the final sections of this paper. 


\subsection{Prior literature}

In recent literature on corporate governance in general (Heath \& Norman, 2004; Kacperczyk, 2009; Slinger \& Deakin, 1999; Stoney \& Winstanley, 2001) and CSR disclosure in particular (Allen, 2005; Collier, 2008; Cormier, et al., 2005; Elkington, 2006; Gray, et al., 1996; Jamali, Safieddine, \& Rabbath, 2008; Solomon, 2007), it is suggested that stakeholder theory provides an appropriate alternative theoretical perspective. This study follows these suggestions and uses a stakeholder perspective for explaining CSR disclosure. So as to investigate to what extent other (than investor) stakeholders influence management's CSR disclosure decisions, its focus is on one particular type of secondary stakeholders, as well on one particular subset of CSR disclosure; that is, it aims at finding out whether differences in environmental disclosure are systematically related with environmental stakeholder attributes.

Given this focus, the literature review will consist of two parts. The first part examines the findings from literature that uses a stakeholder perspective for explaining CSR disclosure. The second part subsequently reviews the literature on the influence of stakeholder attributes on generic management decision-making by discussing the empirical literature on stakeholder salience theory.

\subsubsection{CSR disclosure literature}

Stakeholder theory, although expressed in various ways, broadly refers to the idea that companies have responsibilities toward other groups than their shareholders. Freeman (1984) defines a stakeholder in an organisation as: “ . . . any group or individual who can affect or is affected by the achievement of the organization's objectives ...". Although many researchers have set up empirical research on the broad idea that 'social pressures' affect CSR disclosure (for a review of the literature, see Hibbitt, 2004), there are only a limited number of empirical studies on the appropriateness of stakeholder theory in explaining CSR disclosure.

First of all, there are studies that provide evidence for the general notion that stakeholders are able to influence CSR disclosure, and the conditions under which this influence occurs. One of the first empirical studies providing evidence for the fact that stakeholders are a potentially influencing force in CSR disclosure was done by Tilt (1994) in her survey among environmental pressure groups in Australia. She found that almost all groups considered the CSR disclosures of companies to be insufficient and therefore were attempting to influence these companies. However, the results do not mention the extent to which the influence is effective. Boesso \& Kumar (2007) concluded that voluntary disclosure (among which social and environmental disclosure) is not restricted to satisfying investors' information needs, but a tool for managing broad stakeholder relationships, which is driven by "( . . ) those stakeholders that are important and have influence on company activities". 
Smith, Adhikari \& Tondkar (2005) found that stakeholder-oriented countries have more advanced CSR disclosure than shareholder-oriented countries. A survey-based study among 150 companies included in an ethical index (Knox, et al., 2005) found that only the largest companies identify, prioritise and communicate with (in short: manage) their stakeholders. In a recent study by Reid \& Toffel (2009) it was concluded that companies' disclosure of climate change strategies in response to activist groups' requests are conditional upon their own, as well as other similar companies', prior interactions with activist shareholders and government agencies.

Second, there are empirical studies that more specifically research how stakeholder influence on CSR disclosure takes place. Roberts (1992) and Magness (2006) found evidence for Ullman's (1985) contingency framework for CSR, which states that CSR (disclosure) strategies are determined by stakeholder power, strategic posture, and economic performance. Other disclosure studies that found empirical evidence for stakeholder theory, also mention 'stakeholder power' or related constructs (Deegan \& Blomquist, 2006; Neu, et al., 1998). In addition to power, alternative stakeholder traits have been found such as: a pragmatic and collaborative stand (Deegan \& Blomquist, 2006), and the level of interest in a company (Cormier, et al., 2004). Not addressing exactly CSR disclosure, but nevertheless giving insight into environmental accountability, Darnall, Seol \& Sarkis (2009) find that differences across companies in the use of (largely voluntary) environmental audits can be attributed to variations in stakeholder influences.

In order to establish a consistent framework for the relationship between stakeholders and CSR disclosure, it is necessary to systematically investigate why some stakeholders are better able to influence management decisions on CSR disclosure than others. Thus, insight into the exact stakeholder characteristics that determine CSR disclosure is needed, which relates to the third stream of empirical stakeholder studies. A first insight can be found in Eesley \& Lenox' (2006) study of companies' responses toward environmental stakeholder activism (such as: protests, boycotts and law suits), in which they find that reporting, one of the potential company responses, is positively associated with the power and legitimacy of environmental NGOs. In the only study so far that specifically seeks to explain stakeholder reporting using stakeholder salience theory, Boesso \& Kumar (2009) examine the extent to which annual report disclosure of key performance indicators (KPI) is associated with managers' self-reported perceived salience of a number of stakeholder groups (among which social and environmental stakeholders) for a sample of 72 Italian and US companies. Their results provide some preliminary evidence that for a cluster of social and environmental groups, the level of stakeholder salience for a particular group is associated with the level of managerial efforts directed toward that group, as measured by the voluntary disclosures aimed towards that group. However, these findings are limited to annual report disclosures of a number of social and environmental KPI's in response to the salience of a blend of social and 
environmental groups. Hence, it does not give specific insight into the extent to which environmental stakeholders' characteristics influence environmental disclosure.

The relationship between stakeholder attributes and management decisions is researched in the literature on stakeholder salience theory. Stakeholder salience theory provides in the need for a consistent framework for analysing how stakeholder characteristics influence management decision-making.

\subsubsection{Stakeholder Salience Theory}

Stakeholder salience theory has received considerable attention among scholars in the 'business in society' field. It originates from the observation that virtually anyone can be a stakeholder, yet at the same time managers simply do not have the resources to respond to all claims made by stakeholders. The added value of stakeholder salience theory is that it recognises the practical reality in which managers take into account certain kinds of stakeholder claims - not only because they should, but also in order to achieve certain goals (Mitchell, et al., 1997).

Mitchell et al. (1997) introduce the term 'stakeholder salience', resulting from the degree to which a particular stakeholder has three attributes: power, legitimacy and urgency. The authors take Pfeffer's (1981) definition of power: "a relationship among social actors in which one social actor (A), can get another social actor (B), to do something that B would not have otherwise done". Using Suchman's (1995) definition, they define legitimacy as: "A generalized perception or assumption that the actions of an entity are desirable, proper, or appropriate within some socially constructed system of norms, values, beliefs, and definitions". Urgency refers to "the degree to which stakeholder claims call for immediate attention", on the basis of time sensitivity or criticality (Mitchell, et al., 1997).

Later studies have refined stakeholder salience theory by means of theoretical contributions, stressing the importance of 'stakeholder proximity' (Driscoll \& Starik, 2004), interactions between stakeholders (Neville \& Menguc, 2006) and between stakeholder attributes (Neville, Bell, \& Whitwell, 2004), or corporate culture (Jones, Felps, \& Bigley, 2007).

Empirical studies generally find support for stakeholder salience theory. However, the exact attributes that relate to salience differ from one study to the other. Agle, Mitchell \& Sonnenfeld (1999) found that in case of shareholders, legitimacy and urgency are significantly related to salience, whereas for community stakeholders all attributes are significant. They also provided evidence that the salience of 'traditional stakeholders' (i.e., shareholders, employees and customers) is higher than that of governments and communities, implying the dominance of the 'traditional production view' in large companies (Agle, et al., 1999). Eesley \& Lenox (2006) found that in case of secondary stakeholders salience is a function of a stakeholder's 
power relative to the target company and the legitimacy of the stakeholder's request. Results also indicate that salience is not affected by the urgency of the request, and that the effects of group legitimacy are unclear. Gago \& Antolin (2004) found that in the context of the natural environment, perceived stakeholders attributes and salience are correlated. However, Harvey \& Schaefer (2001), also focusing on environmental issues, concluded that company representatives only see stakeholders with institutional power (such as the Environmental Agency, or other environmental regulators) as having significant salience. This dominance of the power attribute is in line with results from case studies (Neill \& Stovall, 2005; Parent \& Deephouse, 2007).

To conclude, even though the empirical evidence presented in this literature review is mixed, it points towards the fact that in general stakeholders do matter in management decision-making regarding CSR disclosure. Stakeholder salience literature provides evidence of a relationship between stakeholder attributes and management resource allocation toward these stakeholders. This study suggests that stakeholder salience theory contributes to a descriptive framework for stakeholdermanager relations with regard to CSR disclosure.

\subsection{Hypotheses}

One of the key assumptions underlying stakeholder salience theory is that managers allocate resources in response to stakeholder claims, based on their salience (Mitchell, et al., 1997). Following prior research (Eesley \& Lenox, 2006), in this study salience is measured by the degree to which a company responds positively to a stakeholder request, i.e., the degree to which stakeholders' information needs are satisfied. As such, I assume that the level of CSR disclosure is determined by stakeholder power, urgency and legitimacy. This corresponds to findings by Mitchell et al. (1997: 877) suggesting that: “( . . . ) corporations produce reports to legitimate, powerful stakeholders, including annual reports, proxy statements, and, increasingly, environmental and social responsibility reports". I define CSR disclosures as: a company's information disclosure to all of its stakeholders, supplementary to and via its financial accounts, in response to their perceived information needs. Consequently it exceeds the traditional notion of reporting in which a company provides a financial account and accompanying notes to its shareholders. For the purpose of this study, CSR disclosure is limited to public disclosure, i.e., CSR information disclosure into the public domain that is initiated by the company. Consequently, other forms of disclosure - such as information dispersion to individuals (e.g., through questionnaires) or CSR information about a company that is initiated by other parties (e.g., the media) - will not be considered. Next to the annual report, public CSR 
disclosures also include special-purpose reports (e.g., environmental or sustainability report) and corporate websites.

The focus on environmental stakeholders is a deviation from the traditional focus on investors in prior corporate governance research. Environmental stakeholders differ from shareholders in two important ways. First, environmental stakeholders do not own important resources in the same way as shareholders and other resource-based stakeholders. Secondly, their position toward the company is not stipulated in contractual arrangements. Clarkson (1995: 107) classifies shareholders as 'primary stakeholders' and environmental stakeholders as 'secondary'; as opposed to secondary stakeholders, primary stakeholders are "engaged in transactions with the corporation" and "essential for its survival". Nevertheless, both stakeholder groups are typically external to the company, which stresses the importance of public disclosure in disseminating CSR information.

This study starts from the premise that environmental disclosure principally reflects the salience of the environmental NGOs. Since the costs of collecting and analysing CSR information for stakeholders are considerable (Schaltegger, 1997) and stakeholder resources are also limited (Eesley \& Lenox, 2006), stakeholders will prioritise their information requests. In line with previous literature (Grunig, 1983) it is suggested that prioritising is effectuated through active versus passive information behaviour; when stakeholders have a high level of awareness of, and involvement in a problem they will engage in active information collection, whereas passive behaviour - processing the information when it is available - is associated with low levels of involvement and awareness (Grunig, 1983). Since environmental NGOs are the stakeholders that are most aware of, and involved in environmental issues ${ }^{48}$, it consequently will be likely that they spend most resources in obtaining the required environmental information. Yet, as will be explained in the research method section, I do control for the potential influence of other stakeholders that have been suggested by prior literature for their potential demand for environmental information.

Based on the previous, three separate hypotheses are developed to account for the effects of the individual attributes; this is in line with prior empirical research (Agle, et al., 1999; Eesley \& Lenox, 2006). The following hypotheses are developed:

Hypothesis 1: The total level of public environmental disclosure of a company is positively related to the level of power of the environmental NGOs with which it is confronted.

\footnotetext{
${ }^{48}$ Some might argue that governments are at least equally involved in and knowledgeable of environmental issues, yet in the context of environmental disclosure -which is largely voluntary- governments are only indirectly involved.
} 
Hypothesis 2: The total level of public environmental disclosure of a company is positively related to the level of urgency of the environmental NGOs with which it is confronted.

Hypothesis 3: The total level of public environmental disclosure of a company is positively related to the level of legitimacy of the environmental NGOs with which it is confronted.

\subsection{Research method}

\subsubsection{Sample}

As was mentioned in Chapter 3 this study uses a sample of 199 companies that are profiled in the 2004 SiRi database of companies included in the $\mathrm{MSCl}$ World Index. The items covered by the profiles were obtained via active solicitation of information needs with the various stakeholders (such as labour unions, and environmental NGOs) and consultation with experts in the respective fields and therefore can be considered a realistic representation of the actual CSR information needs of the various stakeholders. The SiRi profiles illustrate that the information needs of environmental stakeholders consist of topics such as environmental management systems and policies, certification, emissions, energy consumption, waste and remediation (see Appendix A).

\subsubsection{Measures for dependent variables}

Mitchell et al. (1997: 854) define stakeholder salience as: "the degree to which managers give priority to competing stakeholder claims". Where most empirical studies measure salience by means of surveys on management perception (e.g., Agle, et al., 1999; Harvey \& Schaefer, 2001), more recently Eesley \& Lenox (2006) have defined stakeholder salience as the likelihood of an actual company response to a stakeholder's request. Corresponding to the latter study I operationalise stakeholder salience through the level of response by a company to a stakeholder request. This underlines the importance of management action ${ }^{4}$. More specifically, I assess the level of environmental disclosure of a company in response to the information needs of its environmental stakeholders.

The measure for this environmental disclosure level was constructed using the information items under the theme 'Environment' of the SiRi company profiles, as described in Chapter 3 . These items are considered to represent the information needs of the environmental stakeholders. 


\subsubsection{Measures for explanatory variables}

The main explanatory variables in this study are the attributes: power, urgency and legitimacy. Following suggestions by prior literature to circumvent potential selfreport bias associated with measuring stakeholder attributes by means of management surveys (Eesley \& Lenox, 2006), I develop observable measures for each of the stakeholder attributes at the company level. These measures capture for each company the levels of power, urgency and legitimacy of the environmental stakeholders with which it is confronted. I focus on environmental NGOs, as they are considered to be the stakeholders that are most involved in, and aware of environmental issues. Other stakeholders, such as shareholders and consumers, typically pick up environmental issues only when they have gained publicity through NGOs actions. By choosing these measures, although I recognise that managerial characteristics are a crucial moderator of a company's actions in response to stakeholder attributes (Mitchell, et al., 1997), I assert that management perceptions of stakeholder power and urgency derive from actual stakeholder traits. Table 4.1 provides an overview of the explanatory variables used in this study. The different measures for each stakeholder attribute are discussed individually.

Table 4.1: Explanatory variables*

\begin{tabular}{|c|c|c|}
\hline Attribute & $\begin{array}{l}\text { Variable } \\
\text { name }\end{array}$ & Variable description \\
\hline Power & ENVPOW & $\begin{array}{l}1 \text { if contact between company and NGO is mentioned in company documents } \\
\text { or the press }\end{array}$ \\
\hline \multirow[t]{2}{*}{ Urgency } & ENVURG & $\frac{\text { \# controversial issues in which company has been involved }}{\text { \# controversial issues covered in SiRi profile }}$ \\
\hline & & $\begin{array}{l}\text { Controversial issues covered in SiRi profile: } 1 \text {.Waste management, } 2 . \text { Soil } \\
\text { pollution, 3.Water pollution, 4.Air pollution, } 5 . \text { Resource use/ecosystem } \\
\text { damage, 6.Products \& services, 7.Supply chain issues. }\end{array}$ \\
\hline \multirow[t]{2}{*}{ Legitimacy } & ENVLEG & $\begin{array}{l}\text { \# formal environmental arrangements the company has in place } \\
\text { \# formal environmental issues in total }\end{array}$ \\
\hline & & $\begin{array}{l}\text { Environmental arrangements: 1.environmental department, 2.environmental } \\
\text { management system, 3.formal mechanisms for environmental stakeholder } \\
\text { engagement }\end{array}$ \\
\hline
\end{tabular}

*When it is stated that a variable is given the value ' 1 ' in case a certain condition is met, it is implicitly assumed that in any other condition the variable was valued ' 0 '.

Environmental NGOs lack the direct power associated with control over valuable resources (Pfeffer \& Salancik, 1978). The power of environmental NGOs relates to the extent to which they are able to let primary stakeholders withhold, or conditionally provide, resources to the company, or to involve the government in forcing 
the company to meet their claims (Rowley, 1997). In order to assess the power of a company's environmental stakeholders, the SiRi global profiles were first screened for the names of environmental NGOs that had been able to gain publicity, either in company documents or via any other public media, concerning environmental issues in which the particular company was involved. Underlying this measure is the idea that NGO power can be expressed by means of collaborative or confrontational tactics (Deegan \& Blomquist, 2006). The argumentation is: if an NGO is mentioned in the public disclosure of a company, this signals that it was able to engage in direct dialogue with a company (collaborative power). If the media writes about the relationship between an NGO and a company, this signals that an NGO has been able to gain publicity (confrontational power). For this purpose, a binary variable (ENVPOW) was used which takes the value 1 when contact between company and NGO was mentioned in company or other public documents (such as (inter)national press), and 0 otherwise ${ }^{49}$.

Mitchell et al. (1997) define urgency as the degree to which stakeholders' claims call for immediate attention, on the basis of time sensitivity or criticality. Whereas time sensitivity refers to "the degree to which managerial delay in attending to the claim or relationship is unacceptable to the stakeholder", criticality is related to the "importance of the claim or the relationship to the stakeholder" (Mitchell, et al., 1997: 876). In order to develop a measure for urgency at the company level, for each company I assessed the degree to which in recent years a company had been involved in any major (i.e., critical) controversial environmental issues, or any other environmental controversy that needed immediate attention (i.e., time sensitive). This information was distilled from the SiRi company profiles, by taking into account a category of 7 environmental information items labelled 'major recent controver-

\footnotetext{
${ }^{49}$ Originally, a further sophistication of the environmental power measure was intended, in that as a next step for each of the NGOs mentioned the annual reports or Form 990 were downloaded to discover the amount of total financial assets, which are highly correlated with membership (Deegan \& Blomquist, 2006; Eesley \& Lenox, 2006). I categorised the NGOs into three groups: large (financial assets of over 10 million US\$), medium (between 1 and 10 million US\$ in assets) and small (less than 1 million US\$ in financial assets). The websites of these NGOs were also consulted to find out whether these are internationally organised and if they engage in coalitions with other NGOs. The rationale for including this information is that NGOs with local branches in different countries will have greater availability of resources than those operating from one country, and coalitions of NGOs will be more powerful than each of the NGOs individually (Eesley \& Lenox, 2006; Neville, et al., 2004). Pooling this information resulted in 12 categories of NGOs, ranging from small local NGOs that are not engaged in coalitions (power level = 1) to large international NGOs that are part of a coalition (power level =12). Adding the power categories of all environmental NGO contacts of a company resulted in a power measure at the company level (ENVPOW2). However, this procedure resulted in only 73 observations, which could potentially jeopardise the robustness of the multivariate analysis. Given the multivariate empirical design of this study, my initial measure (ENVPOW) therefore was considered to be the more appropriate measure and consequently in the remainder of this paper the results for ENVPOW will be reported. The statistical results for ENPOW2 will only be reported in case they deviate from ENPOW.
} 
sies'. This information category mentions whether or not companies have been involved in various types of publicly debated controversial issues, comprising both critical issues -such as major environmental accidents (e.g. oils spills, leakage of hazardous waste)- and time sensitive issues -such as being targeted by NGO campaigns (e.g. some of the banks in the sample had been under attack from environmental NGOs for their alleged financing of dams or pipelines, with potentially large negative environmental impact). Typically the companies did not disclose involvement in these controversies, yet the media reported them. The measure of urgency was constructed through application of a simplified version of a decision technique for quantifying the absence or presence of variables (Agle, et al., 1999; Mitchell \& Agle, 1997). By quantifying the absence or presence of involvement in environmental controversies for each company, a basic interval scale (Nunnally, 1978) was formed, ranging from 0 to 7. For reasons of enhanced interpretability of the descriptive results, this number was divided by the total number (i.e., seven) of controversial issues covered in the SiRi profile, resulting in the variable labelled ENVURG. Table 4.1 provides more detail on the nature of these controversial issues.

Mitchell et al. (1997) use Suchman's (1995) definition of legitimacy: “A generalized perception or assumption that the actions of an entity are desirable, proper, or appropriate within some socially constructed system of norms, values, beliefs, and definitions". For the purpose of this research it was necessary to construct an observable measure at the company level. ${ }^{50}$ Hence, for each company in the sample the degree, to which environmental stakeholders were considered legitimate by the company's management, needed to be assessed. For this purpose I build on Suchman's (1995) ideas regarding legitimisation processes in companies, stating that these processes are reflected by activities such as formalisation and professionalisation. Formalisation is described as: (1) "codifying informal procedures, (2) bringing previously marginal activities under official control, and (3) establishing hierarchical links with superordinate environmental units", whereas professionalisation refers to: (4) "linking their activities to external definitions of authority and competence" (Suchman, 1995: 587-589). In line with this, I argue that the legitimacy of environmental stakeholders is reflected by the extent to which a company engages in formalisation and professionalisation in order to respond to the interests of environmental stakeholders. Building on my previous discussion of Suchman's (1995) ideas I propose that (1) is measured by the presence of a formal Environmental Management System (EMS), whereas (2) and (3) are reflected by the presence of an environmental department and (4) by the existence of formal mechanisms for stakeholder engagement. The presence of these three arrangements signals a com-

\footnotetext{
${ }^{50}$ Constructing a 'direct' measure of corporate legitimacy by using 'media coverage', as suggested by recent literature (see e.g., Aerts \& Cormier, 2009; Clarkson, et al., 2008; Deephouse \& Carter, 2005), was thus considered inappropriate, since this construct measures legitimacy at society level.
} 
pany's willingness to incorporate environmental issues in its business conduct. Corresponding to Hart and Milstein (2003) I argue that when managers of a company would perceive environmental stakeholders to be illegitimate, they would not engage in these formal arrangements, since this requires considerable investment of resources. The result of the previous is an observable measure of legitimacy at the company level, reflecting the average 'receptivity' of company's management to the environmental stakeholders and their respective claims.

Similar to the urgency measure, a basic interval scale (Nunnally, 1978) was formed by quantifying the presence or absence of the previously mentioned formal environmental arrangements for each company. After dividing the total number of arrangements by the theoretical maximum -thus enhancing the interpretation of the descriptives- the environmental legitimacy measure ENVLEG was created (see Table 4.1).

Mitchell \& Agle (1997: 862) argue that legitimacy is most pronounced when it is formally encoded (such as via a legal right or title, or as stipulated in a contract). This implies that to a certain extent stakeholder legitimacy may be institutionalised by means of legal or contractual arrangements and accordingly may be more pronounced in some countries than in others. Since this may cause a lack of variance in the legitimacy measures, it could potentially affect the significance of the models. Hence, as part of the multivariate analysis, a sensitivity analysis was carried out.

\subsubsection{Control variables}

Most studies that investigated the determinants of CSR disclosure also included company characteristics. Researchers in this field have suggested a large number of company characteristics associated with CSR disclosure, such as: size, industry affiliation, country, profitability, capital structure, cost of capital and management style (for an overview of 'company characteristics' research, see e.g. Adams, 2002; Brammer \& Pavelin, 2004). However, empirical tests of such associations provide to a large extent inconclusive and even contradictory outcomes. Nevertheless, they consistently tend to conclude that CSR disclosure is associated with size, industry affiliation and country (Adams, 2002; Brammer \& Pavelin, 2004; Gray, et al., 2001). Finally, there is some evidence that institutional investors can influence strategic decisions regarding CSR (Cox, Brammer, \& Millington, 2008; Graves \& Waddock, 1994; Johnson \& Greening, 1999), which also may have implications for CSR disclosure.

Based on the previous a number of control measures were developed (see Table 4.2), which will be discussed more in detail in the remainder of this section.

First, I control for size. The idea is that larger companies have more impact on society and are more visible than smaller companies, and therefore are scrutinised 
more intensively by stakeholders. However, in this study the effect is expected to be modest, given that sample companies are all large multinational companies and size variance therefore will be limited. In this study size is measured by the market value of the companies. This measure was considered to be more appropriate than sales or total assets, since a considerable amount of sample companies are financials. Company data on size (SIZE) were taken from the Datastream financial statistical database.

Second, I control for industry effects by including an industry-dummy that takes account of an industry's issue visibility (IND_VISIB). It builds on the idea that some industries are more visible due to an inherent impact of their activities on society. Bowen (2000) puts forward that issue visibility is high when issues "are easily noticeable by groups inside or outside the organization". This method for controlling for industry effects has been suggested by prior studies, such as: Roberts (1992), Hackston \& Milne (1996) and Brammer \& Millington (2004). This study's measure was based on the classifications of these studies, updated with a number of industries that have faced major CSR issues in recent years (Buchholtz \& Carroll, 2008). Consequently, IND_VISIB takes the value 1 if an industry is classified as having high visibility due to high impact, and the value 0 otherwise ${ }^{51}$.

Table 4.2: Control variables*

Size

SIZE

LNSIZE

Industry

IND_VISIB

Country

STAK

SHR_N_US

SHR_US

Institutional Ownership
$=$ market value of the company, calculated as the number of shares in issue times the share price (\$ millions)

$=$ natural logarithm of SIZE

$=1$ if company operates in an industry with high visibility

$=1$ if a company's country of origin is Belgium, Denmark, Finland, France, Germany, The Netherlands;

= 1 if a company's country of origin is Australia, Canada, Hong Kong, UK;

$=1$ if a company's country of origin is US;

INSTOWN

$=$ the percentage of shares outstanding that are held strategically by governments, pension funds and investment companies, calculated as: $\mathrm{NOSHGV}+\mathrm{NOSHPF}+\mathrm{NOSHIC}$

*When it is stated that a variable is given the value ' 1 ' in case a certain condition is met, it is implicitly assumed that in any other condition the variable is valued ' 0 '.

\footnotetext{
51 The following (GICS) industries have been classified as 'highly visible': oil and gas, chemicals, metals and mining, paper and forest products, aerospace and defence, airlines, cars, textiles, apparel and luxury goods, all retailing, food and staples, beverages, food products, tobacco, household products, personal products, healthcare equipment and supplies, biotechnology, pharmaceuticals, telecommunication services and all utilities.
} 
Third, in order to control for country effects, I distinguish between countries with a stakeholder versus shareholder orientation, in line with previous CSR disclosure research (Holder-Webb, et al., 2008; Simnett, et al., 2009; Smith, et al., 2005). This differentiation is based on the idea that in countries with a shareholder orientation 'other stakeholder groups have less legitimacy and therefore less influence on corporate activities' (Simnett, et al., 2009: 15). Although from a traditional corporate governance point of view it is common to distinguish between the Anglo-American shareholder orientation and Continental European stakeholder orientation, in the specific context of CSR prior studies report on the unique position of the U.S., not only in comparison to stakeholder-oriented countries, but also to other shareholder-oriented countries (Aguilera, et al., 2006; Buhr \& Freedman, 2001; Cormier \& Magnan, 1999; Holder-Webb, et al., 2008). These studies typically refer to the specific legal environment of the U.S., which is characterised by a high risk of litigation. In order to avoid potential lawsuits U.S. companies are inclined to provide mandatory CSR disclosure, but will abstain from disclosing voluntary CSR information (Buhr \& Freedman, 2001). Due to these institutional differences, this study will -next to the dichotomous categorisation between stakeholder and shareholder orientationfurther divide the shareholder-oriented countries into U.S. and non-U.S. countries. This classification is consistent with an earlier study (Meek, et al., 1995) that finds evidence that U.S. companies disclose less CSR information than U.K. and continental European companies. The previous results in three country clusters: STAK (stakeholder-oriented), SHR_N_US (shareholder-oriented non-US) and SHR_US (shareholder-oriented US). Table 4.2 lists the constituent countries of each cluster.

Fourth, I control for the potential influence of institutional investors, since there is some evidence for institutional investors' influence on strategic decisions regarding CSR (Cox, et al., 2008; Graves \& Waddock, 1994; Johnson \& Greening, 1999), as described above. However, there are only a handful of empirical studies on the role of institutional shareholders in CSR disclosure, of which some report on a general passivity of institutional investors (Friedman \& Miles, 2001; Miles, Hammond, \& Friedman, 2002), whereas others observe a trend of growing active engagement of institutional investors (Sparkes \& Cowton, 2004). Hence, it is not clear whether institutional shareholders actually do have an influence on environmental disclosure, let alone whether this influence is of a positive or negative nature. To control for the potential effect of institutional ownership, I included a variable that was calculated as the percentage of shares outstanding that are held strategically by institutional shareholders. These institutional shareholders include: governments, pension funds and investment companies. Data were retrieved from Datastream financial statistical database (codes: NOSHGV, NOSHPF and NOSHIC). The resulting control variable was labelled INSTOWN. 


\subsubsection{Statistical analysis}

OLS multiple regression analysis was used to analyse the relationship between stakeholder attributes and public environmental disclosure, resulting in model 1. The model accounts for the effect of the individual attribute measures separately; this statistical specification is in line with previous empirical studies (Agle, et al., 1999; Eesley \& Lenox, 2006). Nested regressions are specified, including five models labelled A, B, C, D, and E. Models A, B, and C use only (combinations of) the independent variables. In the $D$ model the control variables for size, industry, and country are added. The $E$ model tests the potential influence of institutional shareholders through inclusion of the variable INSTOWN.

This approach is summarised by the following model:

Environmental Disclosure ${ }_{i}=$

$\mathrm{f}$ (Power, Urgency, Legitimacy, Control Variables)

$$
(i=1, \ldots, 199)
$$

\subsection{Results}

\subsubsection{Descriptives}

Table 4.3 shows the descriptive statistics for dependent and explanatory variables. Panel A of Table 4.3 shows the descriptive statistics for the continuous variables. Disclosure levels indicate that, on average, the level of response of companies toward their environmental stakeholders is only $29 \%$. This relatively low level of response is in line with previous research (Agle, et al., 1999) ${ }^{52}$. The average level of urgency (ENVURG) is very low, which indicates that many companies are not involved in any environmental controversies at all. The legitimacy measure (ENVLEG) shows that companies vary considerably in the extent to which they perceive their environmental NGOs to be legitimate. Given that the strength of operationalisation is not equivalent across the various attribute proxies, comparing the descriptive statistics of the various attribute measures is not meaningful (Cooper \& Richardson, 1986).

\footnotetext{
${ }^{52}$ Given the low mean for environmental disclosure, I assessed the number of cases for which this variable equals zero; this turned out to be only one company, and consequently the variable is not truncated at zero, which takes away the need for censored regression.
} 
Table 4.3: Descriptive Statistics

\begin{tabular}{|c|c|c|c|c|c|c|}
\hline \multicolumn{7}{|c|}{ Panel A: Continuous variables } \\
\hline Variable & Description & $\mathrm{N}$ & Min & Max & Mean & S.D. \\
\hline \multicolumn{7}{|c|}{ 1.Dependent/explanatory variables } \\
\hline Disclosure & ENVDISC & 198 & .00 & .77 & .29 & .19 \\
\hline Urgency & ENVURG & 199 & .00 & .71 & .09 & .14 \\
\hline Legitimacy & ENVLEG & 196 & .00 & 1.00 & .51 & .38 \\
\hline Institutional ownership & INSTOWN & 195 & .00 & .62 & .19 & .20 \\
\hline \multicolumn{2}{|c|}{ 2.Control variables } & $\mathrm{N}$ & Min & Max & Mean & S.D. \\
\hline \multirow[t]{2}{*}{ Size } & SIZE * & 195 & 412 & 319848 & 37556 & 52492 \\
\hline & LNSIZE & 195 & 6.02 & 12.68 & 9.87 & 1.19 \\
\hline \multicolumn{3}{|c|}{ Panel B: Dichotomous variables } & \multicolumn{2}{|c|}{ High } & \multicolumn{2}{|c|}{ Low } \\
\hline Variable & Description & $\mathrm{N}$ & Freq & (\%) & Freq & (\%) \\
\hline \multicolumn{7}{|c|}{ 1.Explanatory variables } \\
\hline Power & ENVPOW & 196 & 76 & $(38.8)$ & 120 & $(61.2)$ \\
\hline \multicolumn{2}{|c|}{ 2.Control variables } & $\mathrm{N}$ & \multicolumn{2}{|c|}{ Value $=1$} & \multicolumn{2}{|c|}{ Value $=0$} \\
\hline Sector & IND_VISIB & 199 & 94 & $(47.2)$ & 105 & $(52.8)$ \\
\hline \multirow[t]{3}{*}{ Country } & STAK & 199 & 98 & $(49.2)$ & 101 & $(50.8)$ \\
\hline & SHR_N_US & 199 & 32 & $(16.1)$ & 167 & $(83.9)$ \\
\hline & SHR_US & 199 & 69 & $(34.7)$ & 130 & $(65.3)$ \\
\hline
\end{tabular}

$*$ in millions $\$$

Hence, it cannot be assessed whether companies on average are confronted with NGOs that are more legitimate than urgent. Table 4.3 also includes a new measure for size (LNSIZE), representing the original size measure (SIZE) after logtransformation. These changes were informed by the fact that further descriptive analysis $^{53}$ revealed that SIZE was both peaked and skewed.

Panel B of Table 4.3 lists the frequencies of the dichotomous variables. None of the binary variables has a split above 90:10, hence all categories are fairly represented.

\footnotetext{
${ }^{53}$ For all variables of interest, as a part of the tests for potential violations of the normality assumptions, medians were calculated and compared to the means, dataplots were generated and skewness and kurtosis statistics were analysed. This revealed that for ENVURG, ENVLEG and SIZE medians deviated from the means (respectively, 0.00 versus $0.09,0.67$ versus 0.52 , and 19141 versus 37555 ). Analysis of the skewness and kurtosis statistics showed that only SIZE outside the normal (between -3 and +3 ) range. Nevertheless, given the nature of ENVURG and ENVLEG (basic interval scales of respectively eight and four categories) next to the statistical analyses that will be presented in the following pages, nonparametric univariate tests were performed for these variables. Also, as part of the multivariate analysis I analysed the residuals of the models and, if necessary, ran additional regressions. However, none of these led to different conclusions.
} 


\subsubsection{Univariate analysis}

Table 4.4 presents the correlations between the dependent variable, explanatory attribute variables, as well as the control variables.

When analysing the correlation between the individual attribute measures and the dependent variable, the relationships are in line with what was hypothesised. All stakeholder attributes are significantly positively associated with disclosure. Regarding the control variables the correlation statistics illustrate that the environmental disclosure of companies in highly visible industries and stakeholder-oriented countries is significantly more extensive. Table 4.4 also illustrates that institutional ownership and environmental disclosure are negatively correlated, implying that higher institutional ownership is associated with less extensive environmental disclosure. This finding hints at the idea that next to environmental NGOs, also institutional shareholders have an influence on environmental disclosure.

Table 4.4 also includes the correlations between the individual explanatory variables. It illustrates that each of the stakeholder attributes (ENVPOW, ENVURG and ENVLEG) is positively associated with the others. The correlations between the environmental stakeholder attributes are highly significant, implying that legitimate environmental stakeholders also tend to be powerful and have urgent claims. The strong correlation between power and legitimacy is in line with literature suggesting close ties between the two (e.g. Mitchell et al. (1997) indicate that the constructs are "sometimes overlapping").

Further, Table 4.4 illustrates that larger companies tend to be confronted with more powerful and urgent environmental NGOs. Besides, the significant positive correlations between IND_VISIB on the one hand, and each of the variables ENVPOW, ENVURG and ENVLEG on the other hand, indicate that companies from highly visible industries are confronted with more NGO power and -urgency and tend to perceive environmental NGOs as more legitimate. Table 4.4 also lists some differences between the levels of importance for each of the stakeholder attributes across country clusters. 
Table 4.4: Correlations between dependent, explanatory and control variables

\begin{tabular}{|c|c|c|c|c|c|c|c|c|c|}
\hline & Variable & Type & 1 & 2 & 3 & 4 & 5 & 6 & 7 \\
\hline 1 & ENVDISC & C & 1 & & & & & & \\
\hline 2 & ENVPOW & $\mathrm{D}$ & $.18^{*}$ & 1 & & & & & \\
\hline 3 & ENVURG & C & $.17^{*}$ & $.57^{* *}$ & 1 & & & & \\
\hline 4 & ENVLEG & C & $.62^{* *}$ & $.34 * *$ & $.27^{* *}$ & 1 & & & \\
\hline 5 & LNSIZE & C & .01 & $.25^{* *}$ & $.23 * *$ & .12 & 1 & & \\
\hline 6 & IND_VISIB & D & $.34^{* *}$ & $.18^{*}$ & $.30 * *$ & $.31^{* *}$ & .02 & 1 & \\
\hline 7 & INSTOWN & $C$ & $-.15^{*}$ & .08 & .09 & -.12 & $.29 * *$ & .03 & 1 \\
\hline 8 & STAK & $\mathrm{D}$ & $.24^{* *}$ & -.06 & -.07 & .14 & $-.40 * *$ & .08 & $-.73 * *$ \\
\hline 9 & SHR_N_US & D & .08 & $-.15^{*}$ & $-.20 * *$ & -.04 & $-.15^{*}$ & -.11 & .05 \\
\hline 10 & SHR_US & $\mathrm{D}$ & $-.31 * *$ & $.18^{*}$ & $.24 * *$ & -.11 & $.53^{* *}$ & .01 & $.72^{* *}$ \\
\hline
\end{tabular}

Type $\mathrm{C}=$ Continuous variable

Type $\mathrm{D}=$ Dummy variable

Pearson correlations are tabulated; given the dichotomous nature of some of the variables, as indicated, $\mathrm{I}$ also performed independent sample t-tests and Chi-square tests and compared the results; all results were similar.

$* \mathrm{p}<.05 ; * * \mathrm{p}<0.01$ (two-tailed)

Companies from shareholder-oriented countries tend to be confronted with higher stakeholder power than companies from stakeholder-oriented countries. U.S. companies are confronted with higher stakeholder urgency than other countries, whereas companies from non-U.S. shareholder oriented countries meet environmental NGOs with significantly lower levels of urgency. The results do not show any significant differences between country clusters for legitimacy. Finally, remarkably high correlations were found between country cluster and company size (LNSIZE) and country cluster and institutional ownership (INSTOWN). Results indicate that companies form stakeholder oriented countries (U.S. companies) are confronted with significantly lower (higher) levels of institutional ownership ${ }^{54}$ and are smaller (bigger) in size than companies from other countries. Given the overall importance of the country variables, as part of the multivariate analysis in the next section a sensitivity analysis will be carried out in order to analyse whether the hypothesised relations are consistent across country clusters.

\footnotetext{
${ }^{54}$ This finding corresponds to prior literature addressing the increase in institutional investment (to over $60 \%$ of public equity in 2002) in the U.S. during the last decades (Ryan \& Schneider, 2003), whereas in Europe company ownership is becoming more dispersed.
} 


\subsubsection{Multivariate analysis}

Table 4.5 presents the multivariate results of the ordinary least-squares (OLS) regression analysis for the model specified earlier in equation $(1)^{55}$.

Table 4.5: OLS regression results for environmental disclosure ${ }^{a}$

\begin{tabular}{|c|c|c|c|c|c|c|c|}
\hline \multirow[b]{2}{*}{ Variables } & \multirow{2}{*}{$\begin{array}{l}\text { Dependent } \\
\text { variable }\end{array}$} & \multicolumn{6}{|c|}{ Environmental disclosure } \\
\hline & & $\begin{array}{l}\text { Exp. } \\
\text { sign }\end{array}$ & Model $1 \mathrm{~A}$ & Model 1B & Model $1 \mathrm{C}$ & Model 1D & Model 1E \\
\hline & Explanatory & & & & & & \\
\hline (constant) & & $?$ & $(.128 * * *)$ & $\left(.125^{* * *}\right)$ & $\left(.127^{* * *}\right)$ & $(-.153)$ & $(-.322 * *)$ \\
\hline ENVPOW & & + & -.012 & & -.021 & -.006 & -.001 \\
\hline ENVURG & & + & & .022 & .060 & .057 & .077 \\
\hline ENVLEG & & + & $.327 * * *$ & $.319 * * *$ & $.325^{* * *}$ & $.257^{* * *}$ & $.261 * * *$ \\
\hline & Control & & & & & & \\
\hline LNSIZE & & + & & & & $.019+$ & $.026 *$ \\
\hline IND_VISIB & & + & & & & $.074 * *$ & $.056^{*}$ \\
\hline STAK & & ? & & & & $.129 * * *$ & $.229 * * *$ \\
\hline SHR_N_US & & ? & & & & $.152^{* * *}$ & $.205^{* * *}$ \\
\hline SHR_US & & ? & & & & baseline & baseline \\
\hline INSTOWN & & ? & & & & & $.003^{* *}$ \\
\hline Adj. $R^{2}$ & & & 0.380 & 0.380 & 0.378 & 0.469 & 0.502 \\
\hline F-value & & & $60.549 * * *$ & $60.395^{* * *}$ & $40.361^{* * *}$ & $24.986^{* * *}$ & $24.671 * * *$ \\
\hline $\mathrm{N}$ & & & 195 & 195 & 195 & 191 & 189 \\
\hline
\end{tabular}

The F-statistics show that all models are significant.

\footnotetext{
${ }^{55}$ I also performed a number of additional statistical tests. First, I ran OLS regressions with the previously mentioned alternative environmental power variable ENVPOW2. The results largely remain unchanged, except for a small decrease in the significance levels of the size and industry measures (IND_VISIB and LNSIZE), the latter of which may be attributed to the decrease in sample size to $n=70$. Second, I ran regressions using a dependent variable (ENVDISC2) from which the disclosures on 3 environmental items (i.e., an environmental department, EMS and stakeholder engagement) were excluded. This was done as the existence of these 3 arrangements was also used to construct the legitimacy variable and consequently the strength of the relation between disclosure and legitimacy could have been inflated. Again, this did not change any of the results. Third, I also applied the regressions to a split sample of highlyvisible and non highly-visible companies, in order to account for potential distorting effects of the associations between IND_VISIB and each of the attribute variables. This did not result in any other conclusions.
} 
Models $1 \mathrm{~A}, 1 \mathrm{~B}$, and $1 \mathrm{C}$ include the coefficient estimates for the models with only (some of) the primary explanatory variables, i.e., the individual stakeholder attributes. Given that power and urgency are highly correlated, in Models $1 \mathrm{~A}$ and $1 \mathrm{~B}$ the two variables are individually entered, whereas Model $1 \mathrm{C}$ includes all of the stakeholder attributes. Each of these base models explains approximately $38 \%$ of the variance in disclosure. The coefficients in these models remain stable and confirm what univariate analysis has already uncovered: legitimacy is consistently associated with environmental disclosure. However, different from the univariate results, power and urgency are no longer significantly related to CSR disclosure.

Model 1D includes the control variables for size, industry, and country. This model adds approximately another $10 \%$ to the explanatory power of the previous models. As for the variables of primary interest, the direction and significance of the coefficients of the attributes remain unchanged. Table 4.5 further illustrates that environmental disclosure is (marginally) significantly positively determined by size and industry; and compared to the U.S., companies from non-U.S. countries have significantly more extensive environmental disclosure.

The model in which I control for potential other sources of stakeholder influence by including the proxy for institutional ownership (INSTOWN) is labelled 1E. This model accounts for an additional increase in $\mathrm{R}^{2}$ by approximately $3 \%$ as compared to the $D$ model. As for the variables of primary interest, the model demonstrates the persistent quintessence of legitimacy, as well as non-significant effects of urgency and power. However, it illustrates that in a multivariate setting the level of institutional ownership is positively and significantly associated with environmental disclosure, which is in contrast with the univariate result presenting a negative and significant association. So as to further explore the nature of this change, I ran a regression in which next to the stakeholder attributes only institutional ownership was included as a control. In this model the coefficient for INSTOWN becomes again negative, although insignificant. Hence, a potential explanation for the inconsistent behaviour could be a relationship with any of the other control variables. Given the notably high correlation between the country variables and INSTOWN (see Table 13), differences between country clusters seem to be a likely candidate for the cause of this change in sign of the coefficient. Formal collinearity diagnostics do not indicate any multicollinearity problems. Further insight will be derived from the sensitivity analysis that will be discussed in one of the next sections.

\subsubsection{Mediation test}

The change in the relationship between attributes and environmental disclosure when moving from a univariate to a multivariate context illustrates that mutual relationships between the attributes come into play. Mitchell et al. (1997: 870) acknowledge the importance of potential interrelationships between stakeholder 
attributes by stating: "Legitimacy gains rights through power and voice through urgency". In the case of environmental stakeholders legitimacy seems to take over the individual effects of power and urgency. There is preliminary evidence on the idea that non-resource-based stakeholders need power in order to be considered a legitimate stakeholder (Driscoll \& Crombie, 2001). Based on this literature and statistical results, I will test for a potential mediating role of legitimacy in the relationship between each of the other two attributes (ENVPOW and ENVURG) and environmental disclosure. Baron \& Kenny (1986) provide a basic mediation test, which consists of three regression equations: (1) regressing the mediator on the explanatory variable, (2) regressing the dependent on the explanatory variable, and (3) regressing the dependent on both the explanatory and mediating variable.

According to Baron and Kenny (1986) mediation is established when the coefficient of the explanatory variable in the first two regression equations is significant, and moreover the coefficient for the mediator in the third equation is significant, whereas in case of the explanatory variable the significance of the coefficient decreases.

Table 4.6 provides the results of equations (1) and (2) for both ENVPOW and ENVURG including all covariates.

Table 4.6: Mediation test: OLS regression results for power and urgency with ENVLEG (mediator) and ENVDISC (dependent variable) as dependent variable ${ }^{a}$

\begin{tabular}{|c|c|c|c|c|c|}
\hline \multirow{2}{*}{$\begin{array}{l}\text { Dependent } \\
\text { Independent }\end{array}$} & \multicolumn{3}{|c|}{ ENVLEG } & \multicolumn{2}{|c|}{ ENVDISC } \\
\hline & Exp sign & Power & Urgency & Power & Urgency \\
\hline Explanatory & & & & & \\
\hline (Constant) & ? & $(-.336)$ & $(-.408)$ & $\left(-.404^{* *}\right)$ & $\left(-.422^{* *}\right)$ \\
\hline ENVPOW & + & $.220 * * *$ & & $.067^{*}$ & \\
\hline ENVURG & + & & $.557^{* *}$ & & $.219 *$ \\
\hline Control & & & & & \\
\hline LNSIZE & + & $.056^{*}$ & $.065^{*}$ & $.040 * *$ & $.042 * *$ \\
\hline IND_VISIB & + & $.190 * * *$ & $.186^{* *}$ & $.109 * * *$ & $.103^{* * *}$ \\
\hline STAK & $?$ & $.205^{*}$ & $.222^{*}$ & $.280 * * *$ & $.289 * * *$ \\
\hline SHR_N_US & $?$ & $.179 *$ & $.192 *$ & $.247^{* * *}$ & $.255^{* * *}$ \\
\hline SHR_US & ? & baseline & baseline & baseline & baseline \\
\hline INSTOWN & $?$ & .000 & -.000 & $.002 *$ & $.003^{*}$ \\
\hline F-value & & $8.890 * * *$ & $7.116^{* * *}$ & $13.940 * * *$ & $13.701^{* * *}$ \\
\hline Adj. $R^{2}$ & & 0.220 & 0.163 & 0.292 & 0.287 \\
\hline$N$ & & 190 & 190 & 189 & 190 \\
\hline
\end{tabular}


As Table 4.6 illustrates, both explanatory variables (ENVPOW and ENVURG) are significantly related to both legitimacy (ENVLEG) and disclosure (ENVDISC). Since from Table 4.6 it can be distilled that the coefficient of the potential mediator (ENVLEG) in equation 3 is significant, whereas the coefficients of the explanatory variables (ENVPOW and ENVURG) are insignificant, it can be concluded that the effects of stakeholder power and urgency on environmental disclosure are mediated by legitimacy. This implies that for environmental NGOs the effects of power and urgency on disclosure are of an indirect nature, and consequently that they need power and urgency to become legitimate, which subsequently leads to more disclosure.

\subsubsection{Sensitivity analysis}

Given the patterns in the stakeholder attributes and some of the control variables across country clusters that were previously discussed, a sensitivity analysis was carried out in order to single out any potential biases in the results. Splitting up the sample in U.S. versus non-U.S. companies confirms the results from the univariate analysis. Analysis of the (nontabulated) descriptives learns that non-U.S. companies on average have higher disclosure (ENVDISC: 0.34 vs. 0.21 ) and legitimacy (ENVLEG: 0.54 vs. 0.45 ), but lower urgency (ENVURG: 0.07 vs. 0.14 ), size (LNSIZE: 9.4 vs. 10.7) and institutional ownership (INSTOWN: 8.56 vs. 37.91) ${ }^{56}$. All differences, except legitimacy, are significant $(p<0.001)$. As for stakeholder power (ENVPOW), the descriptives show that non-U.S. companies' distribution over high vs. low power (32.3 vs. 67.7) differs from that of U.S. companies, showing an almost equal dispersion (50.7 vs. 49.3$)$. The means and frequencies of the industry visibility (IND_VISIB) are more or less equal across the country clusters.

The associations between the variables for the split samples (nontabulated) are overall similar to those presented in Table 4.4. The levels of significance for the associations between each of the attributes and environmental disclosure remain the same or slightly increase for both U.S. and non-U.S. samples. The only difference is that INSTOWN, which was negatively and significantly associated with environmental disclosure in Table 4.4, is now positively and significantly associated with environmental disclosure in the non-U.S. sample, whereas this association is negative, yet non-significant, for the U.S. sample.

The results of the separate multivariate analysis for U.S. and non-U.S. companies are presented in Table 4.7. With regard to the independent variables the results are consistent with Table 4.5 , in that the effect of legitimacy is positive and significant, where the effects of power and urgency are non-significant. As for the

\footnotetext{
${ }^{56}$ As the descriptives for the non-U.S. sample illustrated that ENVURG and INSTOWN were peaked, logtransformations were applied to solve the problem. The results of the remainder of the sensitivity analysis are based on these new measures, LN_ENVURG and LN_INSTOWN respectively.
} 
coefficients of the control variables, Table 4.7 demonstrates that size and institutional ownership become non-significant for both specifications, whereas country and industry appear to be relevant for non-U.S. companies only. This implies that the influence of the control variables in model $1 \mathrm{a}$ and $1 \mathrm{~b}$, particularly size and institutional ownership, should actually be attributed to a difference in country settings. Overall, the results imply that the accurateness of the hypothesised relations between stakeholder attributes and CSR disclosure is robust across country clusters.

Table 4.7: Models for Non-U.S. and U.S. ${ }^{a}$

\begin{tabular}{|c|c|c|c|c|c|c|}
\hline \multirow[b]{3}{*}{ Independent } & \multicolumn{6}{|c|}{ Environmental disclosure } \\
\hline & \multicolumn{3}{|c|}{ Non-U.S. } & \multicolumn{3}{|c|}{ U.S. } \\
\hline & Model 2a & Model 2b & Model 2c & Model 2b & Model 2b & Model 2c \\
\hline Explanatory & & & & & & \\
\hline (constant) & $(.176 * * *)$ & $(.001)$ & $(-.035)$ & $(.044+)$ & $(-.156)$ & $(-.369+)$ \\
\hline ENVPOW & -.031 & -.016 & -.006 & .022 & .013 & .020 \\
\hline ENVURG & .197 & .043 & .044 & .153 & .106 & .114 \\
\hline ENVLEG & $.290 * * *$ & $.247 * * *$ & $.244^{* * *}$ & $.302 * * *$ & $.275^{* * *}$ & $.279 * * *$ \\
\hline Control & & & & & & \\
\hline LNSIZE & & .019 & .021 & & .018 & .023 \\
\hline IND_VISIB & & $.085^{* *}$ & $.064^{*}$ & & .050 & .046 \\
\hline STAK & & baseline & baseline & & & \\
\hline SHR_N_US & & .043 & -.019 & & & \\
\hline SHR_US & & & & & & \\
\hline INSTOWN & & & .003 & & & .045 \\
\hline Adj. $R^{2}$ & 0.314 & 0.336 & 0.356 & 0.518 & 0.526 & 0.537 \\
\hline F-value & $20.104 * * *$ & $11.287^{* * *}$ & $10.471 * * *$ & $25.344 * * *$ & $15.893 * * *$ & $13.992 * * *$ \\
\hline $\mathrm{N}$ & 126 & 123 & 121 & 69 & 68 & 68 \\
\hline
\end{tabular}

The previous results section indicates that there is a direct and consistent effect of legitimacy (ENVLEG) on environmental disclosure. From mediation analysis it appeared that NGO power (ENVPOW) and urgency (ENVURG) also significantly influence disclosure, although this effect is of an indirect nature. Based on these findings, all hypotheses can be accepted. Sensitivity analysis illustrated that these findings are robust across different country clusters. The results also indicate that the effects of some company specific characteristics, which have been associated with disclosure in prior studies and are included as a control variable in the model, should be actually attributed to country specific settings. 


\subsection{Conclusion}

This study investigates the influence of stakeholders on CSR disclosure. More precisely it seeks to develop an understanding of the exact stakeholder attributes that drive CSR disclosure. In order to do so I use stakeholder salience theory to explain differences in CSR disclosure across companies. This hypothesised conceptual relation is empirically addressed through assessing the extent to which environmental stakeholders' power, urgency and legitimacy influence the level of management response to the demand for environmental information.

Based on an international sample of 199 large companies I find that the hypothesised relationships between stakeholder attributes and CSR disclosure hold, yet the results indicate that the influence of power and urgency is of an indirect nature, since it is mediated by legitimacy. It is legitimacy that explains most of the variation in CSR disclosure.

I find no convincing evidence for the influence of institutional investors on environmental disclosure. Although the level of institutional shareholding has a significantly positive effect on environmental disclosure in the main model, sensitivity analysis reveals that this effect should be actually attributed to country differences. The same holds for the effect of company size.

The results further show that industry, which has been brought up by prior literature as a determinant, is also relevant in the setting of this study. The level of environmental disclosure is related to whether a company is active in an industry with high or low visibility, although this effect is less relevant for U.S. companies.

As for the difference in country settings, the results indicate that not the difference between stakeholder- and shareholder-oriented countries is the main source of the variation in CSR disclosure, but the difference between U.S. and non-U.S. countries. The lower levels of environmental disclosure for U.S. companies illustrate the importance of the specific legal environment of the U.S., which is characterised by a high risk of litigation and results in greater incentives for providing mandatory CSR disclosure and for abstaining from voluntary disclosure (Buhr \& Freedman, 2001).

The findings from this study have implications for (future) academic research. It contributes to the research field of environmental stakeholders' role in corporate governance, as well as the field of environmental disclosure. With regards to the former stream of research this study demonstrates that stakeholders (other than investors) influence managerial decision-making regarding an important corporate governance phenomenon. It adds to the second field by providing evidence that next to the well-documented effect of company characteristics, stakeholder characteristics influence the extent of environmental disclosure too, particularly by giving specific insight into why some stakeholders are better able to influence management decisions on environmental disclosure than others. Adding to both streams 
are the results that the associations between stakeholder characteristics, other determinants and disclosure may differ across countries; this also implies that the applicability of current research outcomes in this field, which mainly come from U.S. studies, may be limited.

This study also has a number of practical implications. First, for environmental stakeholders the results provide insight into what tactics are associated with success. Environmental stakeholders that would like their information requests complied with by a company seem to benefit most from an increase in their legitimacy as perceived by company management. The high and consistent association between legitimacy and disclosure implies that this is the best way to enhance disclosure. The findings on the indirect effect of environmental power and urgency suggest that for environmental stakeholders increasing legitimacy is associated with putting critical and time-sensitive environmental issues on the corporate agenda, by means of confrontational or collaboration tactics. Second, it provides valuable input for the current debate on the desirability of government regulation regarding CSR disclosure. The evidence on secondary stakeholders providing incentives for voluntary CSR disclosure may call for self-regulation. On the contrary, I also find that overall environmental disclosure is rather low, implying that government regulation might be desirable to impose better accountability. In order to gain a better insight, future research may focus on what types of environmental information companies disclose in response to NGO information requests. Comparing the actual attributes with management perceptions may also be an interesting avenue for future studies in this area.

The results of this study are subject to a number of limitations. First, the results are only applicable to large companies. The relationship between company and stakeholders with regard to CSR disclosure of smaller companies may follow different patterns (Knox, et al., 2005). Secondly, in using measures of actual power and urgency, I did not take into account any biases that stem from the fact that managerial actions are a result of their perceptions of these actual attributes. Third, (prior) interactions of a company with other stakeholders and between stakeholder groups may influence the priority that managers give to one particular stakeholder (Neville \& Menguc, 2006; Reid \& Toffel, 2009; Rowley, 1997); therefore disclosure may reflect the combined attributes of several different stakeholder groups. Given the research design, it was not possible to specifically address any potential interdependencies between stakeholders. Fourth, although causation can never be empirically demonstrated, making causal inferences in cross-sectional research designs is particularly difficult. Nevertheless, the observed regularities and correlations in this study correspond to the theoretical relations from prior research. 


\section{Chapter 5}

\section{Summary and conclusion}

\subsection{Introduction}

This dissertation brings together three empirical studies on CSR disclosure. The first study explores the way in which CSR reporting is internally managed. The second study extends the focus on the internal management of CSR by examining the link between environmental performance and environmental disclosure. The third study focuses on external factors of CSR disclosure; more specifically it addresses the extent to which secondary stakeholders are able to influence CSR disclosure. This final chapter summarises the empirical findings of the three studies, after which a conclusion and implications are provided. Finally, the limitations and suggestions for future research are discussed.

\subsection{Summary}

In the first empirical study I explore how companies manage their CSR reporting process. This focus on internal organisational factors is motivated by the mixed evidence from research on the relationship between CSR reporting and external company factors. Using a qualitative research design I examine the internal factors that are associated with CSR reporting of six Dutch companies with exemplary CSR reports. Seven themes that have been associated with management process optimisation in the strategy literature informed the data collection process. From semistructured interviews based on these themes it is demonstrated that the constellations of structures, systems and processes, with which CSR reporting is managed, varies across companies. Two important factors to which this heterogeneity can be attributed are the level of formalisation of the reporting process and the integration of CSR into everyday management. Based on these two dimensions I develop a typology, with which four types of companies can be distinguished. Improvisers, the first company type, are characterised by a CSR approach that is predominantly informal and is separated from the other (financial) management decisions. Reporters, the second type have formalised the management of CSR reporting; compa- 
rable to the first type, CSR is not integrated into the day-to-day management. For Performers, the third type, the formal management of CSR Reporting forms part of an integrated and formal overall CSR function. Hence, this third company type links formal CSR reporting management to an integrated CSR approach. Notably all three companies that were classified as Performer type were companies from sensitive industries, i.e. chemical and oil companies. Finally, Reformers constitute the fourth type of companies, combining integrated CSR with informal management of CSR reporting. Given the nature of the sample, no companies were found to fit this type, but it is proposed that social entrepreneurial companies may suit the description. Despite the heterogeneity in the internal management of CSR reporting, the homogeneity in the perceived quality of their reports by external parties is notable.

In the second study I investigate the relation between environmental performance and voluntary environmental disclosure. Based on a review of the corporate environmental performance literature, I suggest that conceptually sound environmental performance measures, next to an outcome dimension, also include a process dimension. This process dimension relates to companies' internal environmental management. Drawing on legitimacy theory, I expect outcome-based environmental performance to be negatively, and process-based performance to be positively related to environmental disclosure. In order to address the hypothesised relations empirically, I develop two environmental performance constructs. The outcomebased performance measure is captured by sales-adjusted greenhouse gas (GHG) emissions. Process-based performance is measured by a company's environmental commitment, data for which are retrieved from a proprietary database. In order to ensure that only the truly voluntary disclosure is included, I limit the environmental disclosure variable to public environmental disclosure exclusive of annual report or Form 10-K disclosures.

The results for an international sample of 138 large companies from various industries show that environmental disclosure is first and foremost related to positive process-based performance, i.e. environmental commitment. It appears to be consistently positively associated with environmental disclosure, irrespective of whether industry and other controls are included or not, or the sample used. This confirms the hypothesis. The results for GHG emissions (outcome-based performance) are less consistent. As expected they show that this measure in itself is significantly positively related to environmental disclosure, both across and within industries. However, this only holds to the extent that companies in more polluting industries (i.e., industries with higher GHG emissions) on average have more extensive environmental disclosures than companies in less polluting industries, and nonmanufacturing companies with higher GHG emissions have more extensive disclosures than their lower GHG emissions industry peers. Besides, this relation disappears in models that include GHG emissions and environmental commitment simul- 
taneously. This is partly caused by the significant negative correlation between the two performance measures, which points at the fact that (part of) the positive relation between environmental commitment and disclosure in fact occurs due to inferior outcome-based performance (i.e., higher GHG emissions). Overall the results indicate that disclosure is associated with the visibility of a company, as reflected by industry-affiliation or inferior performance relative to industry peers. Despite the lack of consistency in the results for outcome-based performance with respect to the hypothesis, I therefore conclude that environmental disclosure can be explained by legitimacy theory.

The aim of the third study is to analyse whether and how companies' external stakeholders influence managerial decision making on CSR disclosure. More precisely, I aim to develop an understanding of the exact stakeholder attributes that are associated with the level of environmental disclosure. I empirically investigate whether differences in environmental disclosure among companies are systematically related to differences in the level of power, urgency and legitimacy of the environmental NGOs with which these companies are confronted. Using stakeholder salience theory, I hypothesise that the level of environmental disclosure is positively associated with the level of power, urgency and legitimacy of the environmental stakeholders.

Based on an international sample of 199 large companies I find that the hypothesised relationships between stakeholder attributes and CSR disclosure overall hold. However, the results indicate that the influences of power and urgency are of an indirect nature, since they are mediated by legitimacy. The degree to which an environmental stakeholder is perceived to be legitimate explains most of the variation in CSR disclosure. The results provide no convincing evidence for the influence of other stakeholders (institutional investors) or size on environmental disclosure. Sensitivity analysis learns that the initial significance of their positive coefficients in the main OLS regression model should be really attributed to country differences. The results further show that companies in highly visible industries and non-U.S. companies have higher levels of environmental disclosure than their counterparts.

\subsection{Conclusions and implications}

This dissertation contributes to the development of a more inclusive theoretical framework for CSR disclosure. It does so by including factors, associated with CSR disclosure, which have not been systematically researched before, mainly due to a lack of appropriate research data. Next to the common external factors (i.e., size, industry and country) and external outcome measures of performance, which have been associated with environmental disclosure in prior research (see figure 1.1), this 
dissertation stresses the importance of internal factors, such as the presence of appropriate structures, systems and management commitment. Not only are internal factors indicative for the way in which CSR (disclosure) is managed within companies, they are also important indicators of CSR performance. Another contribution to a theoretical framework for CSR disclosure is the result that stakeholder needs, and particularly their ability to influence company management, are important determinants of CSR disclosure. It advances prior empirical research outcomes indicating that (secondary) stakeholders are able to influence CSR disclosures of companies, by clarifying more precisely how secondary stakeholders influence CSR disclosures.

These contributions are the result of an approach, which is different from prior studies. This approach is based on a focus on 'rich' company information; i.e., data capturing the distinctive (CSR) characteristics of a particular company. First this is accomplished by using company information that is initiated and developed by other than managerial actors and therefore less 'coloured', such as researchers' direct observations or other stakeholders' investigations. This approach also consists of concentrating on internal company factors that are more unique to an individual company than generic external characteristics or accounting figures. The use of a proprietary database containing information from various sources -including the media, NGOs, internal company documents and company interviews by researchers- enabled this approach.

Combining the empirical results from section 5.2, I draw two broad conclusions. First, company visibility appears to be a key-construct underlying most of the outcomes. The following observations from the three studies correspond to this. The first study indicates that (large) companies in highly sensitive industries have exemplary CSR reports due to the fact that CSR is integrated into internal management processes and their day-to-day management. The second study shows that more polluting companies, overall disclose more extensive and have higher levels of environmental commitment. The third study confirms this by indicating that larger companies and companies from highly visible industries are confronted with more advanced levels of power, urgency and legitimacy of environmental NGOs and disclose more extensively. This importance of company visibility corresponds to the reasoning of socio-political theory, in which it is stated that larger company size and affiliation to environmentally sensitive industries are associated with greater public pressure due to increased visibility and consequently with more extensive environmental disclosures.

A second conclusion that can be drawn from the results is that assessing a company's CSR performance on the basis of its CSR disclosure may lead to an inappropriate judgement. That is, in the first study it was illustrated that exemplary CSR reports may be the result of communication departments' efforts to create a corpo- 
rate image that corresponds to state of the art benchmarks, rather than a reflection of the actual CSR performance. Study two shows that the extent of environmental disclosure is mainly associated with the extent of positive performance, i.e., environmental commitment, and besides, that these higher levels of environmental commitment may be associated with higher levels of GHG emissions. Hence, associating CSR disclosures with (social) accountability is problematic. Instead, the previous indicates that CSR disclosure is characterised by a positive bias. This bias is intended to avoid adverse stakeholder (re)actions due to perceptions of illegitimate corporate behaviour.

Based on the broad conclusions that can be drawn from their results, each of the three studies also has a number of specific academic and practical implications, which I discuss in the following.

The findings of the first study suggest that the assessment tools of existing award and benchmarking schemes are not able to distinguish between the decoupled and integrated CSR type. Such raises the question as to whether the assessments lack rigor and whether they are useful in enhancing CSP. Therefore, the institutions behind these schemes (such as governments, rating agencies and the accounting profession) may want to consider other incentives for augmenting CSP than rewarding high-quality CSR reports. Alternatively, they could include internal organisational factors in their schemes to nuance rankings that are strictly based on what is reported. Stakeholders that want to use the CSR reports for assessing the extent to which companies have taken care of their interests, probably also will be interested in the internal organisational factors, since they give valuable context to the information in the reports. However, this internal information will be difficult to obtain. Hence, the inclusion of internal organisational factors in existing measures will serve as a valuable addition to the content in the reports, benefiting the development of a good measure for CSR reporting quality.

The implications of the second study are as follows. First, the non-significance of the model including only outcome-based performance for manufacturing companies may explain the lack of association between environmental performance and disclosure as reported by a number of similar previous empirical studies. Adding process-based performance to the empirical model increases the explanatory power significantly and contributes to a better understanding of the complex relation between different expressions of environmental performance and disclosure. Consequently, studies on the relation between environmental performance and environmental disclosure will benefit from nuancing the commonly used hypotheses that inferior performance is either associated with more extensive or less extensive disclosure, as this relation is dependent on which performance dimension is used. It is therefore important to distinguish between the two dimensions. Second, relating 
disclosure to visibility, rather than performance, will be a more successful tactic for explaining environmental disclosures.

The third study provides relevant input for the on-going debate on the desirability of government regulation regarding CSR disclosure. Whereas many users of CSR information request mandatory CSR disclosure in order to match their demand, companies generally object against CSR disclosure legislation by emphasising the administrative burden associated with compliance and the related negative effect on economic growth. Most governments in Western industrialised societies seem to have accepted the business world's line of reasoning and consequently have largely refrained from introducing mandatory CSR disclosure rules so far. Instead most governments are calling for self-regulation. The presented evidence in this dissertation that secondary stakeholders are able to influence voluntary CSR disclosure, provides arguments in favour of the current positions of governments and companies. In addition, an increasing number of companies have become involved in initiatives associated with improving the quality of CSR disclosure, such as disclosure in line with the $\mathrm{G} 3$ guidelines of the Global Reporting Initiatives and third party assurance of the CSR reports (KPMG, 2008). All this constructs an image of companies increasingly providing high quality CSR information in response to stakeholders' demands. However, this dissertation also finds that public disclosure of environmental information is on average rather low. This finding adds to prior research indicating that supplies of CSR information are yet far from matching demand (e.g., Cho \& Patten, 2007; Clarkson, et al., 2008; Tilt, 1994). Particularly disclosure of the actual impacts of company-behaviour is lacking (Clarkson et al., 2010). This implies that companies' CSR disclosures are not motivated by accountability motives. Selfregulation has led to limited and positively biased disclosures, which nevertheless are in line with quality standards. However, true accountability would require inclusion of more and also more negative expressions of CSR performance. In order to achieve this, mandatory regulation is needed.

For environmental stakeholders the results of the third study provide evidence on what tactics are more successful in having their information demands satisfied. It appears that increasing legitimacy is of vital importance. Putting critical and timesensitive environmental issues on the corporate agenda through confrontational or collaboration tactics can do this. The results also indicate that investors, and particularly institutional investors, either do not demand CSR information from companies or are not able to influence companies' CSR disclosure. The latter explanation seems to be less likely, given that institutional investors are usually considered to be among the most salient stakeholders (e.g., Eesley \& Lenox, 2006; Mitchel et al., 1997). The notion that the CSR information is largely irrelevant to most institutional investors would be in line with the mixed evidence provided by empirical studies on the usefulness of CSR information for investors (Holm \& Rikhardsson, 
2008). This also illustrates that in the context of environmental issues, secondary stakeholders cannot simply piggyback on the salience of primary stakeholders. Given that managers typically consider investors to be among the most important stakeholders, environmental groups thus should also consider some 'missionary work' in alerting investors to the importance of environmental issues.

\subsection{Limitations}

For each of the three empirical studies, a number of limitations were listed in the previous chapters. Nevertheless, the most important limitations are repeated.

For the exploratory part, I distinguish three limitations. First, generalisations on the basis of the results of this study should be done with care for a number of reasons. Primary, only the most knowledgeable representative of each company was interviewed. Also, the small sample size adds to the previous. In addition, the focus of this study is on listed large companies. As a consequence, the results may not be generalisable to SMEs and non-listed companies. Nevertheless, this limitation is inherent to any inductive research approach, which disadvantage is counteracted by the richness of the data that is available per company. Second, although all researched companies are large multinationals (some with cross-listings in the U.S.) a sample from another country may provide different results. However, by focusing on one country, the revealed patterns and regularities between the factors of interest are free from potential country effects. Third, as explained in more detail in Chapter 2, in the Netherlands some mandatory environmental reporting rules exist. Hence, some of the CSR reporting of particularly the chemical and oil companies in this study may be affected by these requirements. Nonetheless, this would affect the extensiveness of disclosure, rather than the observed differences in the management of CSR disclosure between the four types of companies. Hence, the empirical validity of the typology will not be affected.

For the more explanatory part, the limitations are as follows. First, the results are only applicable to large companies. E.g., the relationship between company and stakeholders with regard to CSR disclosure of smaller companies may follow different patterns. Second, although causation can never be empirically demonstrated, making causal inferences in cross-sectional research designs is particularly difficult. Nevertheless, the observed regularities and correlations in the two quantitative studies correspond to the theoretical relations from prior research. Third, both explanatory studies use measures that have not been used before, i.e. salesadjusted GHG emission figures (study 2) and measures of actual stakeholder power and urgency (study 3). Although the construction of the measures has been done with utmost care, more research will be beneficial in order to verify the appropriateness. 
Finally, given that CSR disclosure is a topic that is still developing and will go on developing, certain outcomes of comparable future studies may deviate from the results presented in this dissertation. However, though each of the variables of interest in this study may develop over time, this does not imply that the established relations between the variables in this dissertation also automatically change.

\subsection{Suggestions for future research}

Future studies may consider researching both the topic of internal organisational factors and stakeholder influence determining CSR reporting using a longitudinal research design. Knowledge of the various stages a company goes through in the course of time will be a valuable addition to the results presented in this dissertation. It will also be interesting to look at the same factors (i.e., internal management and external influence) in relation to lower quality reporting, as well as similar research settings in other countries, or based on samples in which SMEs are also included.

Future research may also take into account the mandatory and voluntary disclosures per country in order to come to a more sophisticated voluntary disclosure measure.

Finally, future research may also focus more on disclosure content, in that empirical studies do not only use the extensiveness of disclosure as the dependent variable, yet also study how the information items included are disclosed. Particularly, in the context of the second study it will be interesting to see how the two performance dimensions are disclosed. A potential interesting research question in this context would be the extent to which outcome measures are only disclosed in positive terms (e.g., only focusing on the improvements)? 


\section{References}

Adams, C. (2002). Internal organisational factors influencing corporate social and ethical reporting; beyond current theorising. Accounting, Auditing \& Accountability Journal, 15(2), 223-250.

Adams, C. A., \& Frost, G. R. (2008). Integrating sustainability reporting into management practices. Accounting Forum, 32(4), 288-302.

Aerts, W., \& Cormier, D. (2009). Media legitimacy and corporate environmental communication. Accounting, Organizations \& Society, 34(1), 1-27.

Agle, B. R., Mitchell, R. K., \& Sonnenfeld, J. A. (1999). Who matters to CEOs? An investigation of stakeholder attributes and salience, corporate performance, and CEO values. Academy of Management Journal, 42(5), 507-525.

Aguilera, R. V., Williams, C. A., Conley, J. M., \& Rupp, D. E. (2006). Corporate governance and social responsibility: a comparative analysis of the UK and the US. Corporate Governance: An International Review, 14(3), 147-158.

Al-Tuwaijri, S. A., Christensen, T., \& Hughes, K. E. (2004). The relationship among environmental disclosure, environmental performance, and economic performance: a simultaneous equations approach. Accounting, Organizations \& Society, 29(5/6), 447-471.

Albelda-Pérez, E., Correa-Ruiz, C., \& Carrasco-Fenech, F. C. (2007). Environmental management systems as an embedding mechanism: a research note. Accounting, Auditing \& Accountability Journal, 20(3), 403-422.

Allen, F. (2005). Corporate Governance in emerging economies. Oxford Review of Economic Policy, 21(2), 164-177.

Azzone, G., Nocci, G., Manzini, R., \& Welford, R. (1996). Defining environmental performance indicators: an integrated framework. Business Strategy and the Environment, 5(2), 69-80.

Babbie, E. R. (2008). The basics of social research. Belmont, CA: Thomson Learning.

Bansal, P., \& Roth, K. (2000). Why companies go green: a model of ecological responsiveness. Academy of Management Journal, 43(4), 717-736

Baron, R. M., \& Kenny, D. A. (1986). The moderator-mediator variable distinction in social psychological research: conceptual, strategic, and statistical considerations. Journal of Personality and Social Psychology, 51(6), 1173-1182.

Belkaoui, A., \& Karpik, P. G. (1989). Determinants of the corporate decision to disclose social information. Accounting, Auditing \& Accountability Journal, 2(1), 36-51.

Bewley, K., \& Li, Y. (2000). Disclosure of environmental information by Canadian manufacturing companies: a voluntary disclosure perspective. In M. Freedman \& B. Jaggi (Eds.), Advances in Environmental Accounting \& Management (Vol. 1, pp. 201-226). Amsterdam: JAI Press.

Blacconiere, W. G., \& Patten, D. (1994). Environmental disclosures, regulatory costs, and changes in firm value. Journal of Accounting \& Economics, 18(3), 357-377.

Boesso, G., \& Kumar, K. (2007). Drivers of corporate voluntary disclosure; a framework and empirical evidence from Italy and the United States. Accounting, Auditing \& Accountability Journal, 20(2), 269296.

Boesso, G., \& Kumar, K. (2009). Stakeholder prioritization and reporting: Evidence from Italy and the US. Accounting Forum, 33, 162-175.

Bollen, L. H., Hassink, H. F., Lange, R. K., \& Buijl, S. D. (2008). Best practices in managing investor relations websites: directions for future research. Journal of Information Systems, 22(2), 171-194. 
Bowman, E. H. (1973). Corporate social responsibility and the investor. Journal of Contemporary Business, Winter, 21-43.

Bowman, E. H., \& Haire, M. (1975). A strategic posture towards corporate social responsibility. California Management Review, Winter, 49-58.

Brammer, S., \& Millington, A. (2004). The development of corporate charitable contributions in the UK: a stakeholder analysis. Journal of Management Studies, 41(8), 1411-1434.

Brammer, S., \& Pavelin, S. (2004). Voluntary social disclosures by large UK companies. Business Ethics: $A$ European Review, 13(2/3), 86-99.

Brammer, S., \& Pavelin, S. (2006). Voluntary environmental disclosures by large UK companies. Journal of Business Finance \& Accounting, 33(7), 1168-1188.

Buchholtz, A. K., \& Carroll, A. B. (2008). Business and Society. Mason: South Western/Cengage.

Buhr, N., \& Freedman, M. (2001). Culture, institutional factors and differences in environmental disclosure between Canada and the United States. Critical Perspectives on Accounting, 12(3), 293-322.

Buysse, K., \& Verbeke, A. (2002). Proactive environmental strategies: a stakeholder management perspective. Strategic Management Journal, 24(5), 453-470.

Campbell, D. J. (2000). Legitimacy theory or managerial reality construction? Corporate social disclosure in Marks and Spencer Plc corporate reports, 1969-1997. . Accounting Forum, 24(1), 80-100.

Carroll, A. B. (1979). A Three-Dimensional Conceptual Model of Corporate Performance. Academy of Management Review, 4(4), 497-505.

Cho, C. H. (2009). Legitimation strategies used in response to environmental disaster: A French case study of Total SA's Erika and AZF Incidents. European Accounting Review, 18(1), 33-62.

Cho, C. H., Freedman, M., \& Patten, D. M. (2009). Corporate disclosure of environmental capital expenditures: a test of alternative theories: Working Paper, John Molson School of Business, Concordia University.

Cho, C. H., \& Patten, D. M. (2007). The role of environmental disclosures as tools of legitimacy: A research note. Accounting, Organizations \& Society, 32(7-8), 639-647.

Clarkson, M. B. E. (1995). A stakeholder framework for analyzing and evaluating corporate social performance. Academy of Management Review, 20(1), 92-117.

Clarkson, P. M., Fang, X. H., Li, Y., \& Richardson, G. (2010). The relevance of environmental disclosures for investors and other stakeholder groups: which audience are firms speaking to? Toronto: Working paper Joseph Rotman School of Management, University of Toronto.

Clarkson, P. M., Li, Y., Richardson, G. M., \& Vasvari, F. P. (2008). Revisiting the relation between environmental performance and environmental disclosure: An empirical analysis. Accounting, Organizations \& Society, 33(4/5), 303-327.

Collier, J., \& Esteban, R. (2007). Corporate social responsibility and employee commitment. Business Ethics: A European Review, 16(1), 19-33.

Collier, P. M. (2008). Stakeholder accountability; a field study of the implementation of a governance improvement plan. Accounting, Auditing \& Accountability Journal, 21(7), 933-954.

Cooper, S. M., \& Owen, D. L. (2007). Corporate social reporting and stakeholder accountability: the missing link. Accounting, Organizations \& Society, 32(7-8), 649-667.

Cooper, W. H., \& Richardson, A. J. (1986). Unfair comparison. Journal of Applied Psychology, 71(2), 179184.

Cormier, D., Gordon, I. M., \& Magnan, M. (2004). Corporate environmental disclosure: contrasting management's perceptions with reality. Journal of Business Ethics, 49(2), 143-165.

Cormier, D., \& Magnan, M. (1999). Corporate environmental disclosure strategies: determinants, costs and benefits. Journal of Accounting, Auditing \& Finance, 14(4), 429-451.

Cormier, D., Magnan, M., \& Velthoven, B. v. (2005). Environmental disclosure quality in large German companies: economic incentives, public pressures or institutional conditions? European Accounting Review, 14(1), 3-39. 
Cowen, S. S., Ferreri, L. B., \& Parker, L. D. (1987). The impact of corporate characteristics on social responsibility disclosure: A typology and frequency-based analysis. Accounting, Organizations \& Society, 12(2), 111-122.

Cox, P., Brammer, S., \& Millington, A. (2008). Pension funds and Corporate Social Performance: an empirical analysis. Business \& Society, 47(2), 213-241.

Darnall, N., Seol, I., \& Sarkis, J. (2009). Perceived stakeholder influences and organizations' use of environmental audits. Accounting, Organizations \& Society, 34(2), 170-187.

Deegan, C. (2002). The legitimising effect of social and environmental disclosures - a theoretical foundation. Accounting, Auditing \& Accountability Journal, 15(3), 282-311.

Deegan, C., \& Blomquist, C. (2006). Stakeholder influence on corporate reporting: an exploration of the interaction between WWF-Australia and the Australian minerals industry. Accounting, Organizations and Society, 31(4/5), 343-372.

Deegan, C., \& Gordon, B. (1996). A study of the environmental disclosure practices of Australian corporations. Accounting and Business Research, 26(3), 187-199.

Deegan, C., \& Rankin, M. (1996). Do Australian companies report environmental news objectively?: an analysis of environmental disclosures by firms prosecuted successfully by the Environmental Protection Authority. Accounting, Auditing \& Accountability Journal, 24(1), 101-130.

Deephouse, D. L., \& Carter, S. M. (2005). An Examination of Differences Between Organizational Legitimacy and Organizational Reputation. Journal of Management Studies, 42(2), 329-360.

Dees, J. G. (1998). ). The meaning of "social entrepreneurship". Stanford University: Draft Report for the Kauffman Center for Entrepreneurial Leadership, 6p.

Delfgaauw, T. (2000). Reporting on sustainable development: a preparer's view. Auditing: A Journal of Practice \& Theory, 19(1), 67-74.

Delmas, M., \& Blass, V. D. (2010). Measuring corporate environmental performance: the trade-offs of sustainability ratings. Business Strategy and the Environment, 19(4), 245-260.

Delmas, M., \& Toffel, M. W. (2004). Stakeholders and environmental management practices: an institutional framework. Business Strategy and the Environment, 13(4), 209-222.

Delmas, M. A. (2002). The diffusion of environmental management standards in Europe and in the United States: an institutional perspective. Policy Sciences, 35(1), 91-119.

Donaldson, T., \& Preston, L. E. (1995). The stakeholder theory of the corporation: concepts, evidence and implications. Academy of Management Review, 20(1), 65-91.

Driscoll, C., \& Crombie, A. (2001). Stakeholder legitimacy management and the qualified good neighbor: the case of Nova Nada and JDI. Business \& Society, 40(4), 442-471.

Driscoll, C., \& Starik, M. (2004). The primordial stakeholder: advancing the conceptual consideration of stakeholder status for the natural environment. Journal of Business Ethics, 49(1), 55-73.

Dye, R. A. (1985). Disclosure of non-proprietary information. Journal of Accounting Research, 23(1), 123145.

Eesley, C., \& Lenox, M. J. (2006). Firm responses to secondary stakeholder action. Strategic Management Journal, 27(8), 765-781.

Eisenhardt, K. (1989). Building theories from case research. Academy of Management Review, 14(4), 532-550.

Elkington, J. (2006). Governance for sustainability. Corporate Governance: An International Review, 14(6), 522-529.

Elsayed, K. (2006). Reexamining the expected effect of available resources and firm size on firm environmental orientation: an empirical study of UK firms. Journal of Business Ethics, 65, 297-308.

Eurosif (2008). European SRI study. Paris: Eurosif.

Fekrat, M. A., Inclan, C., \& Petroni, D. (1996). Corporate environmental disclosures: Competitive disclosure hypothesis using 1991 annual report data. The International Journal of Accounting, 31(2), 175195.

Fineman, S., \& Clarke, K. (1996). Green stakeholders: industry interpretations and response. Journal of Management Studies, 33(6), 715-730. 
Freedman, M., \& Wasley, C. (1990). The association between environmental performance and environmental disclosure in annual reports and 10Ks. Advances in Public Interest Accounting, 3, 183-193.

Freeman, R. E. (1984). Strategic management: a stakeholder approach. Boston: Pitman.

Friedman, A. L., \& Miles, S. (2001). Socially responsible investment and corporate social and environmental reporting in the UK: an exploratory study. British Accounting Review, 33(4), 325-548.

Gago, R. F., \& Antolin, M. N. (2004). Stakeholder salience in corporate environmental strategy. Corporate Governance, 4(3), 65-76.

Galliers, R. D., \& Sutherland, A. R. (1991). Information systems management and strategy formulation: the 'stages of growth' model revisited. Information Systems Journal, 1(2), 89-114.

González-Benito, J., \& González-Benito, Ó. (2006). A review of determinant factors of environmental proactivity. Business Strategy and the Environment, 15(2), 87-102.

Gouldson, A., \& Sullivan, R. (2007). Corporate environmentalism: tracing the links between policies and performance using corporate reports and public registers. Business Strategy and the Environment, 16, 1-11.

Graafland, J., Ven, B. v. d., \& Stoffele, N. (2003). Strategies and instruments for organising CSR by small and large businesses in the Netherlands. Journal of Business Ethics, 47(1), 45-60.

Graves, S. B., \& Waddock, S. A. (1994). Institutional owners and Corporate Social Performance. Academy of Management Journal, 37(4), 1034-1046.

Gray, R., Javad, M., Power, D. M., \& Sinclair, C. D. (2001). Social and environmental disclosure and corporate characteristics: a research note and extension. Journal of Business Finance \& Accounting, 28(3/4), 327-356.

Gray, R., Kouhy, R., \& Lavers, S. (1995). Corporate social and environmental reporting: A review of the literature and a longitudinal study of UK disclosure. Accounting, Auditing \& Accountability Journal, $8(2), 47-77$.

Gray, R., Owen, D., \& Adams, C. (1996). Accounting \& accountability: changes and challenges in corporate social and environmental reporting. Hemel Hempstead: Prentice Hall.

GRI (2006). Sustainability Reporting Guidelines. Amsterdam: Global Reporting Initiative.

GRI (2009). Reporting framework overview; development process Retrieved November 19th, 2009, from http://www.globalreporting.org/ReportingFramework/ReportingFrameworkOverview/Development Process/

Grunig, J. E. (1983). Communication behaviors and attitudes of environmental publics: Two studies. Journalism Monographs, 81, 1-47.

Guthrie, J., \& Parker, L. D. (1989). Corporate social reporting: a rebuttal of legitimacy theory. Accounting and Business Research, 19(76), 343-352.

Hackston, D., \& Milne, M. D. (1996). Some determinants of social and environmental disclosures in New Zealand companies. Accounting, Auditing and Accountability Journal 9(1), 77-108.

Halme, M., \& Huse, M. (1997). The influence of corporate governance, industry and country factors on environmental reporting. Scandinavian Journal of Management 13(2), 137-157.

Hammond, K., \& Miles, S. (2004). Assessing quality assessments of corporate social reporting: UK perspectives. Accounting Forum, 28(1), 61-79.

Hart, S. L., \& Milstein, M. B. (2003). Creating sustainable value. Academy of Management Executive, $17(2), 56-69$.

Harvey, B., \& Schaefer, A. (2001). Managing stakeholder relations with environmental stakeholders: a study of U.K. water and electricity utilities. Journal of Business Ethics, 30(3), 243-260.

Hasnas, J. (1998). The normative theories of business ethics: a guide for the perplexed. Business Ethics Quarterly, 8(1), 19-42.

Healy, P. M., \& Palepu, K. G. (2001) Information asymmetry, corporate disclosure, and the capital markets: A review of the empirical disclosure literature. Journal of Accounting and Economics, 31 (1-3), 405-440. 
Heath, J., \& Norman, W. (2004). Stakeholder theory, corporate governance and public management: what can the history of state-run enterprises teach us in the post-Enron era? Journal of Business Ethics, 53(3), 247-265.

Hemingway, C. A., \& Maclagan, P. W. (2004). Managers' personal values as drivers of corporate social responsibility. Journal of Business Ethics, 50(1), 33-44.

Henriques, I., \& Sadorsky, P. (1999). The relationship between environmental commitment and managerial perception of stakeholder importance. Academy of Management Journal, 42(1), 87-99.

Hertzberg, A., Liberti, J. M., \& Paravisini, D. (2010). Information and incentives inside the firm: evidence from loan officer rotation. The Journal of Finance, 65(3), 795-828.

Hibbitt, C. (2004). External environmental disclosure and reporting by large European companies. An economic, social and political analysis of managerial behaviour., Limperg Instituut, Amsterdam.

Hofstede, G., Deusen, C. A. v., Mueller, C. B., \& Charles, T. A. (2002). What goals do business leaders pursue? A study in fifteen countries. Journal of International Business Studies, 33(4), 785-803.

Hoi, C., \& Robin, A. (2010). Agency conflicts, controlling owner proximity, and firm value: an analysis of dual-class firms in the United States. Corporate Governance: An International Review, 18(2), 124135.

Holder-Webb, L., Cohen, J. R., Nath, L., \& Wood, D. (2008). The supply of corporate social responsibility disclosures among U.S. firms. Journal of Business Ethics, 84(4), 497-527.

Holm, C., \& Rikhardsson, P. (2008). Experienced and novice investors: does environmental information influence investment allocation decisions? European Accounting Review, 17(3), 537-557.

Hopwood, A. (2009). Accounting and the environment. Accounting, Organizations \& Society, 34(3/4), 433-439.

Hughes, S. B., Anderson, A., \& Golden, S. (2001). Corporate environmental disclosures: are they useful in determining environmental performance? Journal of Accounting and Public Policy, 20(3), 217-240

Hughes, S. B., Sander, J. F., \& Reier, J. C. (2000). Do environmental disclosures in U.S. annual reports differ by environmental performance? In M. Freedman \& B. Jaggi (Eds.), Advances in Environmental Accounting \& Management (Vol. 1, pp. 141-161). Amsterdam: JAI Press.

Husted, B. W. (2000). A contingency theory of corporate social performance. Business \& Society, 39(1), 24-48.

Ilinitch, A. Y., Soderstrom, N. S., \& Thomas, T. E. (1998). Measuring corporate environmental performance. Journal of Accounting and Public Policy, 17, 383-408.

Ingram, R. W., \& Frazier, K. B. (1980). Environmental performance and corporate disclosure. Journal of Accounting Research, 18(2), 614-622.

Jamali, D., Safieddine, A. M., \& Rabbath, M. (2008). Corporate Governance and Corporate Social Responsibility synergies and interrelationships. Corporate Governance: An International Review, 16(5), $443-$ 459.

Johnson, R. A., \& Greening, D. W. (1999). The effects of corporate governance and institutional ownership types on corporate social performance. Academy of Management Journal, 42(5), 564-576.

Jones, T. M., Felps, W., \& Bigley, G. A. (2007). Ethical theory and stakeholder-related decisions: the role of stakeholder culture. Academy of Management Review, 32(1), 137-155.

Jones, T. M., \& Goldberg, L. D. (1982). Governing the large corporation: more arguments for public directors. Academy of Management Review, 7(4), 603-611.

Judge, W. (2009). Editorial - Toward a global theory of corporate governance. Corporate Governance: An International Review, 17(2).

Kacperczyk, A. (2009). With greater power comes greater responsibility? Takeover protection and corporate attention to stakeholders. Strategic Management Journal, 30, 261-285.

King, A., \& Lenox, M. (2001). Does it really pay to be green? An empirical study of firm environmental and financial performance. Journal of Industrial Ecology, 5(1), 105-116.

Knox, S., Maklan, S., \& French, P. (2005). Corporate social responsibility: exploring stakeholder relationships and programme reporting across leading FTSE companies. Journal of Business Ethics, 61(1), 728. 
Kolk, A. (2003). Trends in sustainability reporting by the Fortune Global 250. Business Strategy and the Environment, 12(5), 279-291.

Kolk, A., Walhain, S., \& Wateringen, S. v. d. (2001). Environmental reporting by the Fortune Global 250: exploring the influence of nationality and sector. Business Strategy and the Environment, 10(1), 1528.

KPMG (2008). KPMG international survey of corporate responsibility reporting 2008. Amstelveen: KPMG Global Sustainability Services.

KPMG/UNEP (2006). Carrots and sticks for starters; current trends and approaches in voluntary and mandatory standards for sustainability reporting. Parktown, South-Africa: KPMG Global Sustainability Services \& UNEP.

Levy, M., Powell, P., \& Yetton, P. (2002). The dynamics of SME information systems. Small Business Economics, 19, 341-354.

Li, Y., Richardson, G. D., \& Thornton, D. B. (1997). Corporate disclosure of environmental liability information: theory and evidence. Contemporary Accounting Research, 14(3), 435-474.

Lin, C. Y.-Y. (2002). Empowerment in the service industry: an empirical study in Taiwan. The Journal of Psychology, 136(5), 555-560.

Lindblom, C. K. (1994). The implications of organizational legitimacy for corporate social performance and disclosure. Paper presented at the Critical Perspectives on Accounting Conference, New York, NY.

Lorange, P., Morton, M. F. S., \& Ghoshals, S. (1986). Strategic control systems. St Paul, MN: West.

Magness, V. (2006). Strategic posture, financial performance and environmental disclosure: An empirical test of legitimacy theory. Accounting, Auditing \& Accountability Journal, 19(4), 540-563.

Mattingly, J. E., \& Berman, S. L. (2006). Measurement of corporate social action: discovering taxonomy in Kinder Lydenberg Domini ratings data. Business \& Society, 45(1), 20-46.

Meek, G. K., Roberts, C. B., \& Gray, S. J. (1995). Factors influencing voluntary annual report disclosures by U.S., U.K. and Continental European multinational corporations. Journal of International Business Studies, 26(3), 555-572.

Mehta, S. C., \& Tambe, H. (1997). Relationship concept and customer services: a case study of corporate banking. Journal of retailing and Consumer Services, 4(2), 129-134.

Miles, M. B., \& Huberman, A. M. (1994). Qualitative data analysis: an expanded sourcebook. Thousand Oaks, CA: Sage Publications.

Miles, S., Hammond, K., \& Friedman, A. L. (2002). Social and environmental reporting and ethical investment. London: ACCA Research report No. 77, Certified Accountants Educational Trust.

Mintzberg, H. (1979). An emerging strategy of "direct" research. Administrative Science Quarterly, 24(4), 582-589.

Mitchell, R. K., \& Agle, B. R. (1997). Stakeholder identification and salience: Dialogue and operationalization. In J. Weber \& K. Rehbein (Eds.), International association for business and society 1997 proceedings (pp. 365-370). Destin, Florida.

Mitchell, R. K., Agle, B. R., \& Wood, D. J. (1997). Towards a theory of stakeholder identification and salience: defining the principle of who and what really counts. Academy of Management Review, 22(4), 853-886.

Mitnick, B. (2000). Commitment, revelation, and the testaments of belief: the metrics of measurement of corporate social performance. Business \& Society, 39(4), 419-465.

Murillo-Luna, J. L., Garcés-Ayerbe, C., \& Rivera-Torres, P. (2008). Why do patterns of environmental response differ? A stakeholders' pressure approach. Strategic Management Journal, 29(11), 12251240.

Neill, J. D., \& Stovall, S. O. (2005). Stakeholder salience and corporate social responsibility: evidence from three companies. Journal of Applied Business Research, 21(3), 71-78.

Neu, D., Warsame, H., \& Pedwell, K. (1998). Managing public impressions: environmental disclosures in annual reports. Accounting, Organizations and Society, 23(3), 265-282. 
Neville, B. A., Bell, S. J., \& Whitwell, G. (2004). Stakeholder salience revisited: toward an actionable tool for the management of stakeholders. Paper presented at the Paper presented at the Academy of Management Conference, New Orleans.

Neville, B. A., \& Menguc, B. (2006). Stakeholder multiplicity: toward an understanding of the interactions between stakeholders. Journal of Business Ethics, 66(4), 377-391.

Nicholls, A. (2009). 'We do good things, don't we?': 'Blended Value Accounting' in social entrepreneurship. Accounting, Organizations \& Society, 34(6-7), 755-769.

Nimwegen, G. v., Bollen, L., Hassink, H., \& Thijssens, T. (2008). A stakeholder perspective on mission statements: an international empirical study. International Journal of Organizational Analysis, 16(1/2), 61-82.

Nunnally, J. (1978). Psychometrics. New York: McGraw-Hill.

O'Dwyer, B. (2003). Conceptions of corporate social responsibility: the nature of managerial capture. Accounting, Auditing \& Accountability Journal, 16(4), 523-557.

O’Dwyer, B., Unerman, J., \& Bradley, J. (2005a). Perceptions on the emergence and future development of corporate social disclosure in Ireland. Accounting, Auditing \& Accountability Journal, 18(1), 14-43.

O’Dwyer, B., Unerman, J., \& Hession, E. (2005b). User needs in sustainability reporting: perspectives of stakeholders in Ireland. European Accounting Review, 14(4), 759-787.

Owen, D. L., Swift, T. A., Humphrey, C., \& Bowerman, M. (2000). The new social audits: accountability, managerial capture or the agenda of social champions? European Accounting Review, 9(1), 81-98.

Parent, M. M., \& Deephouse, D. L. (2007). A case study of stakeholder identification and prioritization by managers. Journal of Business Ethics, 75(1), 1-23.

Parker, L. (2007). Financial and external reporting research: the broadening corporate governance challenge. Accounting and Business Research, 37(1), 39-54.

Pascale, R., \& Athos, A. (1981). The art of Japanese management. London: Penguin Books.

Patten, D. M. (1991). Exposure, legitimacy, and social disclosure. Journal of Accounting and Public Policy, 10(4), 297-308.

Patten, D. M. (1992). Intra-industry environmental disclosures in response to the Alaskan oil spill: A note on legitimacy theory. Accounting, Organizations \& Society, 17(5), 471-475.

Patten, D. M. (2002). The relation between environmental performance and environmental disclosure: a research note. Accounting, Organizations \& Society, 27(8), 763-773.

Pfeffer, J. (1981). Power in organizations. Marshfield, MA: Pitman.

Pfeffer, J., \& Salancik, G. R. (1978). The external control of organizations: a resource dependence perspective. New York: Harper \& Row.

Poel, K. van de, \& Vanstraelen, A. (2011). Management reporting on internal control and accruals quality: insights from a "comply-or-explain" internal control regime. Auditing: A Journal of Practice \& Theory, 30(3), $181-209$.

Polonsky, M., Zeffane, R., \& Medley, P. (1992). Corporate environmental commitment in Australia: A sectorial comparison. Business Strategy and the Environment, 1(2), 25-39.

Prior, D., Surroca, J., \& Tribó, J. A. (2008). Are socially responsible managers really ethical? Exploring the relationship between earnings management and corporate social responsibility. Corporate Governance: An International Review, 16(3), 160-177.

PWC (2007). Transparantiebenchmark 2007. Amsterdam: Pricewaterhouse Coopers/Dutch Ministry of Economic Affairs.

Quaak, L., Aalbers, T., \& Goedee, J. (2007). Transparency of corporate social responsibility in Dutch breweries. Journal of Business Ethics, 76(3), 293-308.

Quazi, A. M. (2003). Identifying the determinants of corporate managers' perceived social obligations. Management Decision, 41(9), 822-831.

Reid, E. M., \& Toffel, M. W. (2009). Responding to public and private politics: corporate disclosure of climate change strategies. Strategic Management Journal, 30, 1157-1178.

Roberts, R. W. (1992). Determinants of corporate social responsibility disclosure: an application of stakeholder theory. Accounting, Organizations and Society, 17(6), 595-612. 
Rowley, T. J. (1997). Moving beyond dyadic ties: a network theory of stakeholder influences. Academy of Management Review, 22(4), 887-910.

Roy, M.-J., Boiral, O., \& Lagacé, D. (2001). Environmental commitment and manufacturing excellence: a comparative study within Canadian industry. Business Strategy and the Environment, 10, 257-268.

Ryan, L. V., \& Schneider, M. (2003). Institutional investor power and heterogeneity. Business \& Society, 42(4), 398-429.

SAI (2008). Social Accountability 8000. New York: Social Accountability International.

Schaltegger, S. (1997). Information costs, quality of information and stakeholder involvement - the necessity of international standards of ecological accounting. Eco-Management and Auditing, 4, 87-97.

Semenova, N., \& Hassel, L. G. (2008). Financial outcomes of environmental risk and opportunity for US companies. Sustainable Development, 16, 195-212.

Simnett, R., Vanstraelen, A., \& Chua, W. F. (2009). Assurance on sustainability reports: an international comparison. The Accounting Review, 84(3), 937-967.

Slinger, G., \& Deakin, S. (1999). Company law as an instrument of inclusion: re-regulating stakeholder relations in the context of takeovers. . Cambridge: ESRC Centre for Business Research, University of Cambridge, Working Paper No. 145.

Smith, J., Adhikari, A., \& Tondkar, R. H. (2005). Exploring differences in social disclosures internationally: A stakeholder perspective. Journal of Accounting \& Public Policy, 24(2), 123-151.

Solomon, J. (2007). Corporate Governance and Accountability. Chichester: John Wiley and Sons.

Sparkes, R., \& Cowton, C. J. (2004). The maturing of socially responsible investment: a review of the developing link with corporate social responsibility. Journal of Business Ethics, 52(1), 45-57.

Staden, C. J. v., \& Hooks, J. (2007). A comprehensive comparison of corporate environmental reporting and responsiveness. The British Accounting Review, 39, 197-210.

Stanwick, S. D., \& Stanwick, P. A. (2000). The relationship between environmental disclosures and financial performance: an empirical study of US firms. Eco-Management and Auditing, 7, 155-164.

Stoney, C., \& Winstanley, D. (2001). Stakeholding: confusion or utopia? Mapping the conceptual terrain. Journal of Management Studies, 38(5), 603-626.

Suchman, M. C. (1995). Managing legitimacy: strategic and institutional approaches. Academy of Management Review, 20(3), 571-610.

Sullivan, R., \& Gouldson, A. (2007). Pollutant release and transfer register: examining the value of government-led reporting on corporate environmental performance. Corporate Social Responsibility and Environmental Management, 14, 5.

Surroca, J., Tribó, J. A., \& Waddock, S. (2010). Corporate responsibility and financial performance: the role of intangible resources. Strategic Management Journal, 31(5), 463-490.

Thijssens, T., Bollen, L., \& Hassink, H. (2010). Secondary stakeholder influence on corporate social responsibility disclosure: an empirical test of stakeholder salience theory. Working Paper, School of Business and Economics/MARC, Maastricht University.

Tilt, C. A. (1994). The influence of external pressure groups on corporate social disclosure; some empirical evidence. Accounting, Auditing \& Accountability Journal, 7(4), 47-72.

Ullmann, A. A. (1985). Data in search of a theory: a critical examination of the relationships among social performance, social disclosure, and economic performance of U.S. firms. Academy of Management Review, 10(3), 540-557.

UNCTAD (2006). Guidance on good practices in corporate governance disclosure. Geneva: United Nations. US SIF (2010). 2020 Report on Socially Responsible Investing Trends. Washington DC: US SIF.

Verrecchia, R. (1983). Discretionary disclosure. Journal of Accounting \& Economics, 5(3), 179-194.

Walden, W. D., \& Schwartz, B. N. (1997). Environmental disclosures and public policy pressure. Journal of Accounting and Public Policy, 16(2), 125-154.

Waterman, R. H., Peters, T. J., \& Philips, J. R. (1980). Structure is not organization. Business Horizons, 23(3), 14-26. 
Weaver, G. R., Trevino, L. K., \& Cochran, P. L. (1999). Integrated and decoupled corporate social performance: management commitments, external pressures and corporate ethics practices. Academy of Management Journal, 42(5), 539-552.

Wheeler, D., \& Elkington, J. (2001). The end of the corporate environmental report? Or the advent of cybernetic sustainability reporting and communication. Business Strategy and the Environment, 10(1), 1-14.

Wiseman, J. (1982). An evaluation of environmental disclosures made in corporate annual reports. Accounting, Organizations \& Society, 7(1), 553-563.

Wood, D. J. (1991). Corporate social performance revisited. Academy of Management Review, 16(4), 691-718.

Wood, D. J. (2010). Measuring Corporate Social Performance: a review. International Journal of Management Reviews, 12(1), 50-84.

Xie, S., \& Hayase, K. (2007). Corporate environmental performance evaluation: a measurement model and a new concept. Business Strategy and the Environment, 16, 148-168.

Yin, R. K. (1994). Case study research: design and methods. Thousand Oaks, CA: Sage Publications. 



\title{
Appendix A
}

\section{Items included in the SiRi company profiles and the environmental disclosure index}

\author{
CATEGORY 1: PRINCIPLES AND POLICIES
}

The company has a formal environmental policy statement

\section{CATEGORY 2: MANAGEMENT SYSTEMS}

The company has Board/Management level responsibility for environmental issues

The company has an environmental department

The company has an environmental management system

The company monitors its environmental impact

The company sets quantitative environmental performance targets

The company conducts internal audits

The company conducts third-party audits

The company conducts environmental training of employees

The company has formal mechanisms for engagement with environmental stakeholders

The company has criteria for the selection of suppliers that include environmental policies or EMS

The company has environmental criteria for the procurement of products/raw materials

The company has programs to take into account environmental impact of products at the R\&D stage

The company has programs to reduce the impact of products at the end of the life-cycle

The company has programs to reduce water consumption

The company has programs to reduce material consumption

The company has programs to reduce air emissions

The company has programs to reduce water pollution

The company has programs to reduce the impact of waste

The company has programs to improve energy efficiency

The company has programs to improve environmental performance of logistics and fleet management

\section{CATEGORY 3: PERFORMANCE}

Data on facilities with environmental certification

Major recent fines

Energy consumption

Electricity consumption

Gas consumption

Oil consumption

Renewable energies

Other energy 
APPENDIX A

Water consumption

Discharges to water

GHG (CO2 equivalents) emissions

VOC emissions

ODC (CFC11 equivalents) use

Other air emissions

Industrial waste

Common waste

Products beneficial to the environment or leading to a reduced environmental impact

Accruals for environmental remediation

Recent controversies over waste management

Recent controversies over soil pollution

Recent controversies over water pollution

Recent controversies over air pollution

Recent controversies over resource use or damage to ecosystems

Recent controversies over products and services

Recent controversies over supply chain issues

Other notable issues 


\section{Appendix B}

\section{Coding protocol}

Major recent controversies/ other notable strengths and weaknesses

Under key data (paragraph 4): there is often a category 'major recent controversies'. If there are no controversies mentioned, how is the source coded? There is no information, and consequently no source. However, if there are any controversies, the source can vary. For the time being: in case of no controversies, apply a code 0 . NB: this is different from the NR (not relevant)-category as mentioned later.

The same goes for the 'other notable strength' (paragraph 5) and 'other notable concerns' (paragraph 6) items, which are present in each section. In case there aren't any, code it as 0.

\section{Multiple sources}

In case of multiple sources per item: assess from which source the majority of the information comes from; this is not only dependent on the extent to which a particular source is mentioned most frequent at the item, because it is possible that e.g. a public (1) source is mentioned most often, whereas the majority of information is originating from another source. With this respect it is important to analyse the textual illustration corresponding to the item (whenever an item is labelled 'yes' there should be a corresponding textual illustration).

When assessing the source of the majority of the information on the basis of the textual illustrations is not possible and one of the sources is private contact (4), code it as 5.

When assessing the source of the majority of the information on the basis of the textual illustrations is not possible and none of the sources is private contact (4), code it as 6 .

\section{Private sources}

The private sources (4) will be split up into: Investor Relations (IR) Department/Officer: 401

General Corporate Social Responsibility/Sustainability Department/Officer: 402

Environmental Department/Officer: 403

Corporate Communications or Corporate/Public Relations Department/Officer: 404

CFO: 405

CEO: 406

Company Secretary of the Board: 407

Human Resources Department/Officer: 408

Other Officers/Departments: 409

In case no officers/departments are mentioned:

Internal Company Documents: 410

Response to Questionnaire: 411

In case only a name (without function/department) is mentioned: the person's name and company name in Google might give the required information. 


\section{$N A / N I / N D / N R$}

When there is no information available for a specific item other then the items as mentioned under 1 , this can be due to:

The fact that it has not been investigated (e.g. due to a lack of resources or time); this should be labelled by the analyst as NI (Not Investigated);

The fact that it is not relevant; e.g.: under the reporting/communications section, the items $1 \mathrm{a}, 1 \mathrm{~b}$ and $1 \mathrm{c}$ give information about whether a company publishes certain reports, whereas items $1 \mathrm{~d}$, $1 \mathrm{e}$ and $1 \mathrm{f}$ give information about the content of the mentioned reports; when all items 1a -1c are labelled 'no' (meaning the company doesn't publish any reports) the items $1 \mathrm{~d}-1 \mathrm{f}$ will consequently be 'not relevant' (NR); sometimes this is not labelled as ' $N R$ ', but as '-', or, incidentally, as a blank.

The fact that the company doesn't want to disclose the information; when the information is both relevant and investigated, data might still be lacking due the company's unwillingness to respond to information requests (e.g. questionnaire). In this case the information is Not Disclosed (ND).

The former implies that the profiles should provide in a qualified 'not available' label; just stating that the information is not available (NA) is not allowed. However, due to the fact that these are the first set of profiles of the SiRi Group, it might be the case that some profiles still contain NA.

Use the same labels (NI, NR, ND, NA) in coding the CSR items for the different companies.

Divide ND items into ND and NI. Sometimes the profile gives a ND code for a specific item, and mentions explicitly that the (public) reports do not provide this information. In this case, the item is in fact not fully investigated, and consequently should be rather coded as NI.

\section{No sources}

In case there are no sources mentioned, it can be sometimes distilled from the textual illustration corresponding to the item (whenever an item is labelled 'yes' there should be a corresponding textual illustration) or the nature of the information (see e.g. Heineken profile, employees dimension, item $4 \mathrm{f}$ and $4 \mathrm{~g}$ : source is not mentioned and no textual illustration, however both items are typically information items that can be retrieved from the annual (financial) report. So, that is why it should be coded 1 . When textual illustration and nature of item do not provide a solution, the item will be treated the same as the $\mathrm{NI}$ (not investigated) items.

\section{Overview of possible source codes}

$0=$ in case of no information for the following items:

paragraph 4: major controversies items (often mentioned as "As of <DATE>, <NAME RATING AGENCY> was not aware of any <TYPE OF MAJOR CONTROVERSY>"

paragraph 5

paragraph 6

1 = public source, or majority of the information as mentioned in textual illustration is public sources;

2 = press source, or majority of the information as mentioned in textual illustration is press source;

$3=$ (Non) Governmental-, other Not-For-Profit Organisations or Associations source, or majority of the

information as mentioned in textual illustration is (Non) Governmental-, other Not-For-Profit Organisations or Associations source;

$401-411$ = private source, or majority of the information as mentioned in textual illustration is private source;

$5=$ in case of a mixture of 4 and 1,2, and 3 and assessing the source of the majority of the information on the basis of the textual illustrations is not possible;

$6=$ in case of a mixture of 1,2 and 3 , and assessing the source of the majority of the information on the basis of the textual illustrations is not possible;

$\mathrm{NA}=$ when the profile mentions that information on the item is NA;

$\mathrm{NI}=$ when the profile mentions that information on the item is $\mathrm{NI}$, or in case that: there are neither 
sources mentioned, nor can the sources be distilled from the textual illustration;

$N R=$ when the profile mentions that information on the item is NR (sometimes labelled as ' - ', or, incidentally, as a blank); it should be clear from the context (e.g. textual illustration) why it is NR.

$N D=$ when the profile mentions that information on the item is ND, and from the context (e.g.: textual illustration) it becomes clear that it is not ND on the basis of the (public) reports.

\section{General company information}

Country information--> make use of codes as listed in document country codes.xls.

Countrycomp = country in which company $\mathrm{HQ}$ is located, as mentioned under Address information in profile.

Countryrat = country in which rating agency is located, not necessarily the same as countrycomp.

Sector/industry information--> make use of sector and industry codes as listed in document GICS codes.xls. 



\section{Appendix C}

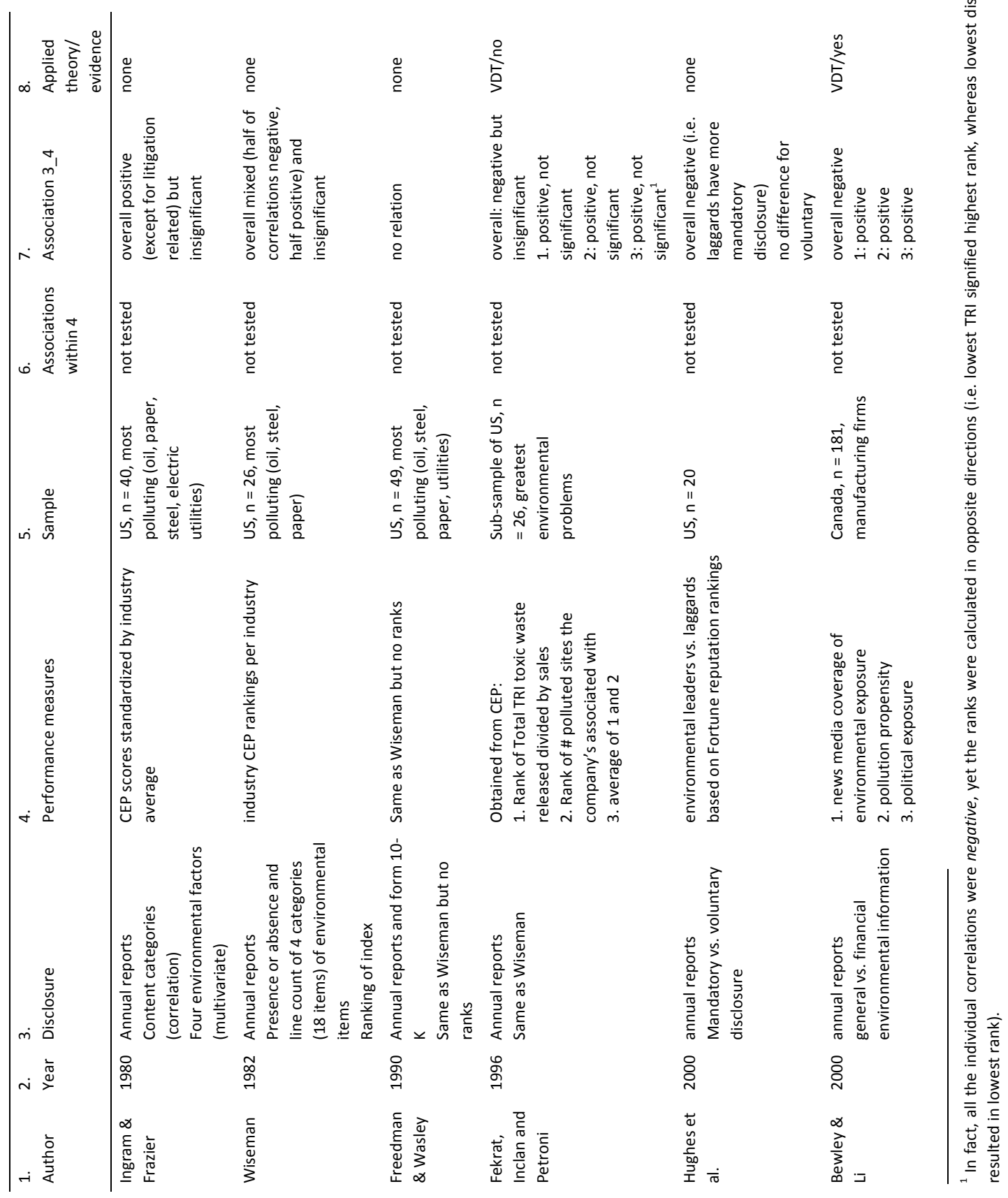




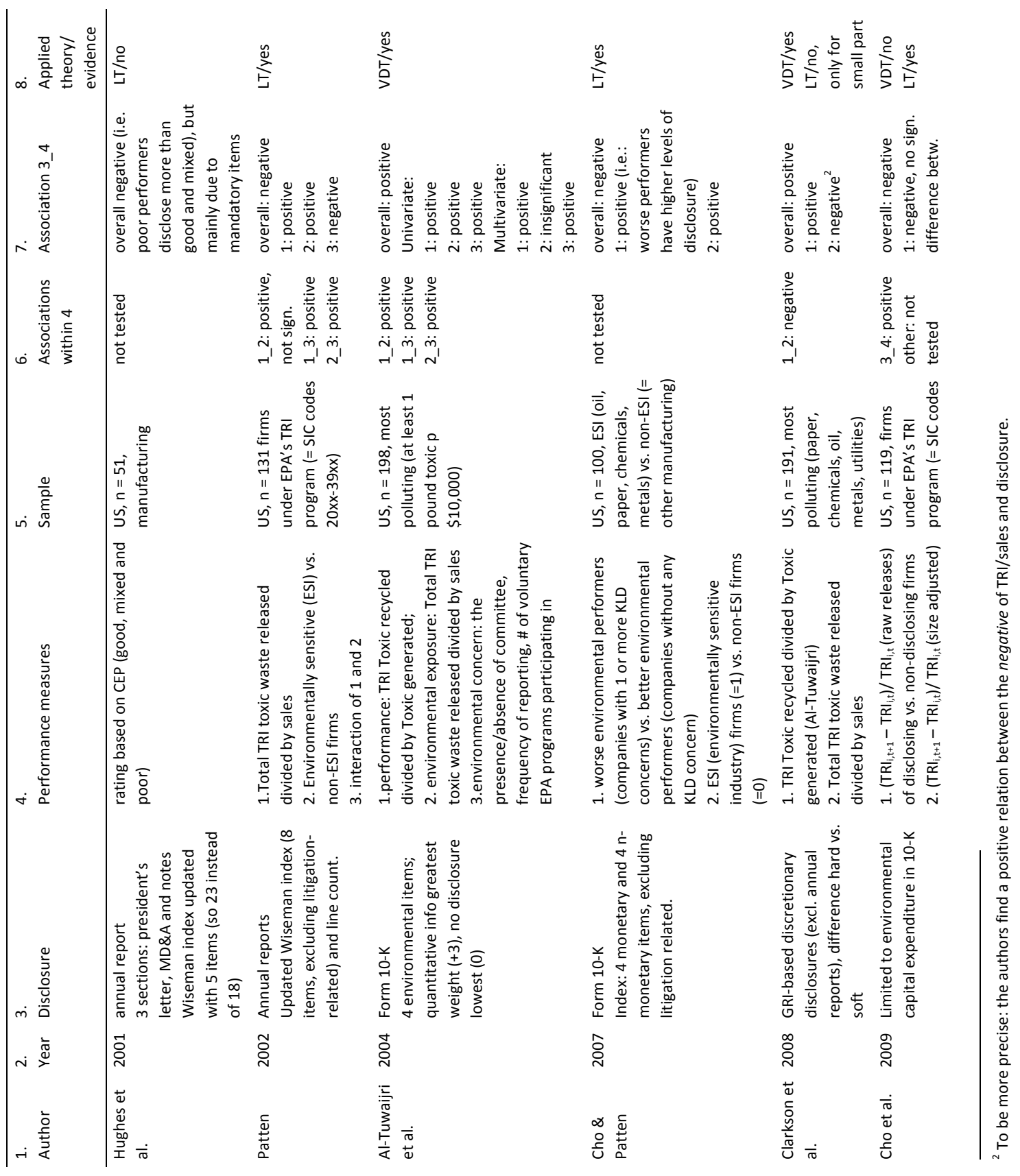




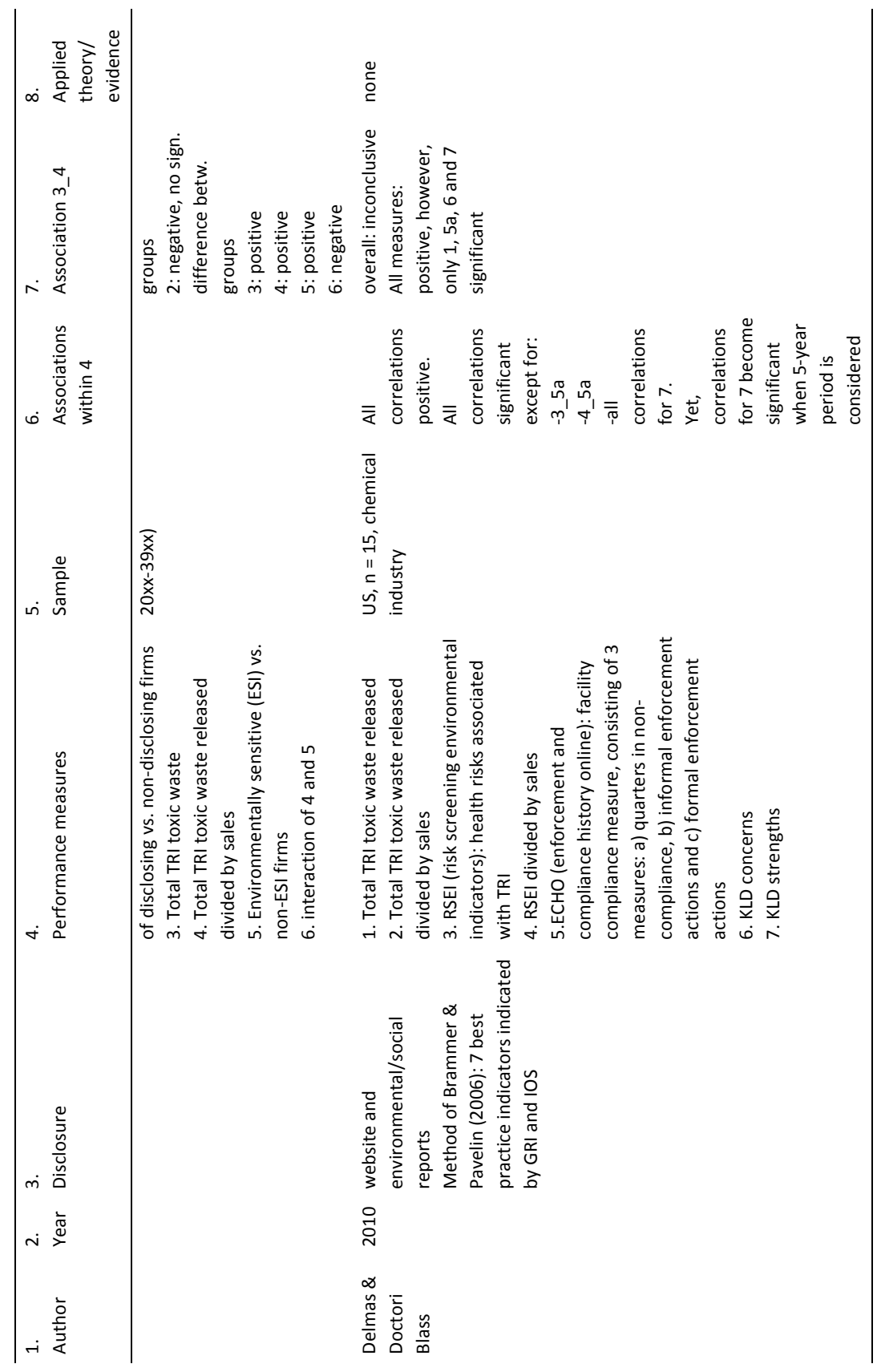





\section{Nederlandse samenvatting}

De uitkomsten van bestaand empirisch onderzoek naar de verslaggeving van ondernemingen over hun Maatschappelijk Verantwoord Ondernemen (MVO) geeft geen eenduidig inzicht in waarom ondernemingen zich met deze grotendeels vrijwillige activiteiten bezighouden. Een antwoord op deze vraag is van belang om in te kunnen schatten of de informatie in dit type verslaggeving bruikbaar is voor beslissingen van de diverse stakeholders ${ }^{57}$. Als MVO verslaggeving niet gemotiveerd is door de behoefte van een onderneming om zich te verantwoorden, maar bijvoorbeeld door de wens om een negatieve publieke perceptie om te buigen, dan is het de vraag of deze verslaggeving wel een getrouw beeld van de werkelijkheid geeft. Beslissingen van stakeholders, gebaseerd op deze informatie, kunnen daarmee suboptimale uitkomsten tot gevolg hebben.

Als gevolg van het ontbreken van eenduidige empirische resultaten bestaat er momenteel geen allesomvattend theoretisch raamwerk voor MVO verslaggeving. Niettemin wordt in dit proefschrift een aantal argumenten aangedragen op basis waarvan gesteld wordt dat stakeholder theorie (stakeholder theory) en de sterk gerelateerde legitimiteittheorie (legitimacy theory), een goed startpunt voor het onderzoeken van deze materie vormen. In dit proefschrift betoog ik verder dat het gebruik van onderzoeksdata die beter dan voorheen in staat zijn de specifieke (MVO) karakteristieken per onderneming te weerspiegelen, in belangrijke mate kunnen bijdragen aan onze kennis over MVO verslaggeving. Data die aan deze omschrijving voldoen zijn bijvoorbeeld die welke zijn gegenereerd door anderen dan managers, zoals directe observaties door onderzoekers of andere stakeholders, dan wel data die inzicht verschaffen in interne ondernemingsfactoren. Het doel van het empirisch onderzoek in dit proefschrift is dan ook om door middel van het gebruik van precies dit type data een bijdrage te leveren aan het oplossen van het bovenstaande vraagstuk en daarmee ook aan een theoretisch raamwerk.

Met dit doel voor ogen zijn in deze dissertatie drie empirische studies over MVO verslaggeving gebundeld.

\footnotetext{
${ }^{57}$ Een Nederlandse vertaling van de Engelse term 'stakeholder' is: belanghebbende. Echter, de term 'stakeholder' is in de loop van jaren ook in de Nederlandse taal zodanig ingeburgerd geraakt, dat in deze Nederlandse samenvatting de oorspronkelijke Engelse term zal worden gebruikt.
} 
De eerste studie betreft een initiële verkenning van de manier waarop ondernemingen hun MVO verslaggeving intern organiseren. Op basis van een kwalitatieve onderzoeksopzet bestudeer ik de interne factoren die zijn gerelateerd aan MVO verslaggeving voor zes Nederlandse ondernemingen, die in brede kring tot de koplopers op het gebied van MVO verslaggeving in Nederland worden gerekend. De dataverzameling werd gestructureerd aan de hand van zeven thema's, die in de strategie literatuur geassocieerd worden met het optimaliseren van managementprocessen. Uit semigestructureerde interviews aan de hand van deze thema's komt naar voren dat de constellatie van structuren, systemen en processen waarmee MVO verslaggeving geoperationaliseerd wordt, verschilt van onderneming tot onderneming. Twee belangrijke factoren, waaraan deze heterogeniteit kan worden toegeschreven, zijn de mate van formalisering van het verslaggevingsproces en de integratie van MVO in de dagelijkse gang van zaken in de onderneming. Op basis van deze twee factoren ontwikkel ik een typologie waarmee vier typen van ondernemingen kunnen worden onderscheiden. Improvisers, het eerste type, worden gekenmerkt door een benadering van MVO (verslaggeving) die hoofdzakelijk informeel is en los staat van de andere (financiële) managementbeslissingen. Reporters, het tweede type, hebben de organisatie van hun MVO verslaggeving geformaliseerd; echter, overeenkomstig met het eerste type, is MVO niet geïntegreerd in de alledaagse praktijk. In het geval van het derde type, Performers, vormt het geformaliseerde management van MVO verslaggeving een onderdeel van een geïntegreerde en geformaliseerde benadering van MVO. Opmerkelijk is dat de drie ondernemingen die tot dit type behoren alle actief zijn in industrieën met een aanzienlijke milieu-impact. Tot slot wordt het vierde type ondernemingen gevormd door Reformers, welke een geïntegreerde MVO-benadering combineren met een informele wijze van organiseren van de MVO verslaggeving. Als gevolg van de wijze waarop de steekproef werd getrokken, voldeed geen van de onderzochte ondernemingen aan de kenmerken voor dit laatste type. Gesuggereerd wordt dat sociale ondernemers (social entrepreneurs) in deze beschrijving zouden kunnen passen.

Ondanks dat de zes onderzochte ondernemingen alle behoren tot een selecte groep van Nederlandse ondernemingen met MVO verslaggeving van de hoogste gepercipieerde kwaliteit, zijn de onderlinge verschillen in de manier waarop zij MVO (verslaggeving) intern organiseren dus groot. Dit impliceert dat 'voorbeeldige' MVO verslaggeving een geïntegreerde en gestructureerde aanpak van MVO kan weerspiegelen, zoals Performers laten zien. Maar het kan ook het gevolg zijn van de wens van een onderneming om invulling te geven aan het voldoen aan verslaggevingsbenchmarks. Immers, Improvisers laten zien dat ook met enige improvisatie en investering van middelen een onderneming een MVO verslag kan publiceren dat voldoet aan een bepaalde standaard. In het laatste geval lijkt het adagium 'what you measure is what you get' van toepassing te zijn. 
De tweede studie bouwt voort op de focus op de interne organisatie van MVO verslaggeving van de eerste studie, door te kijken naar het verband tussen (interne) milieuprestaties en milieuverslaggeving, een onderdeel van MVO verslaggeving. Op basis van een literatuurstudie op het terrein van het meten van milieuprestaties van ondernemingen, suggereer ik dat een conceptueel deugdelijke maatstaf voor milieuprestatie behalve een uitkomstdimensie ook een procesdimensie moet hebben. Deze procesdimensie betreft het interne milieumanagement van ondernemingen. Uitgaande van legitimiteittheorie verwacht ik dat uitkomstgerelateerde milieuprestaties negatief, en procesgerelateerde milieuprestaties positief zijn gerelateerd aan de omvang van milieuverslaggeving. Om deze verwachting empirisch te toetsen, ontwikkel ik twee maatstaven voor milieuprestatie. De maatstaf voor uitkomstgerelateerde milieuprestatie is de hoeveelheid broeikasgasemissies per eenheid omzet. Procesgerelateerde milieuprestatie wordt gemeten door het commitment van een onderneming ten aanzien van het milieu. De data voor deze laatste variabele werden onttrokken uit een gedetailleerde en kwalitatief hoogwaardige private database. Om ervoor te zorgen dat de afhankelijke variabele (de uitvoerigheid van milieuverslaggeving) enkel de werkelijk vrijwillige verslaggeving vertegenwoordigt, werden jaarverslaggeving en Form $10-K$ verslaggeving (in de VS) uitgesloten.

De resultaten op basis van een steekproef van 138 grote ondernemingen, die actief zijn in verscheidene industrieën, tonen aan dat milieuverslaggeving allereerst gerelateerd is aan de positieve procesgerelateerde milieuprestatie, d.w.z. milieu commitment. Deze blijkt consistent positief gerelateerd te zijn met milieuverslaggeving, ongeacht of gecontroleerd wordt voor industrie- en andere effecten of de steekproef. Dit bevestigt de verwachting zoals geformuleerd in de hypothese. De resultaten voor broeikasgasemissie (uitkomstgerelateerde milieuprestatie) zijn minder eenduidig. Zoals verwacht laten ze zien dat deze variabele op zichzelf negatief gerelateerd is aan milieuverslaggeving, zowel binnen, als tussen verschillende industrieën; maar dit resultaat geldt slechts voor de situatie waarin bedrijven in meer vervuilende industrieën (d.w.z. industrieën met hogere broeikasgasemissies) gemiddeld genomen meer uitgebreide milieuverslaggeving hebben dan ondernemingen in minder vervuilende industrieën en, in het geval van niet-industriële ondernemingen, hogere broeikasgasemissies tot meer uitgebreide milieuverslaggeving leidt dan lagere emissies. De relatie tussen broeikasgasemissie en milieuverslaggeving verdwijnt wanneer broeikasgasemissies en milieu commitment gelijktijdig in de modellen worden inbegrepen. Dit wordt mede veroorzaakt door de significant negatieve correlatie tussen deze twee prestatiemaatstaven, hetgeen erop duidt dat de positieve relatie tussen milieu commitment en milieuverslaggeving deels wordt veroorzaakt door een mindere uitkomstgerelateerde milieuprestatie (d.w.z.: hoger broeikasgasemissies). 
Alles opgeteld geven de uitkomsten voor de tweede studie aan dat milieuverslaggeving gerelateerd is aan de zichtbaarheid van een onderneming, zoals weerspiegeld in de industrie waarin ze actief is, of haar mindere prestaties ten opzichte van vergelijkbare ondernemingen in haar industrie. Ondanks de niet volledig consistente resultaten in relatie tot de hypothese voor wat betreft uitkomstgerelateerde milieuprestaties, concludeer ik daarom toch dat milieuverslaggeving zich laat verklaren door legitimiteitstheorie.

De derde studie richt zich op externe factoren, door te analyseren of, en hoe externe stakeholders van ondernemingen in staat zijn om managementbeslissingen ten aanzien van MVO verslaggeving te beïnvloeden. Meer specifiek tracht ik inzicht te verkrijgen in de stakeholderkarakteristieken die van invloed zijn op het niveau van milieuverslaggeving. Ik onderzoek empirisch of verschillen in milieuverslaggeving tussen ondernemingen systematisch gerelateerd zijn aan verschillen in macht (power), de mate van urgentie (urgency) en legitimiteit (legitimacy) van milieugroeperingen waarmee deze ondernemingen te maken hebben (zgn. 'secundaire stakeholders'). Gebaseerd op stakeholder salience theory (de theorie van de opvallendheid van stakeholders), formuleer ik drie hypotheses waarin wordt gesteld dat milieuverslaggeving positief is gerelateerd aan de macht, urgentie en legitimiteit van milieustakeholders.

Op basis van een internationale steekproef van 199 grote ondernemingen vind ik empirisch bewijs voor de in de hypotheses veronderstelde relaties. Echter, de resultaten geven aan dat de invloed van macht en urgentie indirect van aard zijn, omdat het effect van deze wordt overgebracht via de legitimiteit. De mate waarin een milieugroepering als legitiem wordt gepercipieerd door het management, verklaart het grootste deel van de variantie in milieuverslaggeving. In de resultaten kan geen overtuigend bewijs worden gevonden voor een effect van andere stakeholders (institutionele beleggers), noch van ondernemingsgrootte, op milieuverslaggeving. Statistische sensitiviteitsanalyse wijst uit dat de aanvankelijk positieve coëfficiënten van deze variabelen in het reguliere OLS regressiemodel, uiteindelijk moeten worden toegeschreven aan een landen-effect. De resultaten laten verder zien dat ondernemingen in zichtbare industrieën, en ondernemingen uit andere landen dan de VS, meer uitgebreide milieurapportage hebben dan hun tegenhangers.

Dit proefschrift draagt bij aan de ontwikkeling van een theoretisch raamwerk voor MVO verslaggeving. Deze bijdrage is het resultaat van het in het onderzoek opnemen van factoren die geassocieerd worden met MVO verslaggeving, maar waarnaar eerder niet op systematische wijze onderzoek is gedaan; dit laatste is vooral te wijten aan een gebrek aan geschikte onderzoeksgegevens. Behalve de gebruikelijke externe factoren (zoals: ondernemingsgrootte, industrie en nationaliteit) en externe prestatie-indicatoren, die in eerder onderzoek met MVO verslaggeving in verband 
werden gebracht (zie figuur 1.1), benadrukt dit proefschrift het belang van interne factoren, zoals de aanwezigheid van noodzakelijke structuren, systemen en management commitment. Niet alleen zijn interne factoren indicatief voor de manier waarop MVO (verslaggeving) wordt georganiseerd door ondernemingen, het zijn ook belangrijke indicatoren voor MVO prestaties. Een andere bijdrage aan de totstandkoming van een theoretisch raamwerk is de onderzoeksuitkomst dat de wensen van stakeholders, en met name hun vermogen om het management van ondernemingen te beïnvloeden, ook belangrijke determinanten zijn van MVO verslaggeving. Deze bevinding is een aanvulling op eerdere empirische onderzoekuitkomsten die aangeven dat stakeholders in staat zijn om de MVO verslaggeving te beïnvloeden, door meer specifiek te verduidelijken hoe secundaire stakeholders MVO verslaggeving beïnvloeden.

De resultaten van de drie studies bij elkaar optellend, kunnen twee algemene conclusies getrokken worden.

Allereerst blijkt dat de zichtbaarheid van ondernemingen een belangrijke factor is in het kader van MVO verslaggeving. Meer zichtbare ondernemingen hebben uitgebreidere MVO verslaggeving, en worden bovendien gekenmerkt door een groter commitment ten aanzien van het milieu en meer invloedrijke milieugroeperingen. Dit correspondeert met legitimiteitstheorie.

Ten tweede blijkt dat het beoordelen van de MVO prestatie van een onderneming op basis van haar MVO verslaggeving kan leiden tot een onjuiste inschatting. 'Voorbeeldige' MVO verslaggeving kan allereerst het resultaat zijn van de inspanningen van een communicatieafdeling om een bedrijfsimago te creëren dat overeenkomt met hetgeen gewenst is in bepaalde benchmark formats van externe partijen. Bovendien blijkt dat ondernemingen vooral geneigd zijn om in hun MVO verslaggeving positieve zaken te laten zien.

De resultaten van dit onderzoek hebben ook implicaties voor zowel de onderzoekswereld als de praktijk. Zo wordt op basis van de eerste studie aanbevolen om in relatie tot MVO verslaggeving interne bedrijfsfactoren een grotere rol te geven. Daarbij valt te denken aan het toevoegen van interne factoren aan de beoordelingscriteria van partijen die zich bezighouden met benchmarking of verkiezingen ten aanzien van MVO verslaggeving. Ter vergroting van de transparantie zouden ondernemingen in hun verslagen beter kunnen laten zien hoe hun MVO intern georganiseerd is. De tweede studie draagt vooral bij aan een verklaring voor het gebrek aan consistente onderzoeksuitkomsten op het gebied van de relatie tussen milieuprestatie en -verslaggeving. Dankzij het aan het licht brengen van de complexe relatie tussen verschillende maatstaven van milieuprestatie en -verslaggeving, kunnen in toekomstig onderzoek meer genuanceerde hypotheses geformuleerd en getoetst worden. De laatste studie levert waardevolle input voor de discussie over 
de wenselijkheid van wetgeving ten aanzien van MVO verslaggeving door te laten zien dat aan de ene kant milieugroeperingen de verslaggeving kunnen beïnvloeden, maar aan de andere kant die verslaggeving slechts in beperkte mate de informatiebehoefte van deze stakeholders bevredigt. Bovendien toont deze studie aan dat de mate van milieuverslaggeving nauwelijks wordt beïnvloed door institutionele aandeelhouders, ondanks dat dit de groep is met in potentie de grootste invloed, waardoor er een rol lijkt te zijn weggelegd voor milieugroepringen in het bewust maken van deze om daarmee de verstrekking van milieu-informatie door ondernemingen te bevorderen. 


\section{Curriculum vitae}

Thomas Thijssens was born on April 30, 1970 in Maastricht, The Netherlands. He attended secondary school from 1982 until 1988, after which he started studying Business Economics at Maastricht University. He obtained his master degree in 1994 , with a specialisation in organisation. After his graduation, Thomas worked as a consultant at Holtrop Ravesloot \& Partners executive search in Amstelveen. Subsequently, he became a research analyst at the investment branch of Triodos Bank, Zeist. In 2001 he joined Maastricht University as a lecturer/researcher. In late 2006 he started his PhD at the department of Accounting \& Information Management of the same university. He has presented papers related to this dissertation at many international conferences. Since early 2011 Thomas has been working as operations manager at the Network Social Innovation (NSI) at Maastricht University. 